\title{
INVESTIGATING THE CORRELATION BETWEEN FREEWAY TRAFFIC LEVELS AND FREEWAY SERVICE PATROL ASSISTS
}

\author{
A Project \\ presented to \\ the Faculty of California Polytechnic State University, \\ San Luis Obispo
}

\author{
In Partial Fulfillment \\ of the Requirements for the Degree \\ Master of City and Regional Planning/Master of Science in Engineering \\ (Transportation Planning Specialization)
}

by

Nora Chin

August 2015 
(C) 2015

Nora Chin

ALL RIGHTS RESERVED 
TITLE: $\quad$ Investigating the Correlation between Freeway Traffic Levels and Freeway Service Patrol Assists

AUTHOR:

Nora Chin

DATE SUBMITTED:

August 2015

COMMITTEE CHAIR: $\quad$ Cornelius Nuworsoo, Ph.D., AICP

Professor of City and Regional Planning

COMMITTEE MEMBER: $\quad$ Robert L. Bertini, Ph.D.

Associate Professor of Civil and Environmental

Engineering

COMMITTEE MEMBER: $\quad$ Anurag Pande, Ph.D.

Associate Professor of Civil and Environmental

Engineering 


\author{
ABSTRACT \\ Investigating the Correlation between Freeway Traffic Levels \\ and Freeway Service Patrol Assists \\ Nora Chin
}

The Bay Area Metropolitan Transportation Commission's (MTC) Freeway Service Patrol's highway motorist response service is reporting a reduction in their service levels. We analyze the relationship between the reduction in the Bay Area Freeway Service Patrol's (FSP) motorist assists and changes in vehicle miles traveled (VMT), California Highway Patrol (CHP) reported incidents, and cover research on the impact of new and old vehicle fleet turnover. VMT and CHP incidents have differential effects on FSP assists. Although incidents occurring on freeways with high traffic flows tend to cause more congestion, the trend in local VMT along Bay Area freeway corridors does not share a strong correlation with FSP assists. Through a chi-square test, bivariate correlation and cross tabulation, we can see a relationship and pattern between FSP assists, incidents and VMT. Further analysis into the dispersion of assists, incidents and VMT show that the distribution of the FSP assists over CHP reported incidents is not perfectly equal. By analyzing VMT, CHP reported incidents and research around new vehicle fleet turnover affecting FSP assisted-incidents, Metropolitan Transportation Commission staff can systematically improve the FSP operational model; strategize ways to improve service on needier freeway corridors, while reducing unnecessary service in other regions.

Keywords: Freeway Service Patrol, VMT, Incidents, Assists, Beats, Truck Hours 


\section{ACKNOWLEDGMENTS}

I would like to thank Robert Rich, Jamie Maldonado and Stefanie Pow at the Metropolitan Transportation Commission's Service Authority for Freeways and Expressways who provided much of the initial data, other data sources and project development.

I would also like to thank my committee chair and members of the committee who further developed the idea and the project. 


\section{TABLE OF CONTENTS}

LIST OF TABLES viii

LIST OF FIGURES

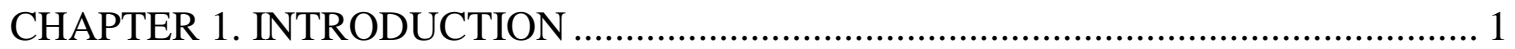

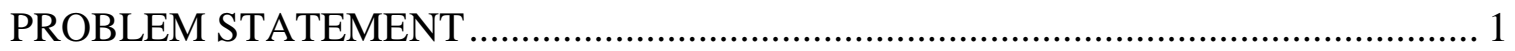

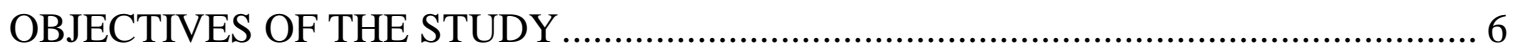

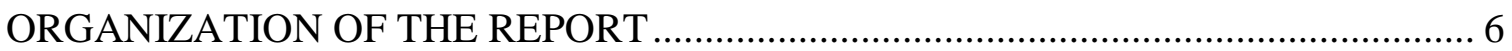

CHAPTER 2. BACKGROUND/LITERATURE REVIEW …………………................ 7

2.1 Bay Area Freeway Service Patrol ..................................................................... 7

2.2 Effectiveness of Bay Area Freeway Service Patrol ................................................ 10

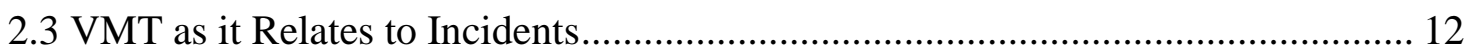

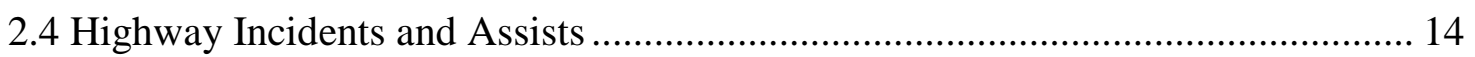

2.5 Overview of U.S. New Vehicle Fleet Turnover and Increase in Dependability.... 16

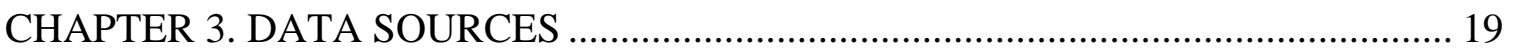

3.1 California Department of Transportation Performance Measurement System....... 19

3.2 Caltrans PeMS Archived CHP Incident Data .......................................................... 19

3.2.1 CHP Reported Incidents .............................................................................. 19

3.2.2 Trends in CHP Reported Incidents between January 1, 2009 to

December 31, 2013 ........................................................................................ 21

3.3 Freeway Service Patrol Assisted Incident Data ..................................................... 22

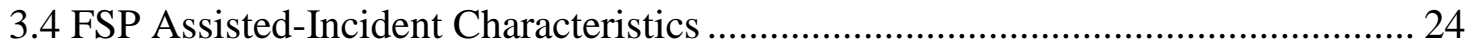

3.5 Caltrans PeMS Archived VMT Data .............................................................. 30

3.6 CHP Reported Incidents, VMT and FSP Assists Data Set .................................... 31

3.6.1 Route/Beat Characteristics ............................................................................. 31

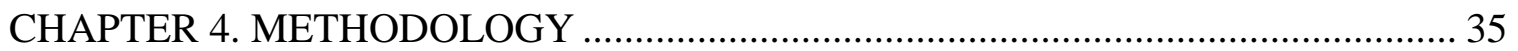

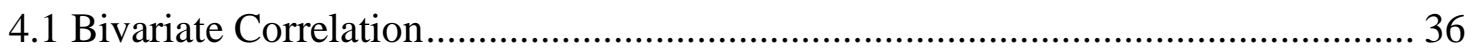

4.2 Lorenz Curve and Gini Coefficient...................................................................... 36

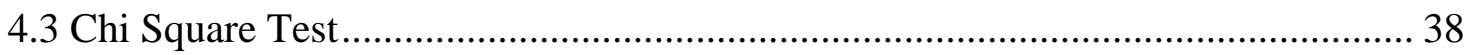

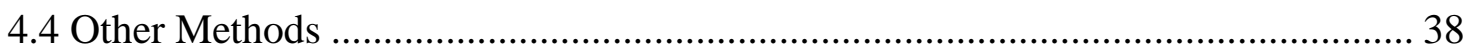

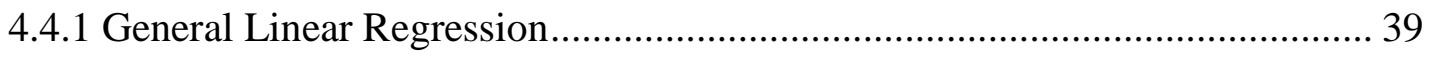

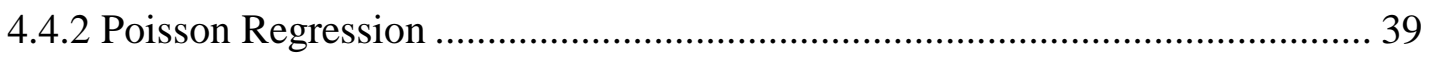


CHAPTER 5. DATA COLLECTION AND PROCESSING ………………………........ 40

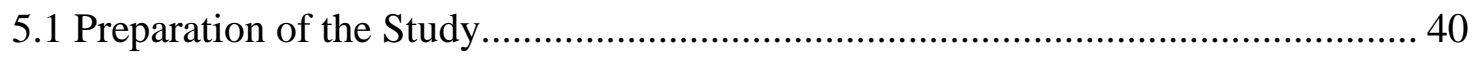

CHAPTER 6. RESULTS AND EVALUATION …………....................................... 42

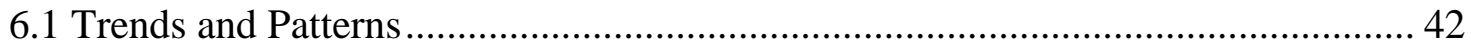

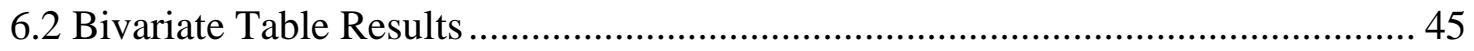

6.3 Lorenz Curve and Gini Coefficient Results ...................................................... 46

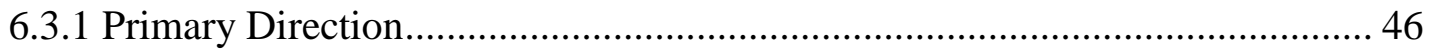

6.3.2 Secondary Direction................................................................................. 49

6.4 Chi Square Test ......................................................................................... 53

6.5 Trends and Patterns of VMT vs. Incidents during Weekdays ................................ 53

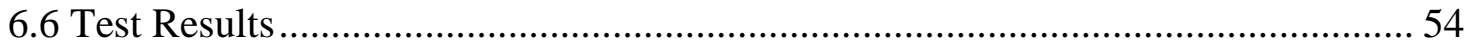

6.7 Trends and Patterns of VMT vs. Assists during the Weekday ............................... 54

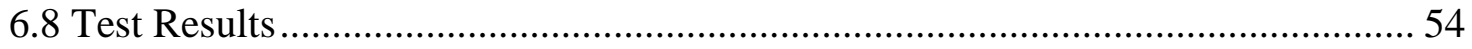

6.9 Trends and Patterns of Incidents vs. Assists during the Weekday .......................... 55

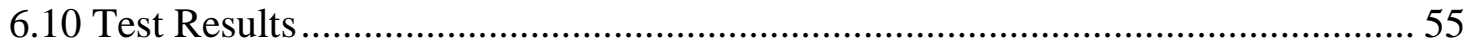

6.11 Trends and Patterns of VMT vs. Incidents during the Weekend ........................... 56

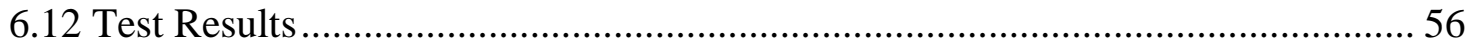

6.13 Trends and Patterns of VMT vs. Assists during the Weekend ............................. 57

6.14 Test Results .................................................................................................. 57

6.15 Trends and Patterns of Incidents vs. Assists during the Weekend ....................... 57

6.16 Test Results .................................................................................................. 58

6.17 Trends and Patterns of Seasonally VMT vs. Incidents during the Weekday........ 58

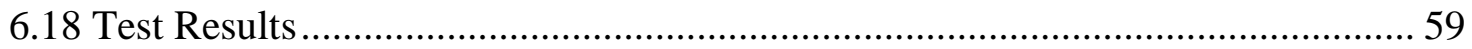

6.19 Trends and Patterns of Seasonal VMT vs. Assists during the Weekday .............. 59

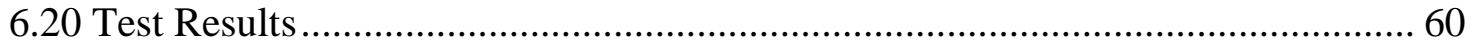

6.21 Trends and Patterns of Seasonal Incidents vs. Assists during the Weekday ........ 60

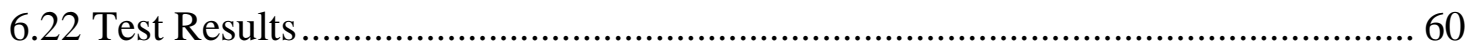

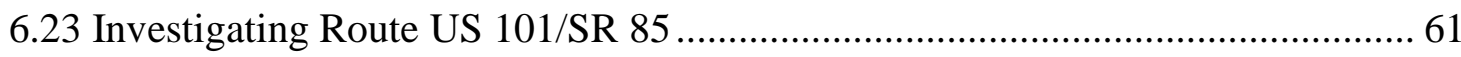

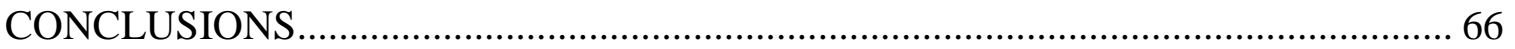

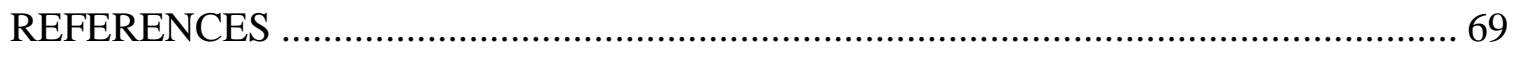

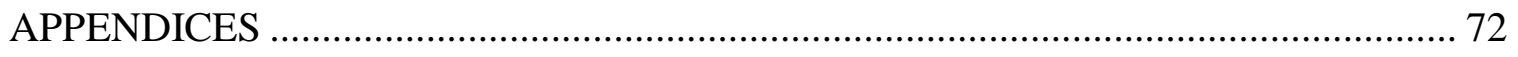




\section{LIST OF TABLES}

Table

1. Route and Beat Characteristics 31

2. Primary and Secondary Direction Bivariate Table Results .................................... 45

3. Chi-Square Test Result for VMT vs. Incidents during the Weekday .......................... 54

4. Chi-Square Test Result for VMT vs. Assists during the Weekday ............................. 55

5. Chi-Square Test Result for Incidents vs. Assists during the Weekday....................... 55

6. Chi-Square Test Result for VMT vs. Incidents during the Weekend ......................... 57

7. Chi-Square Test Result for VMT vs. Assists during the Weekend ........................... 57

8. Chi-Square Test Result for Incidents vs. Assists during the Weekend........................ 58

9. Chi-Square Test Result for Seasonal VMT vs. Incidents during the Weekday ............ 59

10. Chi-Square Test Result for Seasonal VMT vs. Incidents during the Weekday .......... 60

11. Chi-Square Test Result for Seasonal Incidents vs. Assists during the Weekday ....... 60

12. Lorenz Curve and Gini Coefficient - Assist and Incident Distribution Table

for the Primary Direction..... 75

13. Lorenz Curve and Gini Coefficient - Assist and VMT Distribution Table for the Primary Direction

14. Lorenz Curve and Gini Coefficient - Incident and VMT Distribution Table

for the Primary Direction

15. Lorenz Curve and Gini Coefficient - Assist and Incident Distribution Table

for the Secondary Direction 78

16. Lorenz Curve and Gini Coefficient - Assist and VMT Distribution Table for the Secondary Direction

17. Lorenz Curve and Gini Coefficient - Incident and VMT Distribution Table for the Secondary Direction

18. Lorenz Curve and Gini Coefficient - Incident and Assists Distribution

Table for Peak Travel Times. 81 
19. Lorenz Curve and Gini Coefficient - Assists and VMT Distribution

Table for Peak Travel Times 82

20. Lorenz Curve and Gini Coefficient - Incident and VMT Distribution

Table for the Secondary Direction 83

21. Primary Direction Chi Square Test for Months vs. Incidents 87

22. Secondary Direction Chi Square Test for Incidents and Months 87

23. Primary Direction Chi Square Test for Incidents and Time of Day ......................... 88

24. Secondary Direction Chi Square Test for Incident and Time of Day....................... 88

25. Secondary Chi Square Test Results for Incidents and Day of the Week.................. 89

26. Primary Direction Chi Square Test Results for Incidents and Vehicle Miles

Traveled 90

27. Secondary Direction Chi Square Test Results for Incidents and Vehicle Miles

Traveled 90

28. Primary Direction Chi Square Test Results for Assists and Months 91

29. Secondary Direction Chi Square Test Results for Assists and Months ..................... 91

30. Primary Direction Chi Square Test Results for Assists and Time of Day ................. 92

31. Secondary Direction Chi Square Test Results for Assists and Time of Day............. 92

32. Primary Direction Chi Square Test Results for Assists and Day of the Week .......... 92

33. Secondary Direction Chi Square Test Results for Assists and Day of the Week ....... 93

34. Primary Direction Chi Square Test Results for Assists and Vehicle Miles Traveled 93

35. Secondary Direction Chi Square Test Results for Assists and Vehicle Miles

Traveled 94

36. Primary Direction Chi Square Test Results for Assists and Incidents. 95

37. Secondary Direction Chi Square Test Results for Assists and Incidents 95

38. VMT Totals for Monthly Chi Square Comparison. 96 


\section{LIST OF FIGURES}

$\begin{array}{lll}\text { Figure } & \text { Page }\end{array}$

1. Bay Area Freeway Service Patrol Coverage............................................................... 3

2. Assists per Truck Hour and Total Assists Distributed over 20-Years .......................... 4

3. Number of Trucks and Service Miles over 20-Years ............................................. 5

4. Freeway Service Patrol Assisted Incident Data, January 1, 2009 to

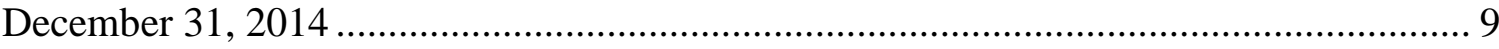

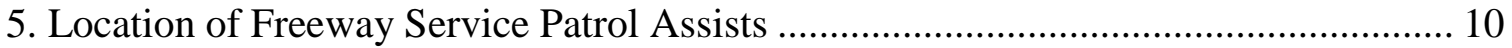

6. Total VMT, CHP Incidents and FSP Assists Distributed over January 1, 2009 to

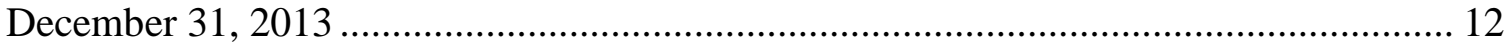

7. Total Registered Vehicles Divided by Annual Sales Rate......................................... 17

8. Total Incidents and Assists over the Primary Direction, January 1, 2009 to

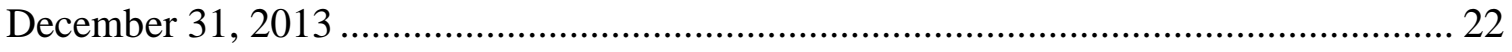

9. Total Incidents and Assists Distributed over Freeway Service Patrol Routes .............. 22

10. Overall Changes in Assists over Five-Years .......................................................... 26

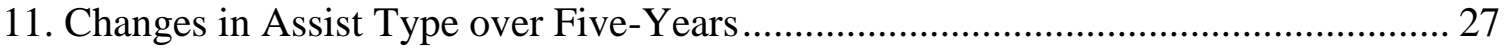

12. Study Area of Seven Freeway Service Patrol Routes ............................................ 29

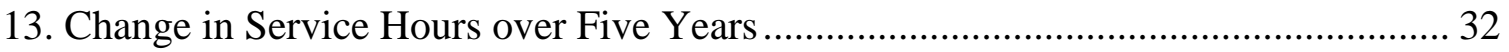

14. Total VMT, CHP Incidents and FSP Assists Distributed over 24-Hours,

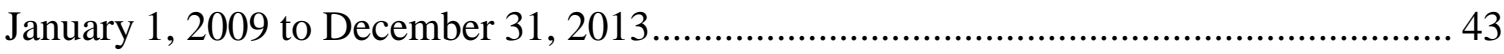

15. Freeway Service Patrol Assists Distributed over Primary Direction,

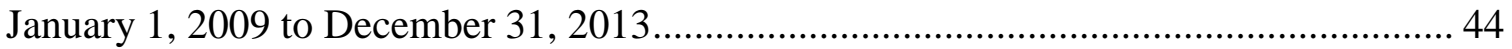

16. Freeway Service Patrol Assists Distributed over Secondary Direction,

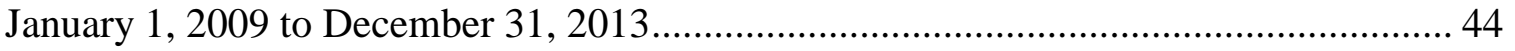

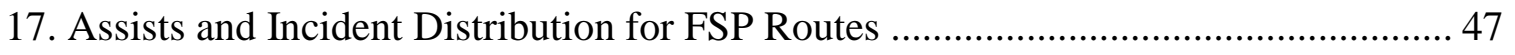

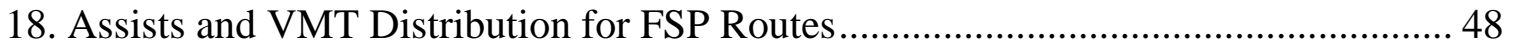

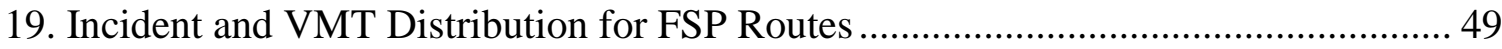


20. Assists and Incidents Distribution for FSP Routes ………...................................... 50

21. Assists and VMT Distribution for FSP Routes .......................................................... 51

22. Assists and Incident Distribution for FSP Routes …………………...................... 52

23. Freeway Service Patrol Assists Distributed over Weekdays, January 1, 2009 to

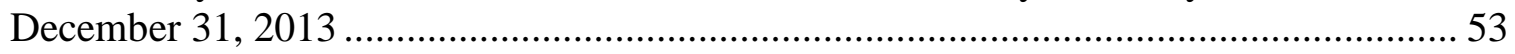

24. Freeway Service Patrol Assists Distributed over the Weekend, January 1, 2009 to

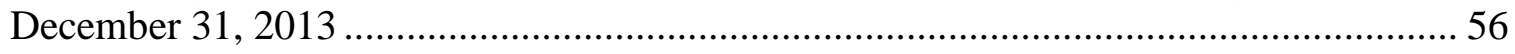

25. Freeway Service Patrol Assists Distributed Seasonally, January 1, 2009 to

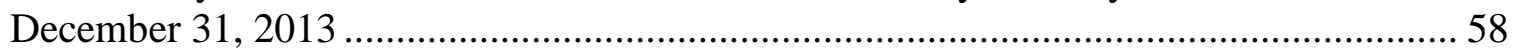

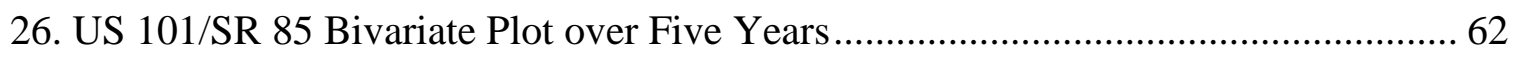

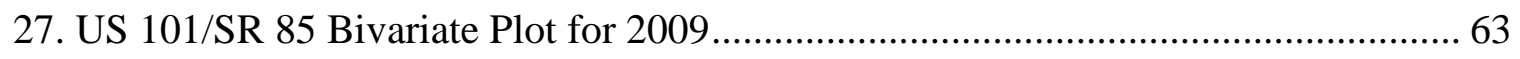

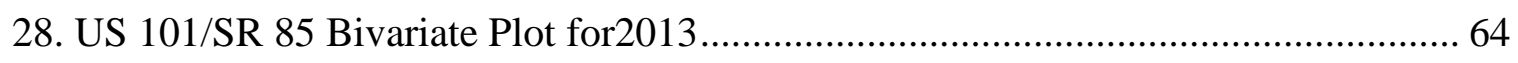

29. Incident Tree for Total Assist Type ……………............................................... 72

30. Number of Trucks over Five Years ...................................................................... 74

31. FSP Route Length over Five Years ................................................................. 74

32. Assists and Incidents Distribution for FSP Routes during Peak Travel Time ............ 84

33. Assists and VMT Distribution for FSP Routes during Peak Travel Time.................. 85

34. Incident and VMT Distribution for FSP Routes during Peak Travel Times .............. 86 


\section{CHAPTER 1. INTRODUCTION}

According to Skarbadonis et al.'s 1998 economic evaluation of the Freeway Service Patrol (FSP), the FSP was a cost-effective operational program. Staff makes strategic decisions on how to optimally deploy FSP service on existing or new FSPdesignated freeway routes or beats. An evaluation of the corridor level and the program's current benefit/cost ratio of 5.8 indicate the service provides added value by reducing the potential for recurrent and incident-related congestion, increasing motorist and responder safety, and decreasing auto emissions along Bay Area freeway beats as shown in Figure 1. Skabardonis, et al. (1991) noted "incident type, severity and the type of assistance provided were the major factors affecting incident durations." Despite cost-effectively procuring tow contractor service and designating service boundaries, MTC prepared a 20year time series analysis of FSP assist data, showing that the total program assist levels decreased over years 2011 to 2013.

\section{PROBLEM STATEMENT}

Presently, FSP operates a fleet of 80 roving trucks deployed during peak travel times to detect and clear incidents, assist motorists and remove dangerous debris from freeways. (Caltrans' Quarterly Reports, 2006-2014). The program has provided 2.4 million assists over its 21-year operation. It is administered and managed by the Metropolitan Transportation Commission's Service Authority for Freeways and Expressways (MTC SAFE), California Highway Patrol (CHP) and California Department of Transportation (Caltrans). In the nine-county Bay Area, FSP trucks operate along 35 beats, covering 545 miles of freeway. The State Highway Fund, the federal government 
and regional motor vehicle registration fees fund this free service. Based on area population size, and congestion information, federal Moving Ahead for Progress in the $21^{\text {st }}$ Century Act (MAP-21), congestion mitigation funds and other state and local sources are allocated to the Bay Area FSP.

FSP service is provided by private tow truck companies, under contract to MTC, selected through a competitive bid process. During the procurement process, the Bay Area FSP typically selects private contractors that fit a specified set of criteria including: minimum experience under CHP's rotation tow list, submission to inspection of facilities and a yard within 20 minutes of beat accessibility. Figure 1 shows the area road network served by the FSP program. As shown in Figure 2, since inception, the program's assist rate consistently exhibits a steady decline in assists per truck hour. The historical number of total assists increased steadily since program inception and began declining in 20092010. Within the years 2011 to 2013 period, the number of assists and the assist rate both decreased. Although staff allocated additional service hours to meet the changes in motorist assists, the number of assists and the assist rate plateau and eventually, begins a decline. The study period of January 1, 2009 to December 31, 2013 shows the pattern of change in total FSP assisted-incidents tracks a similar trend to Bay Area VMT and incidents. Upon closer examination, the relationship between VMT and incidents to assists vary. 
Figure 1. Bay Area Freeway Service Patrol Coverage Bay Area Freeway Service Patrol

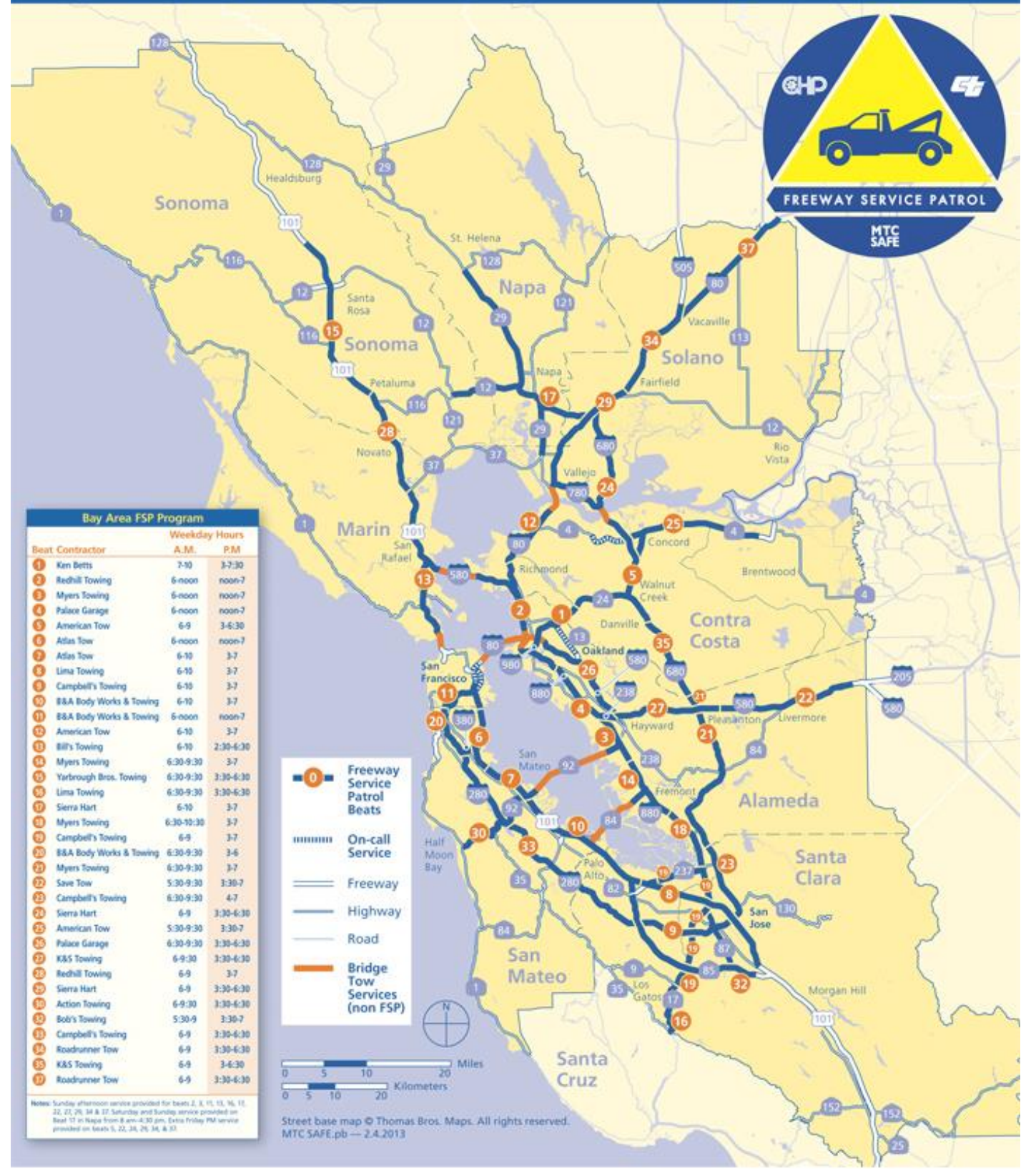


Figure 2. Assists per Truck Hour and Total Assists Distributed over 20-Years

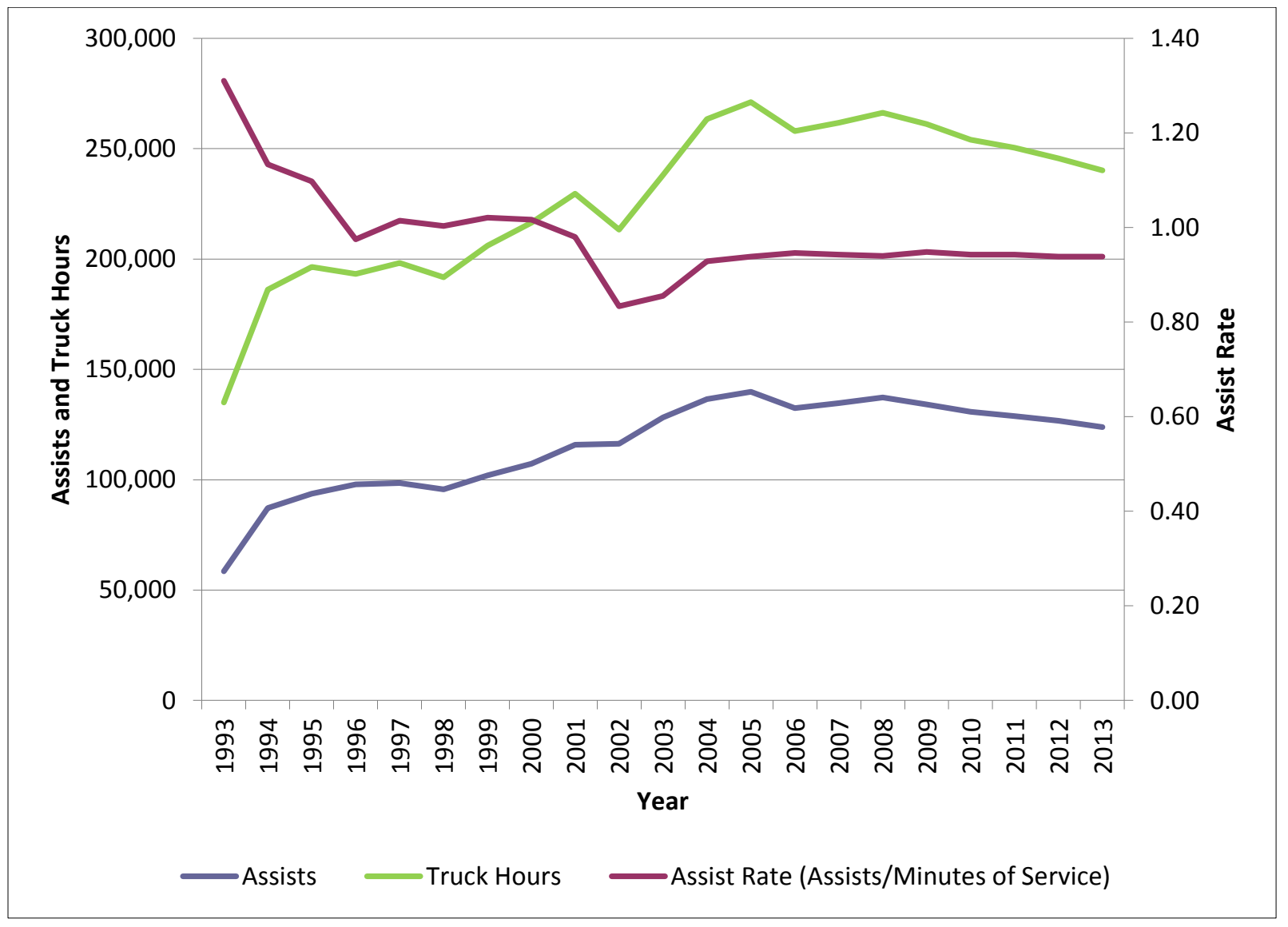

Figure 3 demonstrates the program's total number of tow trucks and allotted service miles shown over the 20-year period. Designated freeway corridors and the allotted truck hours have increased over the twenty-years of the program's inception. As seen in Figure 3, the length of the service miles, the number of trucks and truck hours dedicated towards specific routes ultimately influences the number of assists detected, based on the degree of exposure to incidents on the highway. Though the program's allotted service time has remained consistent for the past five years, the number of assists and the assist rate declined. 
Figure 3. Number of Trucks and Service Miles over 20-Years

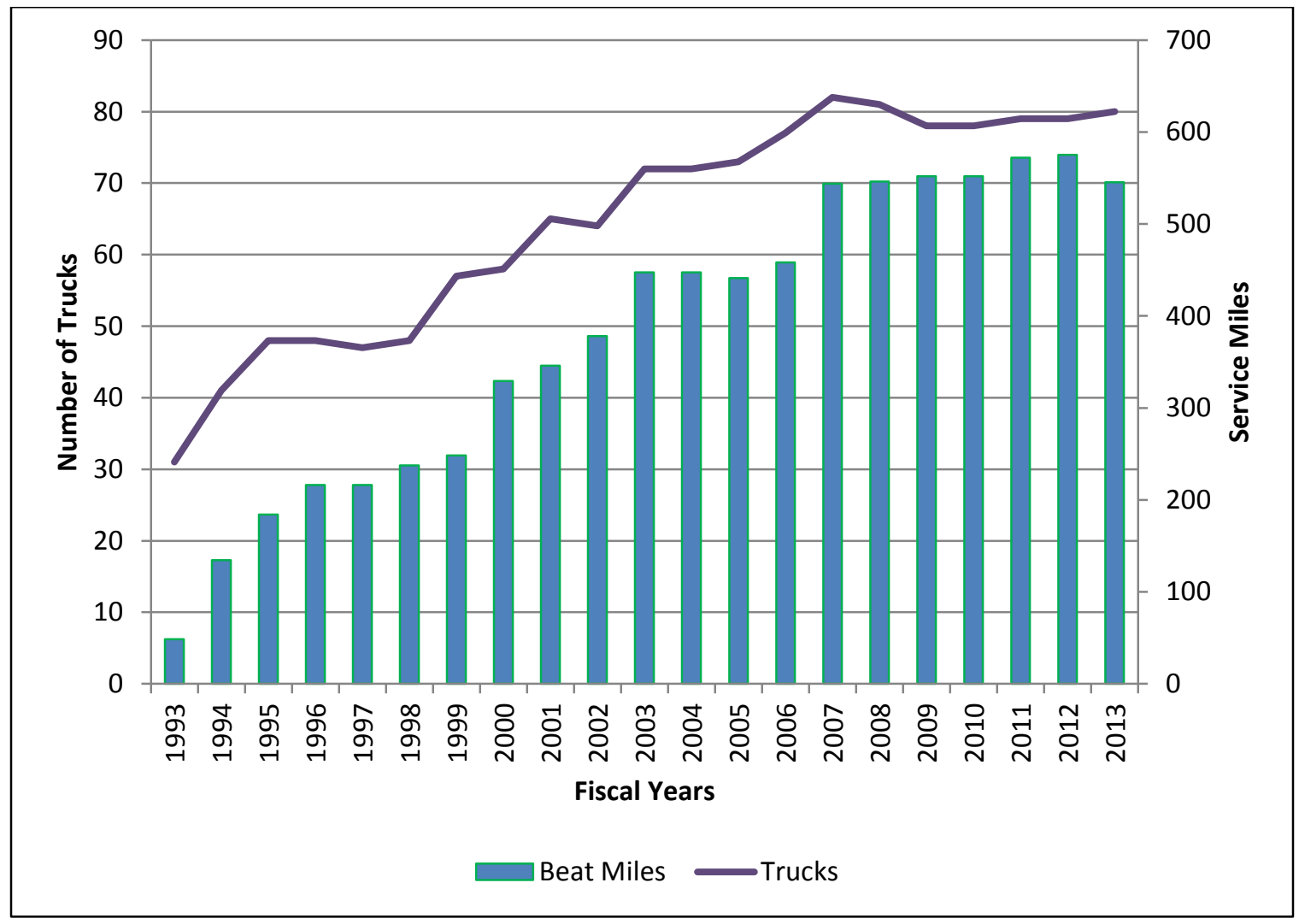

This study focuses primarily on seven FSP designated routes in the primary direction, which is the daytime choice route and secondary directions, the evening choice route: US 101/ SR 85, US 101, I-680, I-80, SR 242 and SR 85. These seven routes provided consistent and available data to analyze and evaluate. Over the past five years, the seven FSP route designations have remained relatively consistent because the tow contractor procurement period is on a four-year interval. Between January 1, 2009 to December 31, 2013, a combined total of 68 trucks roved the designated corridors. This means, an average of 17 FSP trucks circulated these routes, annually. (Bay Area FSP Program - Number of Centerline Miles by Year, 2014) 
To a lesser extent, we also evaluate research on the national U.S. vehicle fleet turnover review the effect of fleet turnover strategies, aiming to encourage the removal of older vehicles, possibly mitigating the need for roadway assistance such as the Freeway Service Patrol.

\section{OBJECTIVES OF THE STUDY}

The objective of the research project is to investigate the decrease in MTC's FSP assists and the assist rate. We are interested in whether there is a relationship between VMT, CHP reported incidents and FSP assisted incidents along the same corridors. Second, we analyze research on NHTSA's Cash for Clunkers program and its impact on the U.S.'s old and new vehicle fleet during the 2009-2013 study period. This study looks at FSP assisted incidents, VMT, and CHP reported incidents for Bay Area FSP routes US 101/SR 85, US 101, I-680, I-80, SR 242, SR 4 and SR 85. (Caltrans' PeMS, n.d.) Research covering the changes in national vehicle sales and turnover through the period is reviewed.

\section{ORGANIZATION OF THE REPORT}

This report presents the problem, and evaluates the existing FSP program's performance. In Chapter 1, the study provides background of the FSP program. Chapter 2 and 3 discuss related literature, data sources and trends in the data. Chapter 4 covers the methodology of the tests. Chapter 5 describes the data collection and processing. Chapter 6 presents the findings and summarizes results of the study. 


\section{CHAPTER 2. BACKGROUND/LITERATURE REVIEW}

This chapter discusses existing FSP operations and performance used to inform staff's decision-making for tow truck deployment and beat boundary designations. We review research about the effectiveness, cost-efficiency, added value and impacts of FSP deployment on freeways. Further, we evaluate the current VMT trend, freeway incidents as it relates to FSP assists, the U.S. vehicle fleet turnover and look at Li et al.'s study on the U.S. "Cash for Clunkers” program. (Li, Linn, \& Spiller, 2013)

\subsection{Bay Area Freeway Service Patrol}

Incidents and crashes, defined as vehicle breakdowns and other random events, reduce the capacity of the road and cause congestion. In response to the impacts of incidents on traffic flow, incident management programs were initiated in metropolitan areas to clear incidents and provide aid to motorists for minor events like flat tires and breakdowns. In order to respond to incidents, Freeway Service Patrol designates specific freeway corridors or "beats" with traffic and incidents. These freeway beats are Freeway Service Patrol designated sections of freeways where tow trucks rove for motorists in need of aid as well as objects obstructing the road for a specified period of time. This designated time, otherwise known as "truck hours," is usually dependent on the level of traffic volume and incidents experienced on the highway. In this case, the morning (7:00AM to $10: 00 \mathrm{AM})$ and evening peak periods (4:00PM to $8: 00 \mathrm{PM})$ during the weekday are the standard service times for FSP. FSP is effective in removing debris and breakdowns, which traditionally cause congestion along freeway corridors.

In the Bay Area, the program is jointly administered by the Metropolitan Transportation Commission, the California Department of Transportation, and the 
California Highway Patrol. The Bay Area FSP currently covers 35 designated routes or beats along I-880, I-80, SR 242, SR 92, SR 24, I-680, US 101, I-280, SR 4, SR 92, and SR 85 in Alameda, Contra Costa, Marin, San Francisco, San Mateo, Santa Clara, Santa Cruz and Sonoma counties. For the period of January 1, 2009 to December 31, 2013, FSP reported a total of 37,724 assists on seven routes. Figure 4 shows the breakdown of assists by route. Most FSP assists involved breakdowns such as flat tire changes and mechanical issues. Much like past trends, assistance was provided predominantly on the right shoulder of the corridor as shown in Figure 5. Small changes in the FSP's assist types reflect broader trends in CHP reported incidents and motor vehicles. 
Figure 4. Freeway Service Patrol Assisted Incident Data, January 1, 2009 to December 31, 2014

- US 101/SR 92

- US 101/SR 85

- SR 237/I-880/SR 17

$1-580$

- |-680

- SR 4/SR 242

- US 101

- SR 85

- $1-280$

- $1-80$

- 1-680 (Alcosta to Stone)

- I-80 (I-505 to Richards)

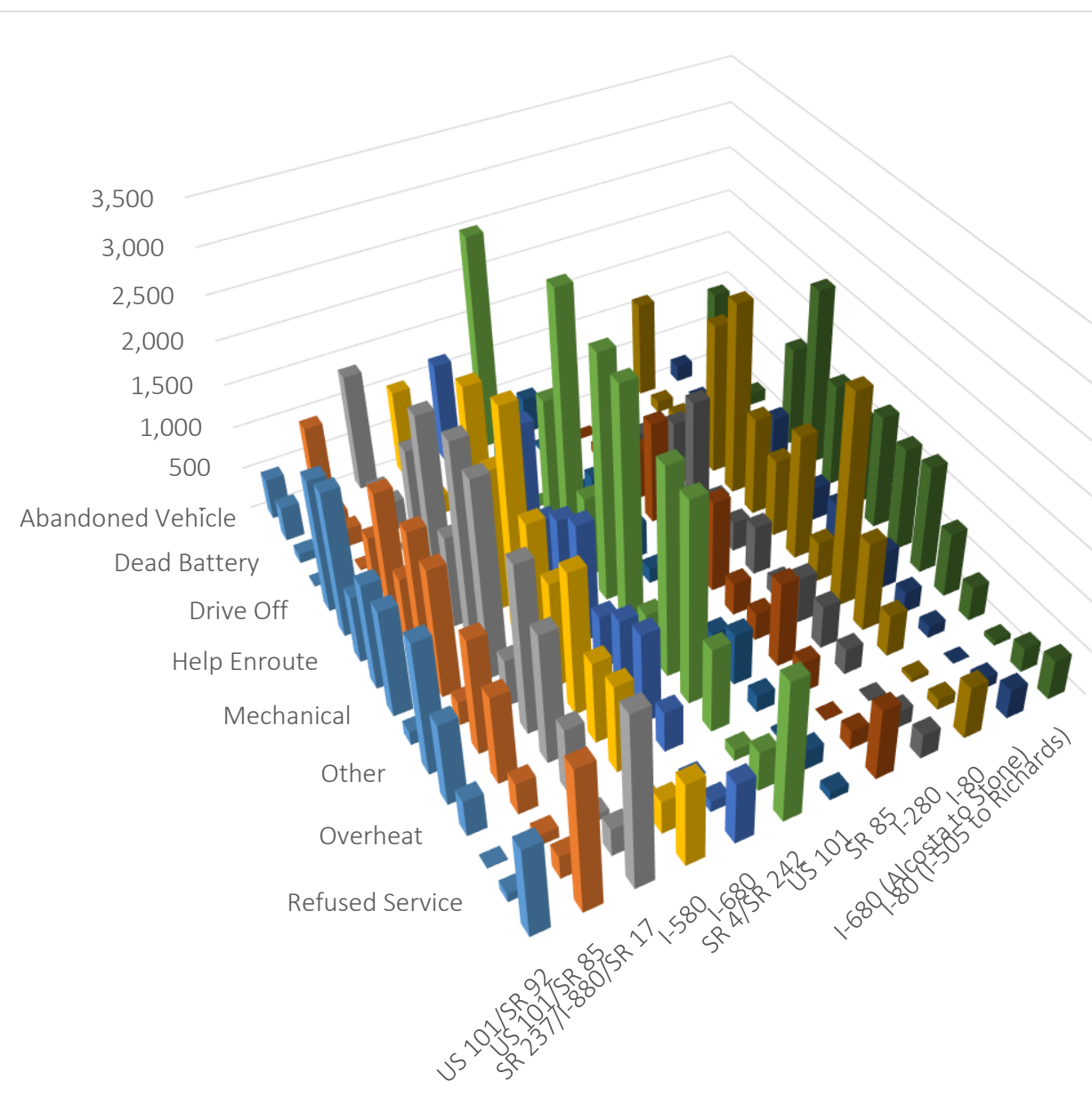


Figure 5. Location of Freeway Service Patrol Assists

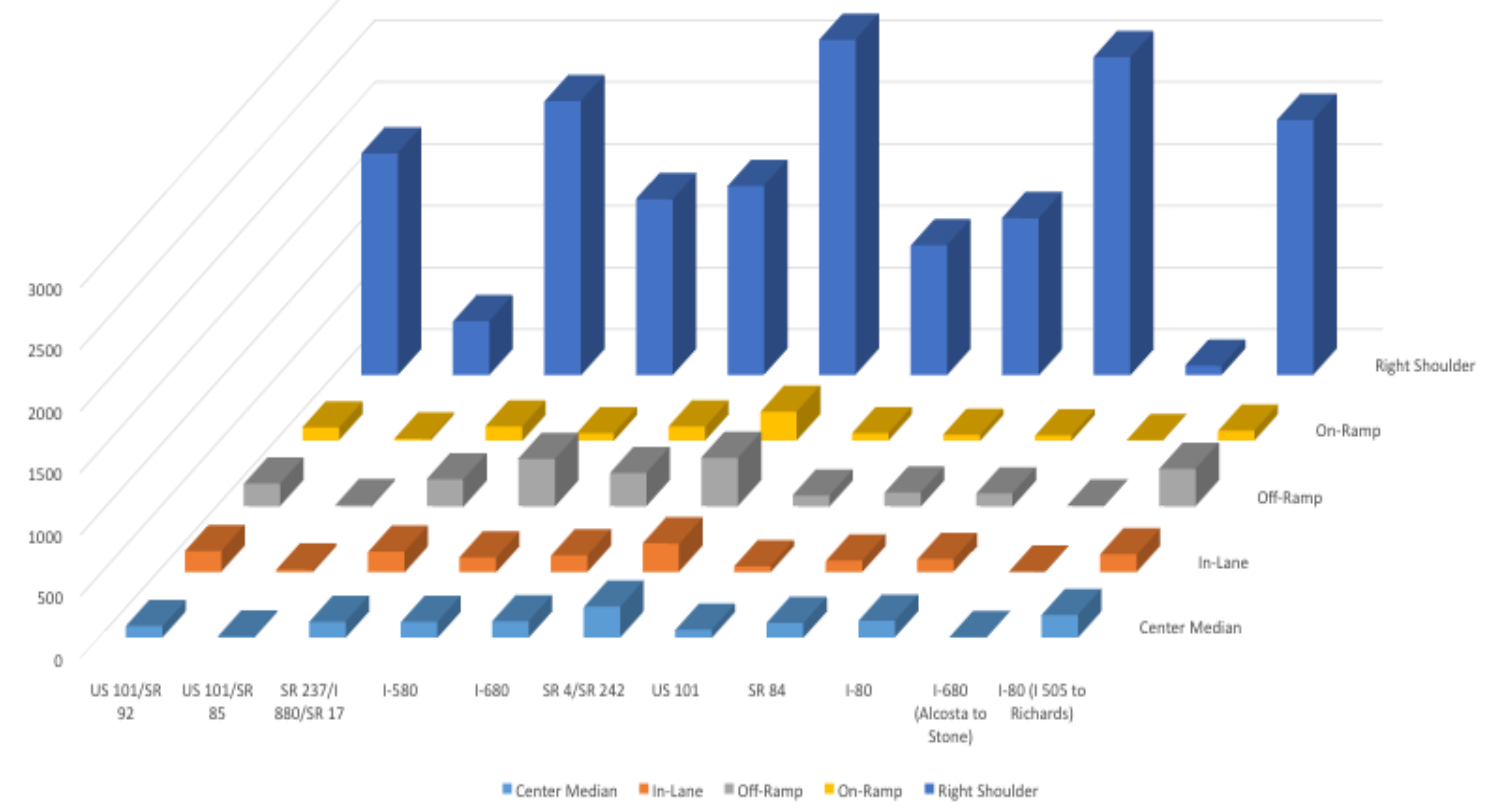

\subsection{Effectiveness of Bay Area Freeway Service Patrol}

The Bay Area Freeway Service Patrol has provided 2.4 million assists over its 21year operation. According to Skabardonis et al. (1994), The FSP program is effective. There are benefits to motorists assisted by FSP.

"Drivers and passengers of the vehicles assisted by FSP receive time savings because of faster response time, and direct cost benefits because of the free service and responders." In addition to added values to the motorist, there are benefits to freeway operators. "FSP service provides faster recovery of the freeway to normal conditions, and improved incident detection capabilities." (Skabardonis, et al., 1994).

The added value of FSP includes reduced delay, reduced fuel consumption, emissions, increased travel timesaving and improved safety and secondary crashes. The effectiveness of FSP is dependent on the "beat's geometric and traffic characteristics, and 
the frequency and type of assisted incidents." Incidents occurring on freeways with high traffic flow tend to cause more congestion than incidents on freeways with lower volumes. The FSP mitigates the impacts of incidents on upstream traffic through the provision of free services like tire changes, supply of gasoline, and leading vehicles off the highway to safety and providing mechanical assistance. During accidents, FSP drivers can assist in redirecting traffic and assisting emergency services. (Mauch, et al., 2005).

Additionally, the program's overall FSP benefit/cost (B/C) ratio of 5.8, a performance measure, suggests the program is cost-effective. For the past five years, the Bay Area FSP's B/C ratio has been increasing. The benefits of FSP are based on the savings in the incident delay and fuel consumption due to the FSP service excluding ancillary assists. (Skabardonis, et al., 1994). These benefits are derived from a deterministic queuing model, using static parameters such as Caltrans' current traffic, geometric and assist data, and the Environmental Protection Agency's (EPA) emissions standards. Pal \& Sinha, 2002 note that since FSP is a low-cost solution, there has not been much effort in designing such programs systematically so that better results can be obtained through efficient uses of existing resources. In its existing state, the FSP was designed with static parameters. (Pal \& Sinha, 2002). Though the B/C model is effective in providing a broad overview of the program, it does not provide an accurate or detailed evaluation of the Bay Area FSP's performance. Despite a fairly high $5.8 \mathrm{~B} / \mathrm{C}$ ratio, the program's reported assists declined for two years. 
Figure 6. shows historical patterns of FSP assists, CHP reported incidents, and VMT along Routes US 101/SR 85, US 101, I-80, I-680, SR 4, SR 85 and SR 242 for the five year period from 2009 through 2013. The three major areas of analysis are local VMT along the Bay Area FSP beats, local incidents as well as an assessment of the vehicle fleet turnover.

Figure 6. Total VMT, CHP Incidents and FSP Assists Distributed over January 1, 2009 to December 31, 2013

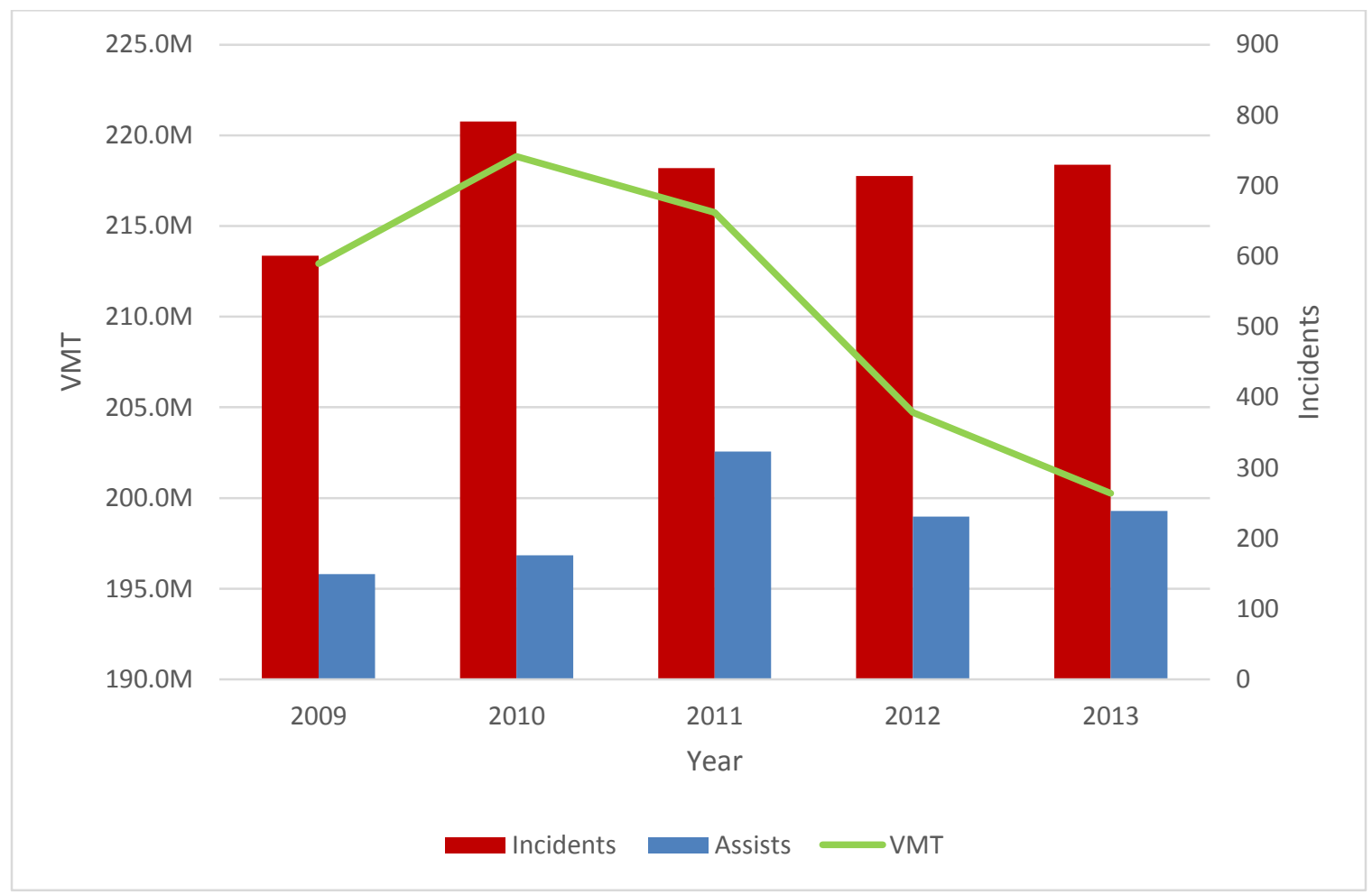

2.3 VMT as it Relates to Incidents

According to the U.S. Department of Transportation, for the last nine years, national per capita VMT has plateaued. (U.S. Department of Transportation, 2013) Traditionally, VMT is the most basic indicator of aggregate travel, gross domestic product and economic activity. Further research shows that the rising GDP has less 
impact on VMT than it has in the past. Traditionally, VMT per adult and per capita income trends tracked one another closely between 1966 and 2000. However, beyond 2000, the positive relationship becomes unclear - the relationship between per capita income and VMT is more volatile. (Hymel, 2014)

In the United States, there have been indications of total passenger travel flattening out. Changes in passenger travel are linked to the leveling of the GDP, demographic shifts, and higher fuel prices, but the root cause has not been isolated. Additionally, growth in car ownership has slowed and has even declined in the United States since 2007. Other indications of a change in VMT may be related to "peak travel" or a saturation of travel demand. In addition to motorized travel demand leveling out, car ownership continues to rise at a slower rate with people driving them less. (Millard-Ball \& Schipper, 2011). Other investigations such as Lave's “Things Won't Get a Lot Worse: The Future of U.S. Traffic Congestion," speculate that the extrapolation of the U.S. VMT trends was misguided since society and the economy continuously change. (Lave, June 1991)

More succinctly, there is not often a forthright demand for vehicular travel. When fewer people drive during peak periods, congestion declines. When congestion decreases, the cost of driving also decreases. This lower cost induces drivers to make more trips than they otherwise would have. Following a reduction in congestion, the flow of traffic and VMT usually bounces back. (Hymel, 2014). 
Many studies have investigated the change in VMT. Konduri, et al., 2013 looked further into VMT, the most basic measurement of traffic volume, as it relates to incident frequency. The authors stated that traffic volume was significantly different from one, demonstrating a non-linear relationship between incident frequency and traffic volume. Additionally, they noted that traffic volume turned out to be one of several important explanatory variables that directly influence incident frequency. Though there is a margin of error in Caltrans PeMS VMT data, the VMT trend experiences a slight dip over the same period as FSP assists. (Konduri, Labi, \& Sinha, 2013) Similarly, aggregate incident data track VMT. Thus, broader changes in VMT can be influential in the occurrence of incidents and therefore, can affect the number of motorists who need assistance.

\subsection{Highway Incidents and Assists}

There are three types of traffic events. These include work zones, weather and traffic incidents. Incidents are the focal point of discussion. Traffic Incidents, as defined by the US DOT, are events that disrupt the normal flow of traffic, usually by physical impedance in the travel lanes. These events can include: vehicular crashes, breakdowns, and debris in travel lanes. Blocking the travel lanes physically on the shoulder or roadside can also influence traffic flow by distracting drivers, leading to changes in driver behavior and ultimately leading to the degradation of traffic flow. (U.S. Department of Transportation Federal Highway Administration, 2013). These traffic congestion-related occurrences are defined by two main types of congestion, recurring and incident-related. Incident-related congestion usually occurs when an accident or a stalled vehicle causes

traffic to slow down significantly. About 25 percent of congestion in the United States is 
incident-related. These incident-related congestion events were mostly vehicles with mechanical or electrical issues, flat tires and cars that had run out of gas. (Lou, Yin, \& Lawphongpanich, 2010)

Incident management strategies like FSP can quickly address these types of occurrences and help in the recovery of operations. Benefit/cost studies and qualitative evaluations have documented that service patrols are one of the most effective elements of a transportation incident management program. (Federal Highway Administration, Federal Highway Administration Service Patrol Handbook, 2005). Thus, the quick removal of incidents also known as an assist, can reduce incident duration, remove debris, assist stranded motorists and crash victims and manage traffic. FHWA's 2012 Urban Congestion Trends Operations: The Key to Reliable Travel noted that congestion levels remained relatively unchanged in 19 metropolitan areas including, San Francisco, CA. Congestion levels across all of the congestion measures remained below the levels experienced in 2007. FHWA reports that "all three congestion measures -daily hours of congestion, time penalty for each trip, and worst-trip time penalty - have decreased or remained the same." (Federal Highway Administration, 2012 Urban Congestion Trends Operations: The Key to Reliable Travel, 2012) The reduction and plateau in congestion measurements indicate that all congestion events including incident-related congestion experienced the same pattern. With less incident-related congestion, there may be fewer FSP assists than in previous years. 


\subsection{Overview of U.S. New Vehicle Fleet Turnover and Increase in Dependability}

The national vehicle fleet turnover ratio is the total number of registered vehicles in the U.S. divided by the sales of all automobiles. The vehicle fleet turnover ratio does not provide the age, make or model of the composition of the fleet. Unlike VMT and CHP reported incidents and FSP Assist data, the vehicle fleet turnover ratio is a nonoperational performance measure. Figure 7 shows historical trends in vehicle turnover in the US. Vehicle fleet turnover can be policy-induced. (McBride, 2014) In 2009, U.S. motor vehicle production and sales experienced one of the worst sales periods. There was a decline in production and sales of motor vehicles in the winter and spring of 2009 due largely to the recession. The U.S. production fell to 3.7 million vehicles compared to 10.7 million units in January 2009. The U.S. vehicle incentive program, "Cash-for-Clunkers," increased the production of vehicles in July and August to 6.2 and 5.9 million seasonally adjusted, and greatly reduced inventories. (Yacobucci \& Canis, 2009) According to the U.S. Bureau of Economic Analysis of the U.S. Department of Commerce, for the periods between January 2008 and January 2011, there were "wild swings" in the vehicle fleet turnover ratio, due to the Cash-for-Clunkers incentive program. The degree to which the period of time for when the Cash-for-Clunkers program could impact the U.S. vehicle

fleet mix and produce ancillary results like improved vehicle quality and dependability would vary. These effects could show subtly over a long range of time. 
Figure 7.Total Registered Vehicles Divided by Annual Sales Rate

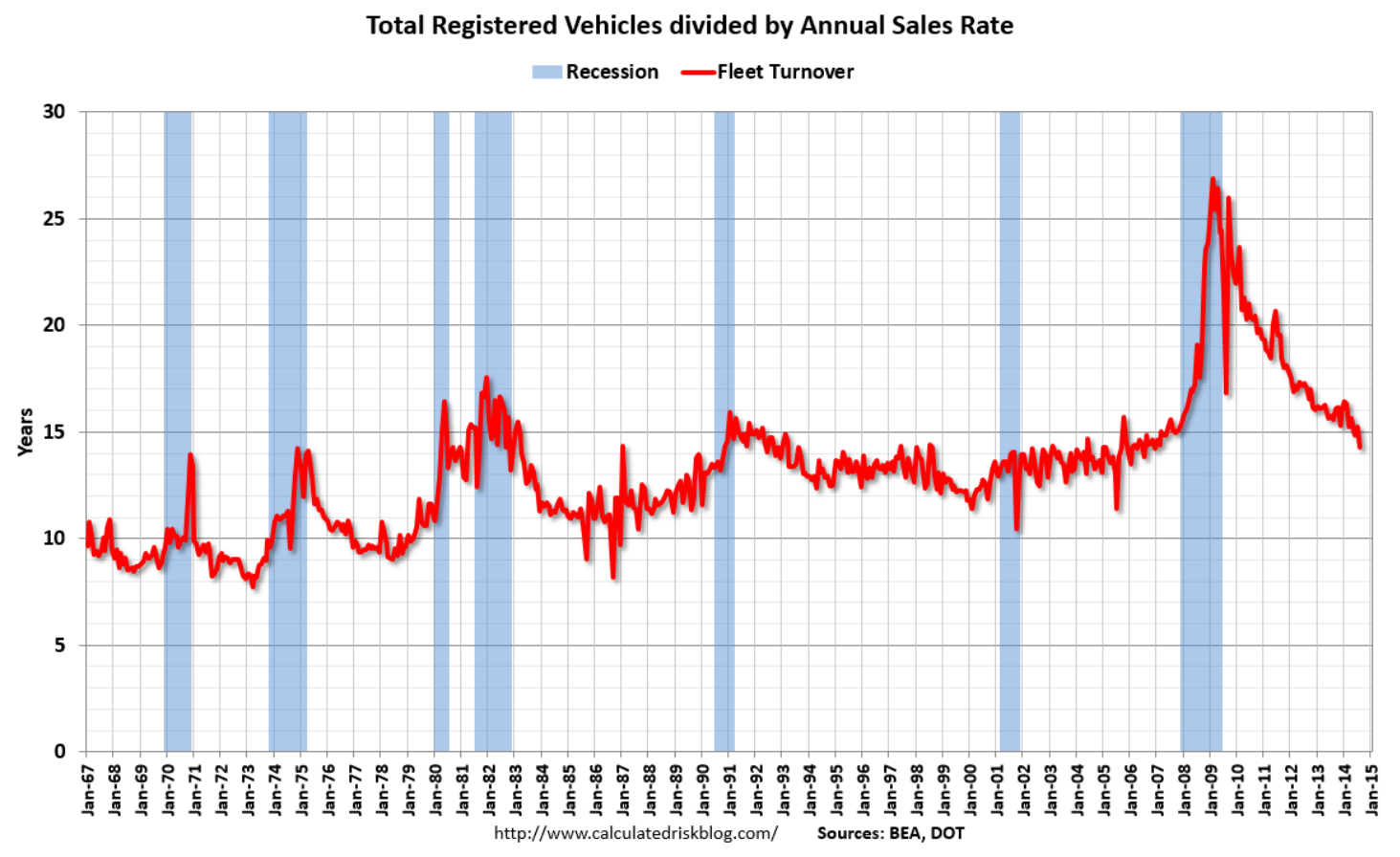

More directly, the induced change in vehicle types and technology on highways has had an impact on the dependability of vehicles. According to J.D. Power and Associates' 2013 U.S. Vehicle Dependability Study, "the long-term dependability of three-year-old models has improved year-over-year." Along with meeting Environmental Protection Agency (EPA) issued standards for vehicle emissions, improved electronic equipment in vehicles also improved vehicle performance and safety. (J.D. Power and Associates, 2013) This specific policy-forcing change in the U.S. vehicle fleet mix beginning in 2009 influenced the types of vehicles driven on the highway today.

In Chapter 2, we reviewed research on the Freeway Service Patrol, current trends in incidents and VMT. We looked at anecdotal information pertaining to new car 
technology and the turnover in the U.S. vehicle fleet. Next, we cover the data sources for this study. 


\section{CHAPTER 3. DATA SOURCES}

This section discusses data sources used in this study. It also includes descriptions of key statistics and characteristics of the data sets. The data sources were gathered through the California Department of Transportation Performance Measurement System (Caltrans PeMS), archived FSP incident data from Caltrans and quarterly Caltrans FSP reports were referenced.

\subsection{California Department of Transportation Performance Measurement System}

The Caltrans PeMS is a freeway performance measurement system for all of California. It collects real time traffic data from sensors and generates performance measures of vehicle miles traveled, hours traveled, and travel time. The system processes loop detector and sensor data in real time in order to produce information for use by staff and researchers to address metropolitan freeway congestion. The PeMS system has a web interface which is accessible to traffic engineers, planners, and researchers. In 2011, Iteris, Inc. acquired Berkeley Transportation Systems, Inc. (BTS), and its accompanying projects including Caltrans PeMS. This is the source of the VMT data used in this project. Data was gathered directly through Iteris, Inc.

\subsection{Caltrans PeMS Archived CHP Incident Data}

\subsubsection{CHP Reported Incidents}

Traffic characteristics such as incidents are recorded to aid in the evaluation of the

program's performance. Law enforcement and transportation operators define traffic incidents differently. Because the FSP program is a joint effort between CHP, MTC and 
Caltrans, data collected is carefully reviewed. Incidents, as defined by the Institute of Transportation Engineers (ITE) and American Association of State Highway and Transportation Officials (AASHTO) are "unplanned randomly occurring traffic events that adversely affect normal traffic operations." (U.S. Department of Transportation, 2013) Transportation agencies classify incident types in order to measure the quality of service response and impact on traffic flow. FSP tow truck drivers patrol freeways to help with on-road incidents such as mechanical problems, flat tires, stalled vehicles and various obstructions to free flow of traffic. These disabled vehicles disrupt the normal flow of traffic. By removing these physical disruptions, FSP aims to mitigate congestion that may follow as a result.

Data on incidents and traffic flow are collected from Caltrans and CHP as well as through FSP's computerized automatic vehicle location system (AVL). The AVL system is used to supervise tow truck drivers manage the fleet of 80 trucks, validate invoices, and receive reports from FSP drivers on their activities.

California Highway Patrol incident data was acquired through Caltrans PeMS. Data regarding incidents on the freeway is recorded by CHP officers on computerized incident logs. The location, direction, type and degree of severity including fatality, noninjury and injury are distinguished when recording in computer-aided dispatch (CAD system). The CHP/CAD center in the Bay Area receives calls about incidents on freeways from CHP officers, motorists, call boxes, other public agencies as well as FSP drivers. FSP only records incidents when and where they are operating. PeMS collects 
and archives CHP incident data from the reports on their Traffic Incident Information Page (http://cad.chp.ca.gov). These are "reported" incidents, though the actual number of incidents is unknown.

\subsubsection{Trends in CHP Reported Incidents between January 1, 2009 to December 31, 2013}

Over the five year period, Freeway Service Patrol recorded a total of 64,578 assists for these seven FSP routes. Although the data set provides the location, time, date and frequency of occurrence, the data set lacks incident type and description, which limits our ability to compare incident type with assist type. In the primary direction, over the seven-day week, 15.9 and 17.3 percent of incidents occurred on Thursdays and Fridays. 31.6 percent and 33.7 percent of incidents were reported during the evening peak period of 3:00 PM to 8:00 PM and mid-day period of 10:00 AM to 2:00 PM, respectively. Incidents reported during the year were consistent, with an almost even distribution of incidents during the aggregate 12-month period. CHP reported incidents experienced slight decreases, dropping 10 percent and 12 percent during the 2012 and 2013 period as shown in Figure 8. Similarly, FSP assists saw dramatic increases during the 2009 to 2011 period, but saw a decline of 16 percent and 30 percent in 2012 and 2013. As seen in Figure 9, FSP assists also track incidents when distributed over the FSP routes.

Of course, this aggregate overview of CHP reported incidents does not provide a complete scope of incidents. Similarly, FSP assists for the seven routes vary based on the following: location, weekday, and weekend, FSP "beat" length, truck hours and the number of trucks deployed. 
Figure 8. Total Incidents and Assists over the Primary Direction, January 1, 2009 to December 31, 2013

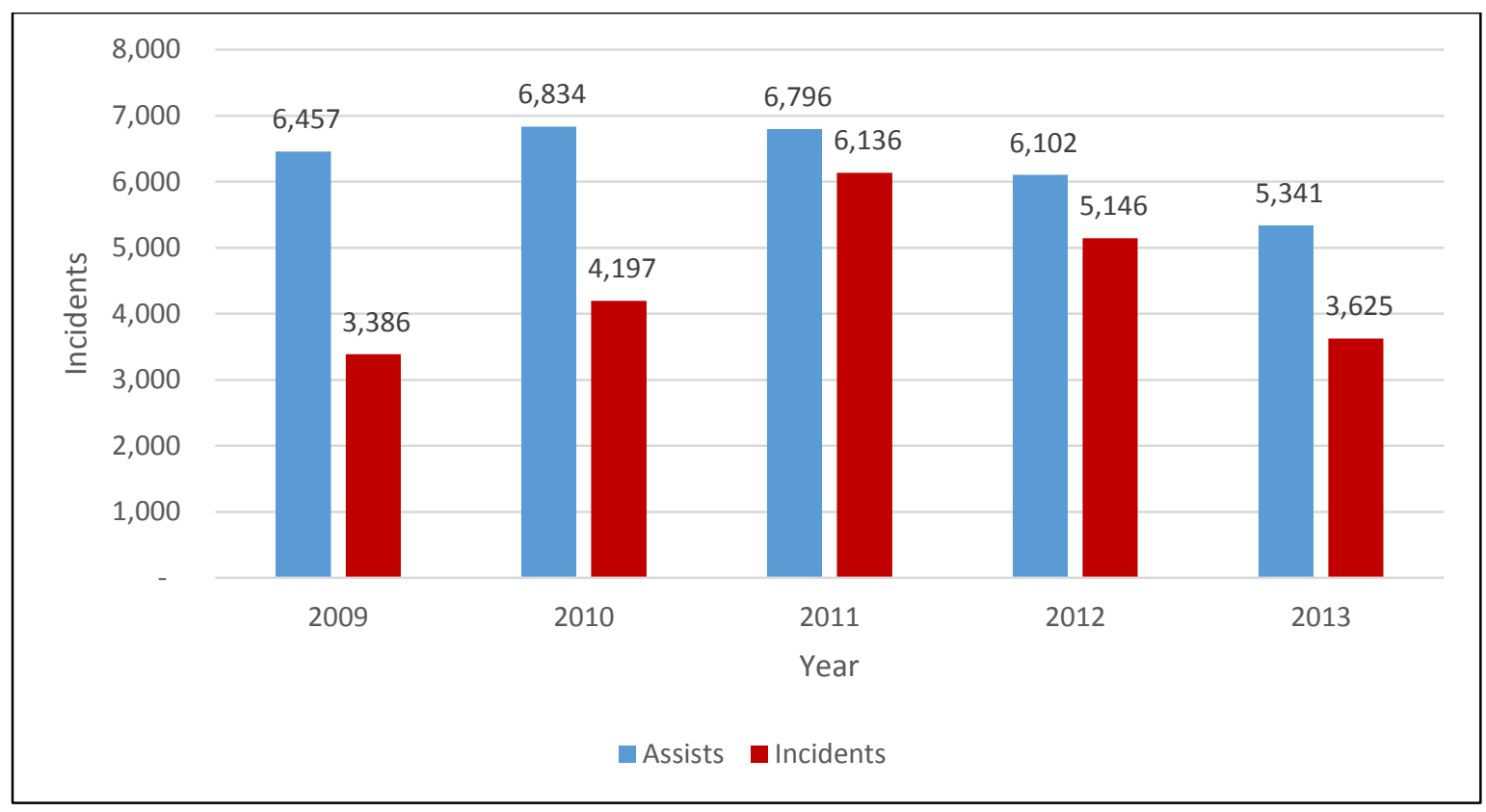

Figure 9. Total Incidents and Assists Distributed over Freeway Service Patrol Routes

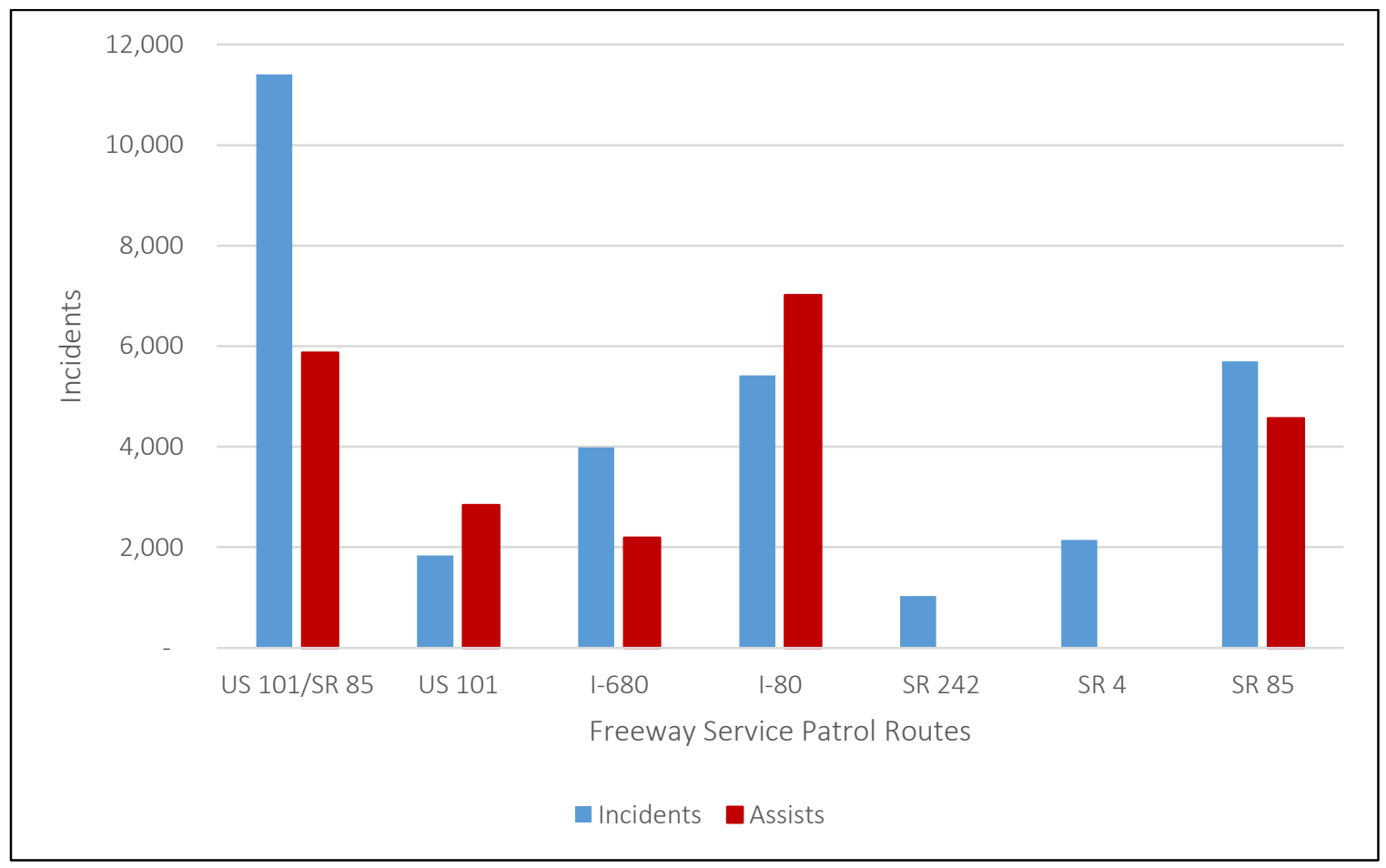

3.3 Freeway Service Patrol Assisted Incident Data 
In order to measure the aid given in response to incidents, FSP records the number of "assists" provided to motorists. The FSP is a solution to aid in the quick removal of incidents, provision of service to motorists and clearance of designated roadways or "beats" during commute hours. To evaluate the effectiveness of FSP response, the program notes the number of assists performed annually, quarterly, monthly and the types of assists encountered. The time, location and position of the assists provided are also reported. Along with the collection of motorist assistance data through patrol logs, emergency service providers such as CHP, use a computer-aided system to $\log$ incident data. These details are integral to determining the effectiveness of service, deployment of service, and management of funds for the incident management program.

The Bay Area MTC's FSP assist information involves both an electronic incident reporting system and paper-based procedures. Each FSP tow truck is equipped with a Ranger System, which transmits incident reports to the FSP database. Tow truck drivers also write down assist records into Daily Shift Records (DSR's). Caltrans staff compiles FSP assist characteristics from this database. The FSP partners review aggregate statistics from the database on a monthly basis. A consultant combines database and paper information and prepares the finalized FSP Annual Report. Program staff currently adheres to a process when preparing biennial implementation plans and contract invoice updates. The process includes a regular review of violations, backup services and costs as well as additional transportation management plan. 


\subsection{FSP Assisted-Incident Characteristics}

The FSP data set contained data for 12 of the 35 routes. Of the 12 records, only seven routes were used for the full analysis because of data consistency and availability. The overall trend in assists can be observed in Figure 10. Upon closer examination, Figure 11 shows the pattern of specific assist types. The seven routes contained available and consistent data in order to perform the study. Because the FSP reporting system is both electronic and manual, there is a margin of error when discerning the type of assist and the number of assists. In this section, we describe the characteristics of the assists for the 12 routes. The assist types changed over the course of the five-year period, with breakdowns such as flat tire changes, mechanical issues and in-lane hazards as the leading assist types. In comparing the overall reduction in assists to the individual assist types, we can see that the number for all activity types is decreasing except for traffic collisions. This trending downward is consistent with the changes in CHP reported incidents.

"Other" assist type follows closely behind flat tire changes. In comparing the change of activities like assisting FSP Beat Partner, collecting debris, drive-offs or refused service, to primary activities like helping with flat tires or removing in-lane hazards, non-primary activities, make up an average of 29 percent of the FSP program's full assists over the course of the five years. Mechanical issues, abandoned vehicles, and vehicles with dead batteries make up an average of 71 percent of the activity types. In

general, the number of assists is decreasing proportionally in various categories. This 
could mean the change in activity types might not actually create a significant difference in the two-year reduction of assists. Rather, motorist assists is decreasing as a whole 
Figure 10. Overall Changes in Assists over Five-Years

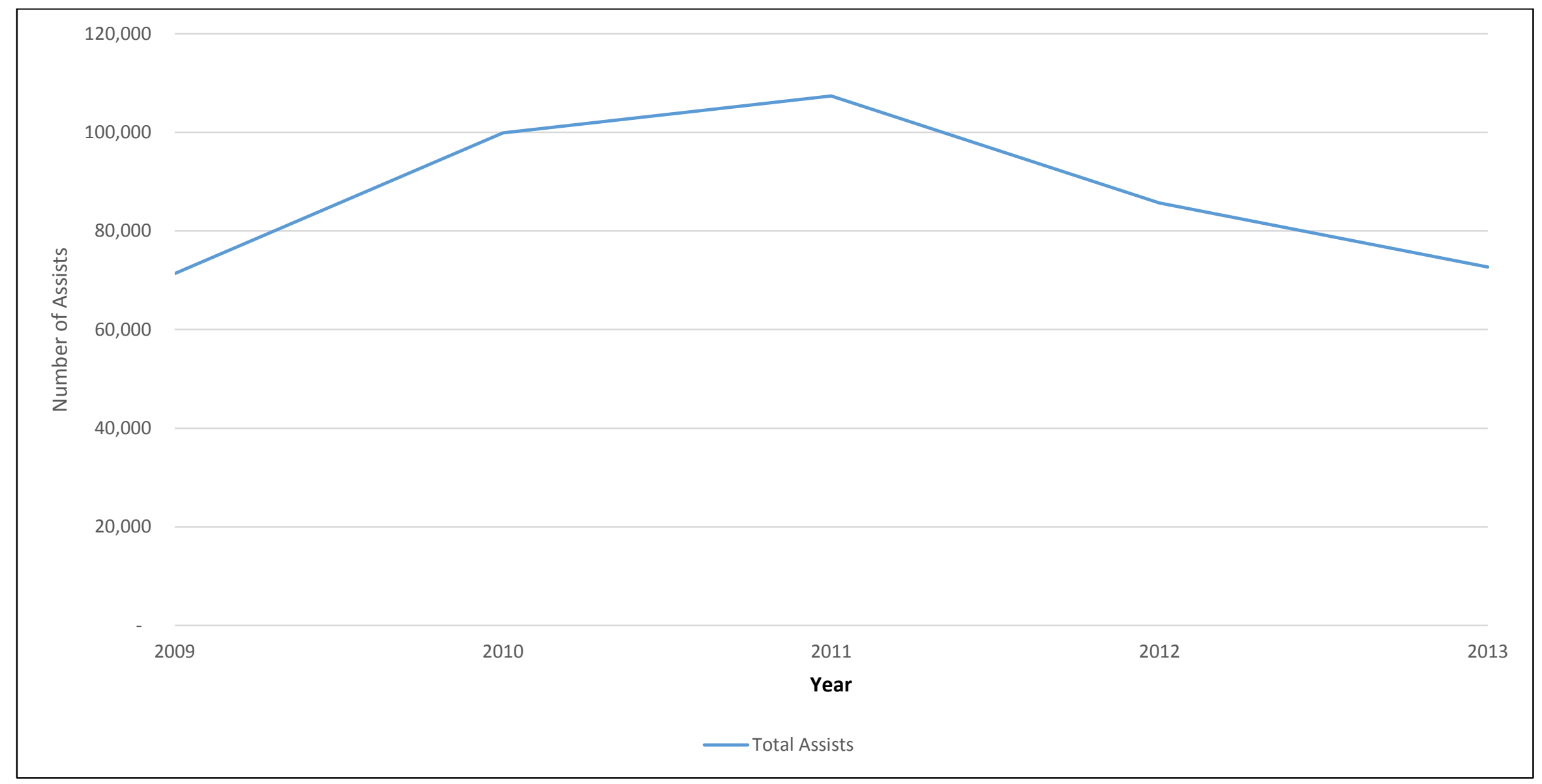


Figure 11. Changes in Assist Type over Five-Years

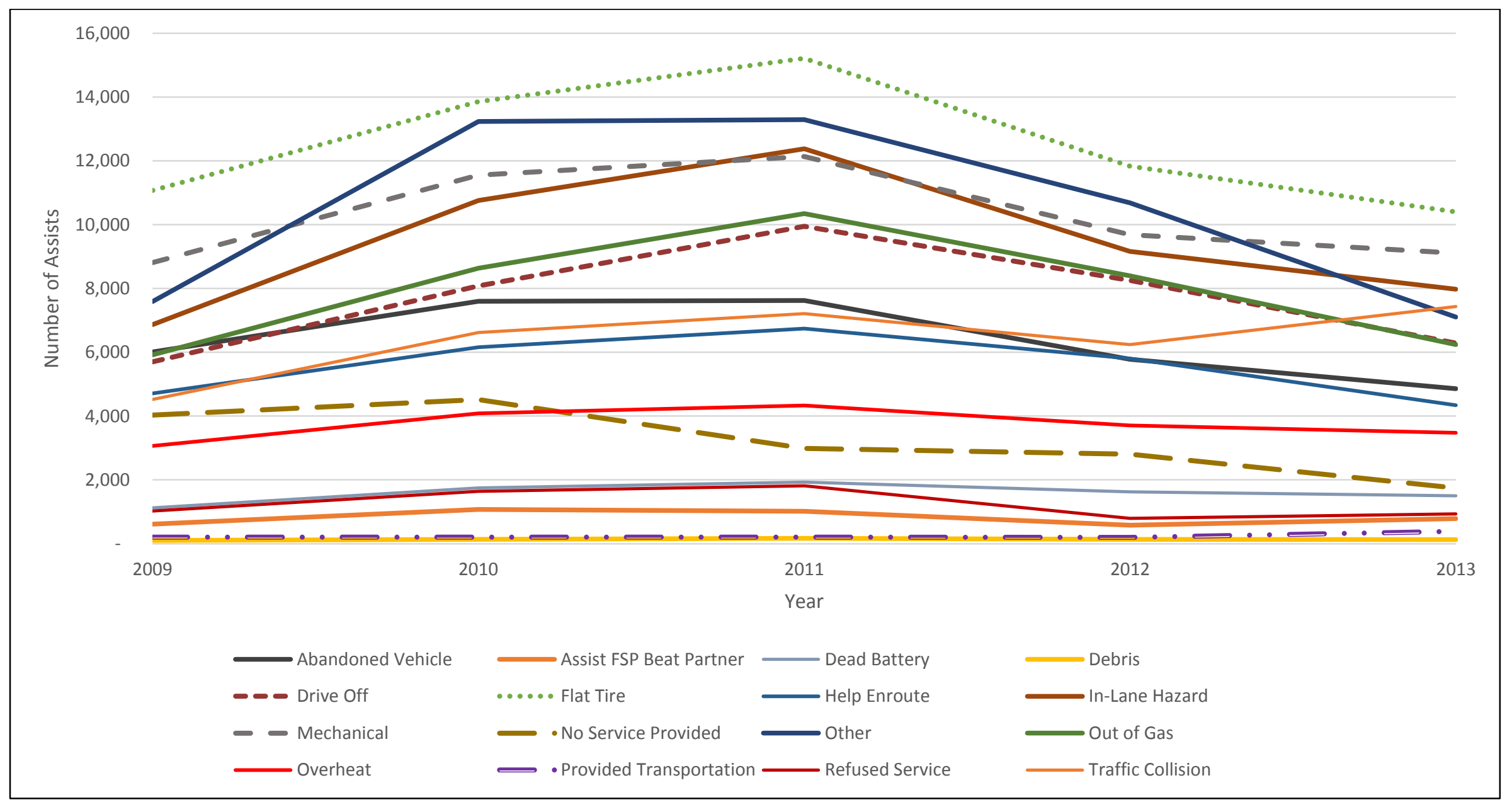


In analyzing the full FSP assist data set, we also look further into the primary and secondary directions of the FSP designated routes for the seven routes US 101/SR 85, US 101, SR 242, SR 85, I-80, I-680 and SR 4. These routes can be seen in Figure 12. The primary direction of the FSP route indicates the direction that motorists typically drive during the morning peak period. The secondary direction follows the evening peak period, with a tendency towards less volume and less incidents. Key statistics show a total of 31,530 incidents for the primary direction and 25,739 for the secondary direction over the five year period. Of the 31,530 incidents in the primary direction, FSP assisted with 6,306 or 24 percent of CHP reported incidents during the five-year period. In the secondary direction, FSP assisted with 3,943 or 15 percent of CHP reported incidents. This is because traffic is generally lower on the secondary direction. With less FSP service and exposure, there tends to be less incidents detected. 
Figure 12. Study Area of Seven Freeway Service Patrol Routes

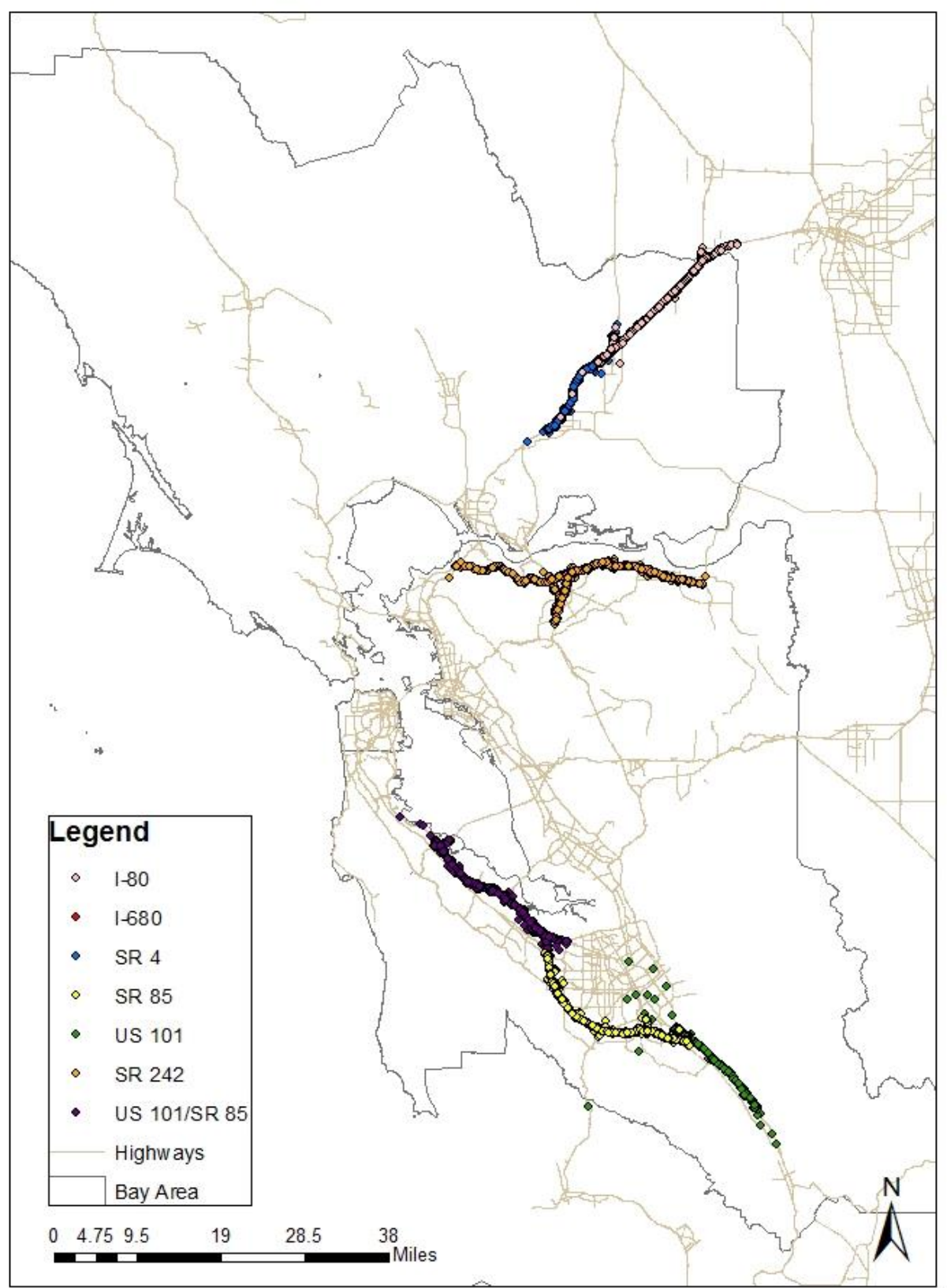




\subsection{Caltrans PeMS Archived VMT Data}

Average daily traffic is collected through Caltrans maintained loop detectors positioned along Bay Area freeways. Loop detector data is logged through Caltrans' webbased Performance Measurement System (PeMS). The MTC maintains a Freeway Service Patrol interface on the PeMS website, which allows data to be collected for specific FSP designated stations based on the length of the FSP Beat. The VMT data set for the period between January 1, 2009 and December 31, 2013 was obtained through Caltrans' consultant Iteris, Inc.

As with any data set, the Caltrans VMT data used has a margin of error. Data fidelity for the loop detectors in the PeMS system has an average of 69 percent accuracy for the five-year study period. Three to six percent of the loop detectors did not collect any data, with nearly 12 percent of controllers and two percent of the detectors were not in working condition. Despite the 30 percent chance of inaccuracy, the VMT data used provides a base for data comparison between CHP Incidents and FSP Assists.

VMT for the seven routes also dipped during 2012 and 2013 during the five-year study period. VMT distributed over the seven routes showed little change, but the total VMT for the seven routes track CHP incident and FSP assist. 


\subsection{CHP Reported Incidents, VMT and FSP Assists Data Set}

\subsubsection{Route/Beat Characteristics}

The route characteristics for this study vary by location, length, and time of day, day of the week, truck hours and the number of trucks deployed as shown in Table 1. Similarly, statistics on VMT, incidents and assists distributed over the routes also vary based on these factors.

Table 1.Route and Beat Characteristics

\begin{tabular}{|l|l|l|l|l|l|l|l|}
\hline 2012-2013 & $\begin{array}{l}\text { US 101/ } \\
\text { SR 85 }\end{array}$ & US 101 & SR 242 & SR 85 & I-80 & I-680 & SR 4 \\
\hline $\begin{array}{l}\text { Number of } \\
\text { Trucks }\end{array}$ & 3 & 2 & 3 & 2 & 2 & 1 & 1 \\
\hline Length (mi) & 18.37 & 13.6 & 23.79 & 13.6 & 12.54 & 10.36 & 11.8 \\
\hline $\begin{array}{l}\text { Truck Hours (h) } \\
\text { Benefit/Cost } \\
\text { Ratio }\end{array}$ & 5,448 & 3,030 & 5,202 & 2,724 & 3,426 & 1,476 & 2,262 \\
\hline
\end{tabular}

(Bay Area FSP Program - Number of Centerline Miles by Year, 2014)

There are reasons why certain beats have higher assists and more incidents. For instance, US 101/SR 85 has a beat length of 18.37 miles, with three trucks deployed over this designation. SR 4 shows lower VMT and fewer incidents, with a shorter beat designation and fewer truck hours. Over 3.2 trillion VMT traversed the US 101/ SR 85 beat during the five years compared to 487 million VMT along the SR 4 beat. Total CHP reported incidents also followed this pattern for the seven routes. The benefit/cost ratio as shown in Table 1 for the seven routes, evaluates the cost effectiveness of the FSP program. Staff use a spreadsheet model to estimate the benefits and costs of each FSP route. The model assumes response time and reduction and calculates incident delays and delay savings as a function of assist totals by type and positon, traffic data and beat 
geometry. Thus, the $\mathrm{B} / \mathrm{C}$ ratio is based on a set of assumptions and is updated every four years, when contracts with tow truck services are renewed.

Though staff strategically allocated the number of truck hours over the corridors, as shown in Figure 13, the length of the beat and the number of trucks remained consistent for the past five years. This can be observed in the Appendices, Figures 30 and 31. This provides an opportunity for reevaluating the allotted number of truck hours to “needier" FSP routes.

Figure 13. Change in Service Hours over Five Years

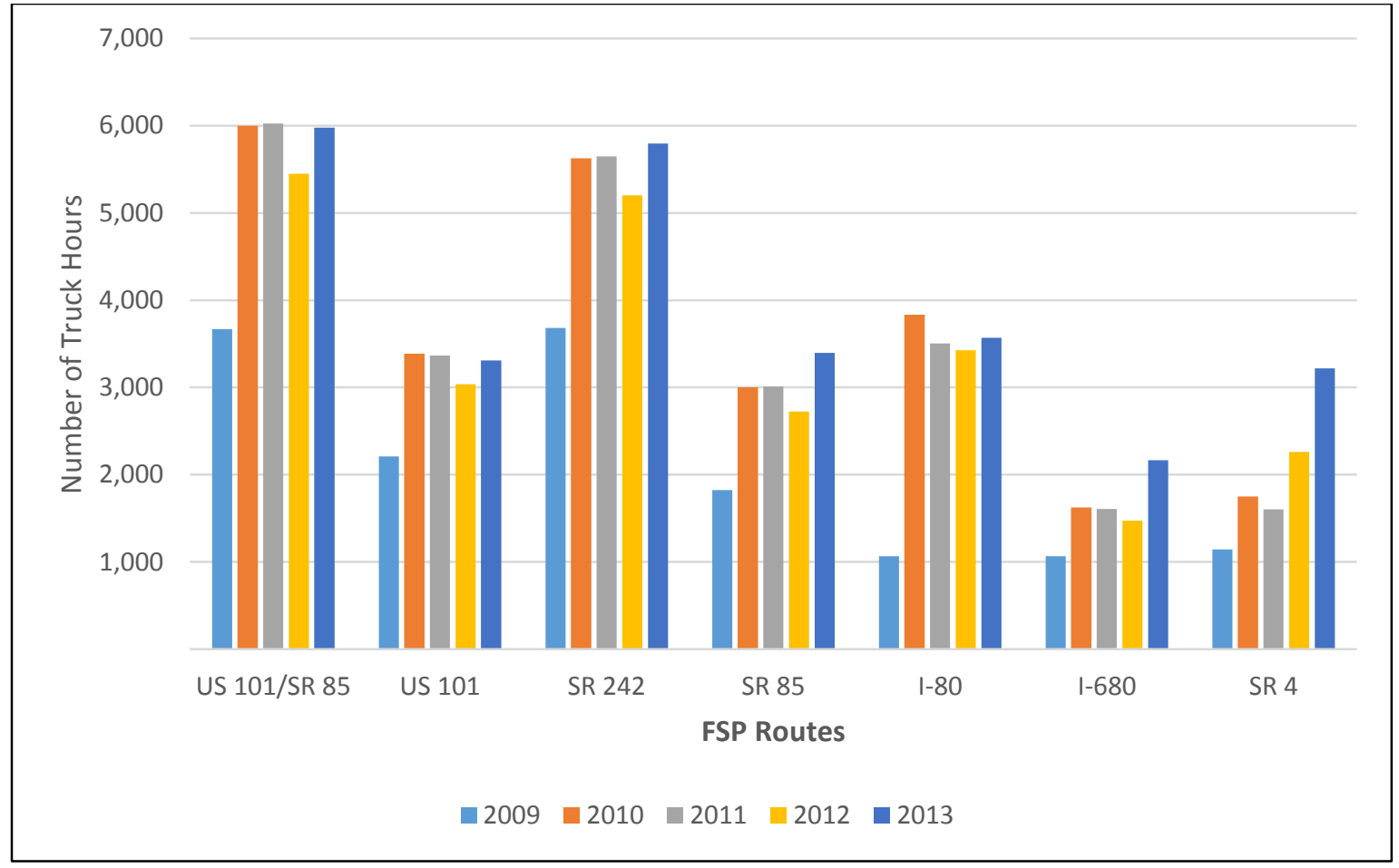

Generally, the location of the freeway plays a large role in attracting VMT and increasing travel demand. Ewing and Cervero, 2001 noted that the built environment is a significant factor in increases in traffic volume. Since certain Bay Area beats are designated within attractive locations, there may be more VMT, increasing the likelihood of incidents and FSP response. However, since FSP assists are not equally proportional to 
every CHP reported incident that occurs, there is a degree of variability between FSP assists and incidents. FSP truck deployment is based on the level of congestion and delay that route experiences. The more VMT, congestion and delay the route experiences, the "needier" that route is considered. There is one exception: the FSP program designated more trucks and truck hours on SR 242 because of anticipated construction. Because construction had not yet occurred, the number of FSP assists was lower than all other routes. The number of trucks and truck hours distributed for that route also determines the number of motorist assistance provided.

The number and types of FSP assists varied over the primary and secondary directions. In the secondary direction, the AM and PM peak periods lasted for a shorter period of time at 6:00 AM to 9:00 $\mathrm{AM}$ and 3:00 PM to 6:00 PM, respectively. The primary direction morning peak began at 6:00 $\mathrm{AM}$ and ended at 10:00 $\mathrm{AM}$ while the evening peak started at 3:00 PM and ended at 7:00 PM. The number of assists also varied, with the primary direction of routes experiencing 39 percent more breakdownrelated assists and 44 percent more accidents, followed by 41 percent more miscellaneous assists than the secondary direction.

In this chapter, we evaluated the data sources and provided background information on the Freeway Service Patrol's assist information, their reporting system, Caltrans PeMS' VMT and CHP reported incidents data. We identified and reviewed factors that influence the exposure of tow trucks to incidents due to traffic volume, truck 
hour service, length of the FSP route and number of trucks on the shift. In the next chapter, we describe the methodologies used. 


\section{CHAPTER 4. METHODOLOGY}

In previous research, methods were developed to model congestion, accidents and incident prediction. The benefits, costs and effectiveness of the Freeway Service Patrol program were analyzed. Other topics addressed the deficiencies in the FSP program through the development of simulation models, which accounted for queuing and route diversion. Other studies typically used incident rates (number of incidents/VMT, or incident/AADT), while more recent studies used the absolute number of incidents as the response variable. Using incidents as the absolute variable allows for estimation of direct relationship between the VMT and assists. This approach does not imply a linear relationship and is less restrictive (Konduri, et al., 2013). This study evaluates the relationship between VMT, CHP reported incidents and FSP Assists in the Bay Area through bivariate correlation and a chi square test. (Healey J. , Chi Square Testing, 2011)

We test whether there is a relationship between VMT, CHP reported incidents and FSP assists for the seven FSP routes in the primary and secondary directions. We test to see if FSP assists is independent of VMT and incidents. First we create ranges (low, low-

medium, and high) for VMT and incidents and utilize two-way frequency tables to observe the dependence between VMT, assists and incidents. We use the Lorenz Curve and Gini Coefficient to evaluate the distributions between assists, incidents and VMT. To further analyze the dependence, we perform a chi square test. Using SPSS for our chi square test and bivariate tables, we identified:

- Rows: VMT, Incidents, and Assists 
- Columns: Weekday, Weekend, VMT Category and Seasonality (months of the year)

The correlation between VMT, CHP reported incidents and FSP assists are evaluated through the following methods:

\subsection{Bivariate Correlation}

VMT, incidents and assists were displayed in bivariate tables at the same time. The nonzero values of our chi square statistic indicate that there is some conditional association between VMT, incidents and assists. Bivariate correlation was used to ascertain whether the three variables are correlated with one another. Our dependent variable, FSP assists and independent variables, VMT and CHP incidents are displayed in columns and the dependent variables of incidents and VMT are displayed in the rows. We visualize the variability of VMT, incident and assists through the Lorenz Curve and Gini coefficient methods.

\subsection{Lorenz Curve and Gini Coefficient}

The Lorenz Curve and Gini Coefficient are economic and statistical methods normally used to represent income inequality and poverty in countries. The Lorenz curve graphically displays cumulative distribution of the empirical probability of two variables. The curve shows the proportion of overall the first variable assumed by the bottom percentage of distributions, but can be used to represent the probability distribution of continuous functions such as FSP Assists, CHP reported incidents and VMT. The Gini coefficient is the ratio of the area between the line of perfect equality and the observed Lorenz curve to the area between the line of perfect equality and the line of perfect inequality. (Huang, Kuo, \& Kao, 2003) The higher the coefficient, the more unequal the 
distribution is. When the coefficient is closer to zero, it expresses maximal equality among values. A greater value than one represents a negative contribution to the total.

There are advantages to using the Gini coefficient to explore the relationship between the distributions of variables. Given that most of the incident and assist data are ones and zeroes, the Gini coefficient does not consider the size of the data set, which provides a level of independence for both scale and size.

Therefore, we evaluate the relationship between assists, incidents and VMT over the seven FSP routes: SR 242, SR 4, I-680, US 101, SR 85, US 101/ SR 85 and I-80, by displaying the variability between the variables through the Lorenz curve and finding the Gini coefficient. Our inputs are:

- $\quad$ Routes: SR 242, SR 4, I-680, US 101, SR 85, US 101/SR 85 and I-80

- Total Assists, Total Incidents and Total VMT per route

Using the Gini coefficient formula, we explore the paired relationship between assists and incidents, assists and VMT, incidents and VMT. We find the cumulative percentages of all incidents, assists and VMT per route. We are able to see graphically the percentage in which VMT, incidents and assists are distributed and how far apart they are.

There are limitations in using the Gini coefficient to measure our traffic level data set. For instance, there may be systematic and random errors in the data, making the Gini coefficient outputs less accurate. The Gini coefficient is influenced by the granularity of the measurements. This means, lower granularity data will yield a lower Gini coefficient 
while higher granularity data will yield a more accurate distribution. Since the totals of assists, incidents and VMT were aggregated over a route, these inputs are considered lower granularity. The totals of the three variables provide a broad overview. (Huang, Kuo, \& Kao, 2003)

\subsection{Chi Square Test}

Our null hypothesis for our chi square is that VMT, incidents and assists are independent. We want to disprove this assumption that VMT, incidents and assists occurred by random chance. (Healey J. F., 2012). Our null hypothesis is false if there is a large difference between our expected and observed frequencies for our variables. If there are differences between our observed and expected frequencies, there is less of a chance that FSP assists are independent of VMT and incidents. This means, we are likely to reject the null hypothesis. (Healey J. , Chi Square Testing, 2011)

Testing our hypothesis with the chi square method has limitations. First, chi square becomes difficult to interpret when the variables have many categories. Second, the probability of rejecting the null hypothesis increases as the number of cases increases, regardless of any other factor. Chi square is sensitive to sample size. The value of $\mathrm{x}^{2}$ (obtained) increases at the same rate as the sample size. There is a degree of uncertainty as the larger sample size may lead to a decision to reject the null when the actual relationship is trivial. Our sample size is $\mathrm{N}=616,583$ cases, which means there is a higher rate of sensitivity. (Healey J. F., 2012)

\subsection{Other Methods}


We experimented with other methods. We found that these methods did not properly explain the connection between the three variables in a direct way.

\subsubsection{General Linear Regression}

General linear regression assumes that the relationship between data points form a straight line. Since our data set of VMT which is interval-ratio and CHP reported incidents and FSP assists are categorical, in nature, the outputs of the general linear regression only explained 13.5 percent of the data. This means, the data was not a strong fit for the linear regression model. However, there was significance in the data when the time period, and location of the beats was factored in. Since some of the variables are not interval-ratio in a level of measurement, this was not a "good" fit for a linear pattern.

\subsubsection{Poisson Regression}

Poisson regression was also used to model the relationship between CHP reported incidents and FSP assists. Incident and assist data are discrete events which means incident and assist data are corresponding integer counts. Poisson regression attempts to model a non-linear relationship between random occurrences such as incidents and assists. The model again found a significance with the time period and location of the beats for the incidents and assist data. This did not explain the level of association between incidents and assists, but suggests that multiple factors contribute to a relationship.

In Chapter 4, we discussed the different methodologies used including two-way frequency tables, the Lorenz Curve and Gini Coefficient as well as chi square testing to explain FSP service assists' dependence on traffic volume and incidents. In Chapter 5, we discuss the data collection and process of this information. 


\section{CHAPTER 5. DATA COLLECTION AND PROCESSING}

\subsection{Preparation of the Study}

VMT, CHP reported incident data and FSP assist information for the period of January 1, 2009 to December 31, 2013 was processed through Microsoft Access, Excel, and SPSS. VMT, CHP Incident and FSP assist data were joined to meet specific criteria such as similar dates and times when incident and assists occurred, and the specific beat. The data match between FSP assists and VMT, and CHP Incident data was further paired down to prepare a complete data set. Data for FSP assists, VMT and CHP incidents provide available and consistent data for seven FSP routes for both the primary and secondary directions. These routes include: US 101/SR 85, US 101, SR 242, SR 85, I-80, I-680 and SR 4 which correspond with Beats 10, 31, 25b, 32, 34, 35, and 36, respectively.

First, the data set was evaluated through the preparation of time series plots for VMT, CHP reported incidents and FSP assists. VMT, incidents and assists were aggregated for all weekdays and weekends throughout January 1, 2009 to December 31, 2013. The variables were also aggregated based on time of day, day of week, and month of year. Separately, FSP assist data for January 1, 2009 to December 31, 2014 was analyzed. FSP assist data included manual inputs from tow truck drivers, GPS longitudinal and latitudinal coordinate data, descriptions of the incident and the position of the incident. The data was aggregated based on activity categories like "crashes, breakdowns, hazards/blocking, response/no delay and miscellaneous/no delay." The purpose of the incident tree as seen in the Appendices, Figure 29, is to show the proportion of incident types. The full data set included recoding of times of day, VMT 
levels, days of the week and day of the year. The recodes changed string data to numerical data, allowing SPSS to statistically evaluate the data set.

The aggregated data for each session was charted on bar graphs and line graphs year-to-year, over a 24 hour period of time and monthly. A pattern appeared to arise, given that the peaks and valleys of CHP incidents and assist data followed a similar pattern to that of VMT. To verify that VMT and incidents are correlated with assists, the validity of the trend that appeared was tested in SPSS, using the Gini Coefficient and Lorenz Curve, bivariate tables and chi square testing. 


\section{CHAPTER 6. RESULTS AND EVALUATION}

Bivariate correlation and chi square testing was used for the full data set. The entire data set was tested based on the weekend, weekday and seasonal ranges. The following sections discuss the relationship between the number of incidents, VMT ranges and the number of FSP assists.

\subsection{Trends and Patterns}

The primary direction data set has $\mathrm{N}=312,750$ cases and the secondary direction contained $\mathrm{N}=313,214$ cases, but with fewer incidents and assists. This data set is derived from the number of VMT records and posted times for incidents and assists. Each corresponding assist and incident is joined with the posted VMT hour. Usually, the primary direction is selected for the commute time, duration and distance. The primary direction and secondary directions for our study experiences similar levels of incidents. The secondary direction shows lower levels of assists. VMT for the primary and secondary direction were consistent. As seen in Figure 14, incidents, assists and VMT followed a similar AM and PM peak pattern, with VMT rising during the morning and evening hours, much like incidents and assists. While Figure 14 appears to show an increase in FSP response to incidents, in fact, there is more service exposure during that

period of time than incidents. During off peak periods, CHP reported incidents still occurred without FSP service. 
Figure 14. Total VMT, CHP Incidents and FSP Assists Distributed over 24-Hours, January 1, 2009 to December 31, 2013

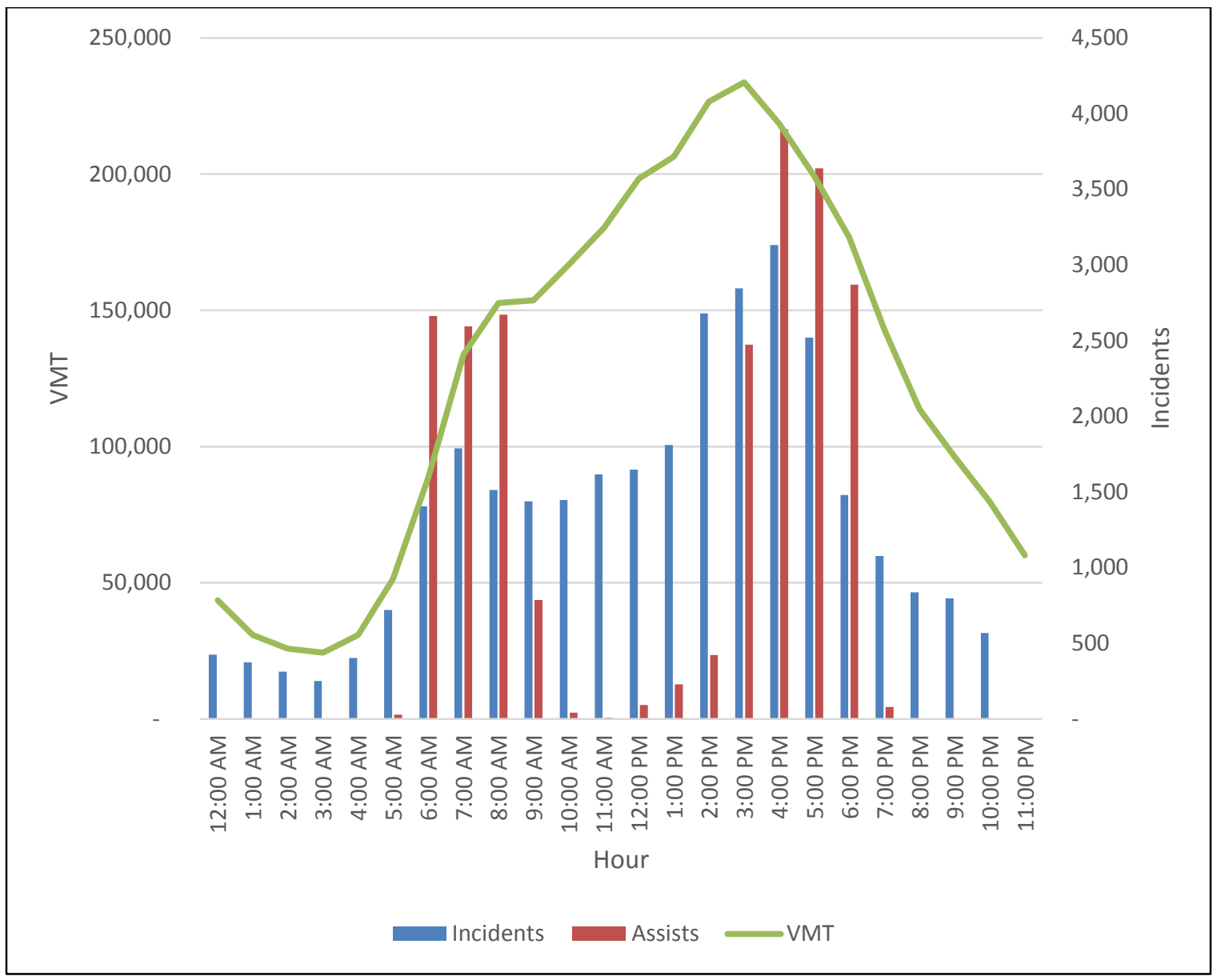

The number and types of FSP assists varied over the primary and secondary directions as seen in Figures 15 and 16. In the secondary direction, the AM and PM peak periods lasted for a shorter period of time at 6:00 AM to 9:00 AM and 3:00 PM to 6:00 PM, respectively. The primary direction morning peak began at 6:00 AM and ended at 10:00 AM as shown in Figure 14 while the evening peak started at 3:00 PM and ended at 7:00 PM. The number of assists also varied, with the primary direction of routes experiencing 39 percent more breakdown-related assists and 44 percent more crashes, followed by 41 percent more miscellaneous assists than the secondary direction. 
Figure 15. Freeway Service Patrol Assists Distributed over Primary Direction, January 1, 2009 to December 31, 2013

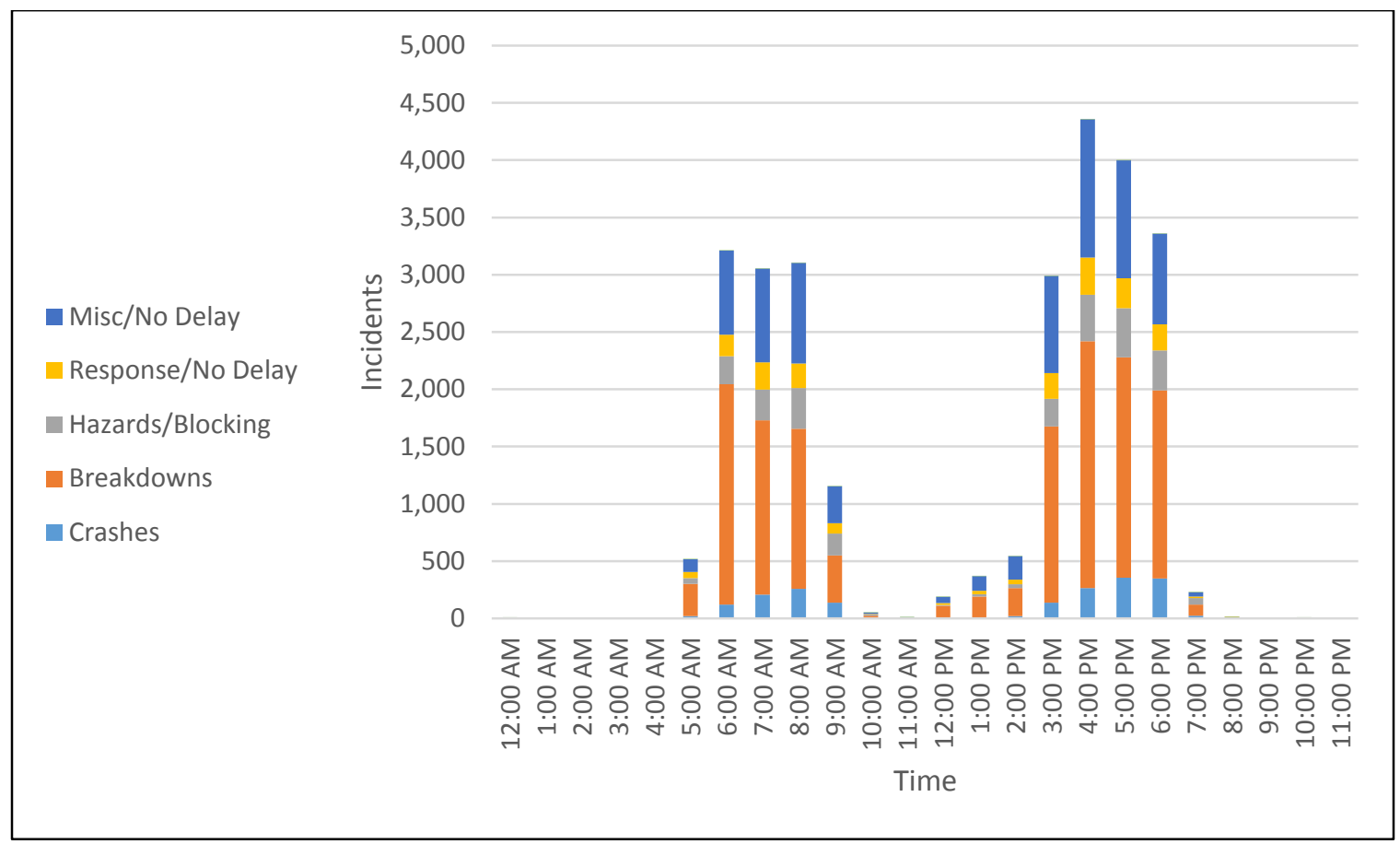

Figure 16.Freeway Service Patrol Assists Distributed over Secondary Direction, January 1, 2009 to December 31, 2013

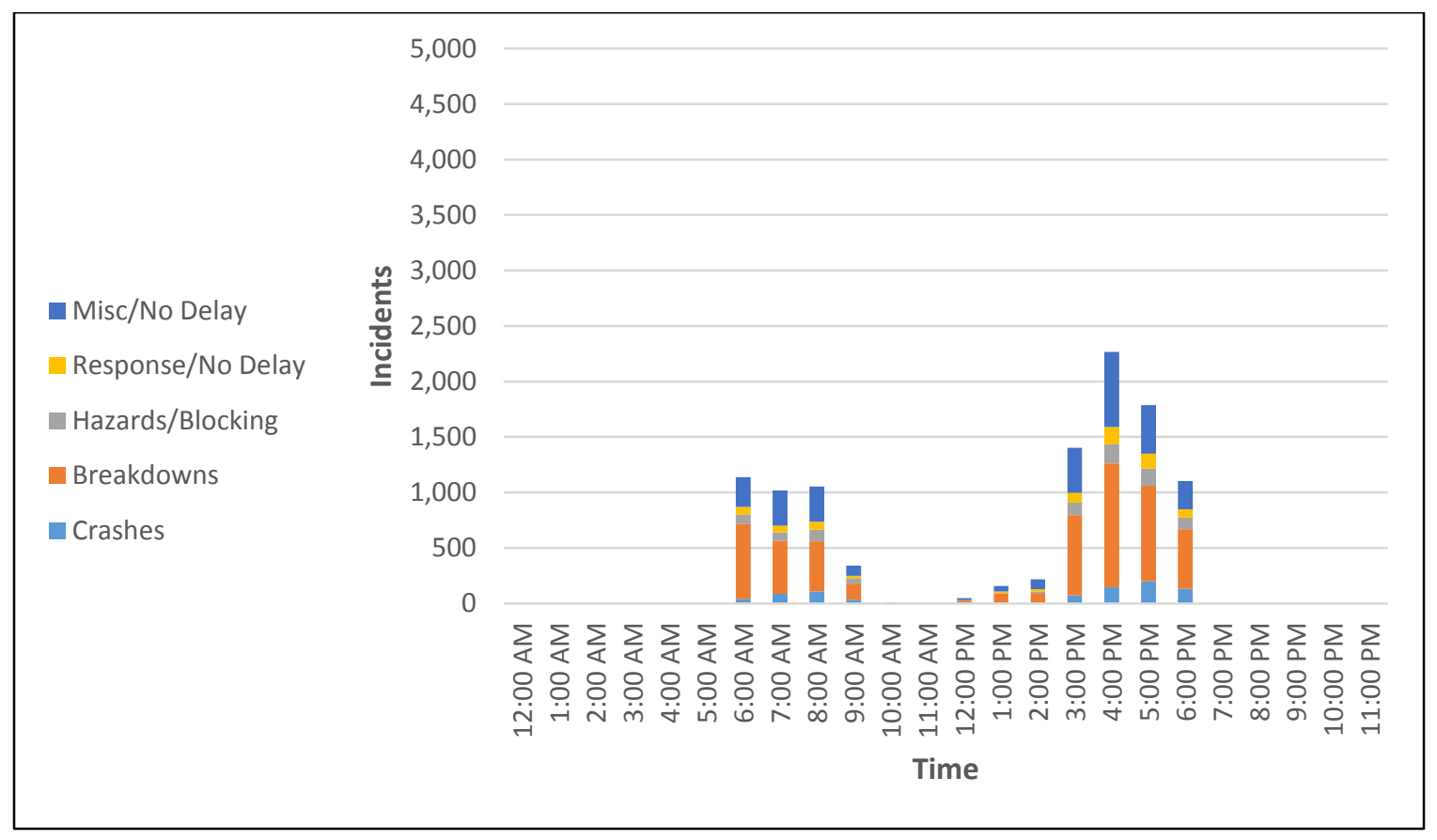




\subsection{Bivariate Table Results}

Since the number of incidents, assists and VMT follow a similar pattern, we test the statistical variation to see if there is any significance between the three variables. Bivariate tables and chi square testing for the full data sets show correlation among all variables.

The bivariate table shows the level of involvement in voluntary associations between our three variables. As shown in Table 2, the correlation between VMT and incidents is 0.320 , indicating that there is a shared association, less than 1 , but closer to 0 .

Table 2. Primary and Secondary Direction Bivariate Table Results

\begin{tabular}{|l|l|l|l|l|l|l|}
\hline \multirow{2}{*}{} & \multicolumn{3}{|l|}{ Primary Direction } & \multicolumn{3}{l|}{ Secondary Direction } \\
\cline { 2 - 7 } & VMT & Incidents & Assists & VMT & Incidents & Assists \\
\hline VMT & 1 & 0.32 & 0.331 & 1 & 0.304 & 0.269 \\
\hline Incidents & 0.32 & 1 & 0.166 & 0.304 & 1 & 0.116 \\
\hline Assists & 0.331 & 0.166 & 1 & 0.269 & 0.116 & 1 \\
\hline
\end{tabular}

The correlation between VMT and assists is 0.331 while the correlation between incidents and assists is 0.166 . Correlation for both the primary and secondary directions between assists and incidents revealed a 0.116. Although there is a correlation between incidents and assists, the greater number of zeroes compared to ones, which indicates an incident or assist having occurred, suggests that the number of FSP assists per route is not proportional to incidents. The covariance of the data set represents the estimated variance or mean squares of the variable. The covariance between VMT and incidents as well as assists is greater, representing the degree of how much the data changes together. The covariance between incidents and assists is below 1 , and is closer to 0 , indicating a lower 
covariance. Following, we demonstrate the variability between the three factors through the Lorenz Curve and Gini Coefficient.

\subsection{Lorenz Curve and Gini Coefficient Results}

\subsubsection{Primary Direction}

The results of the Lorenz curve and Gini coefficient evaluation for the seven FSP routes indicate a level of inequality between the three variables. The primary direction data for aggregated VMT, assists and incidents for the seven day week over the 24 hour period was used for the Lorenz curve graphs and Gini coefficient calculations. The Gini coefficient results were closer to zero than one. This suggests that the level of dispersion between the distributions of assists, incidents and VMT are linked, but are not completely equal. In Figure 17, assists and incident distribution for FSP shown has a Gini coefficient of 0.251 or 25 percent deviation from the blue line of equality. 
Figure 17. Assists and Incident Distribution for FSP Routes

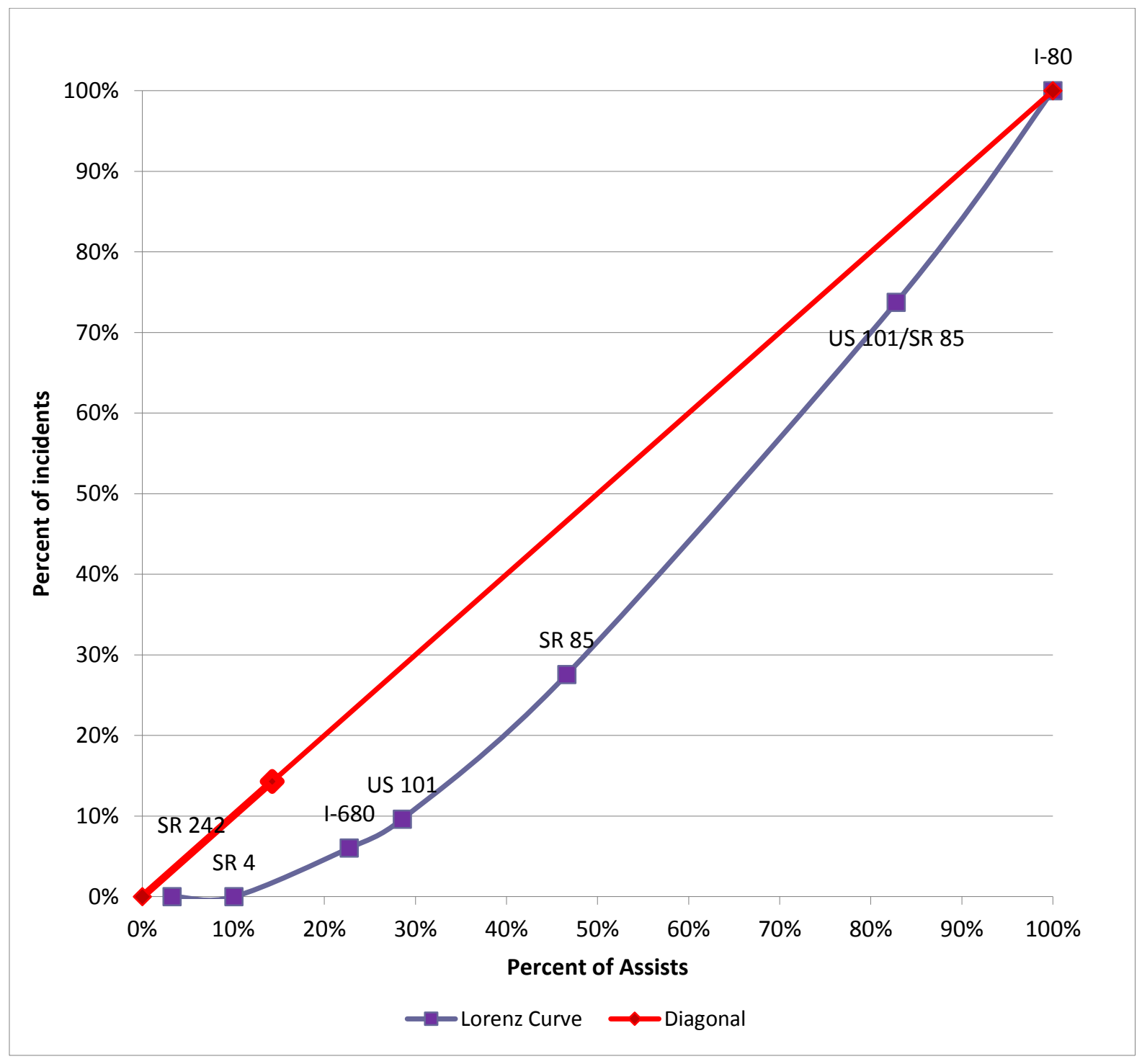

In Figure 18, the distribution of assists and VMT for FSP revealed a coefficient of 0.217 or 21 percent. The dispersion between assists and VMT is less than assists to incidents, which correlates with the two-way frequency results. Results suggest that the variability between VMT and assists is less than that of assists and incidents. In the bivariate tables, the correlation between assists and VMT was 0.347 for the primary direction data set. 
Figure 18. Assists and VMT Distribution for FSP Routes

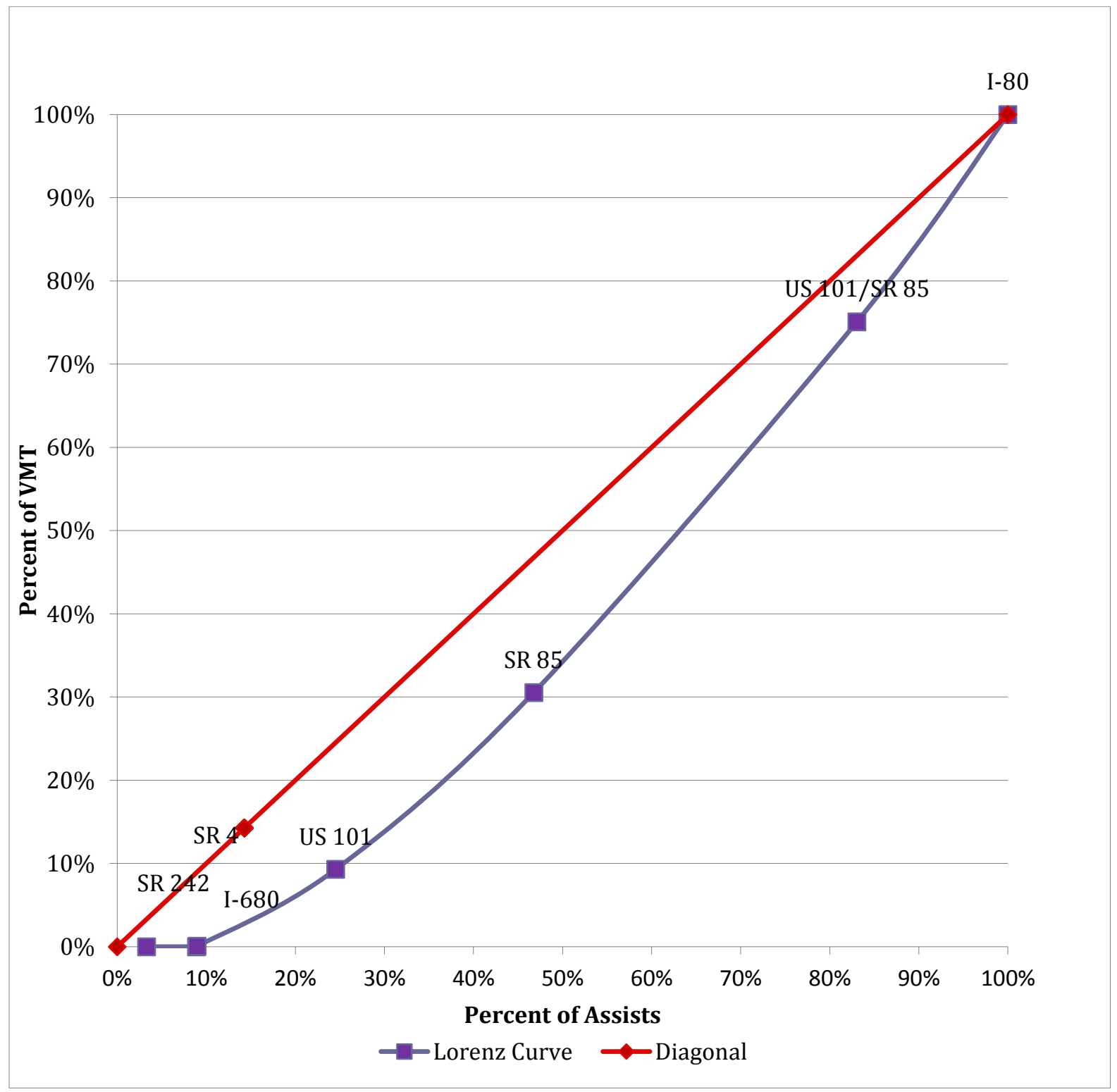

The incident and VMT distribution for FSP in Figure 19 shows a Gini coefficient of 0.305 or 30 percent. There is greater degree of inequality between incidents and VMT for the FSP routes, which again, pair with the bivariate correlation results that show a weaker association. 
Figure 19. Incident and VMT Distribution for FSP Routes

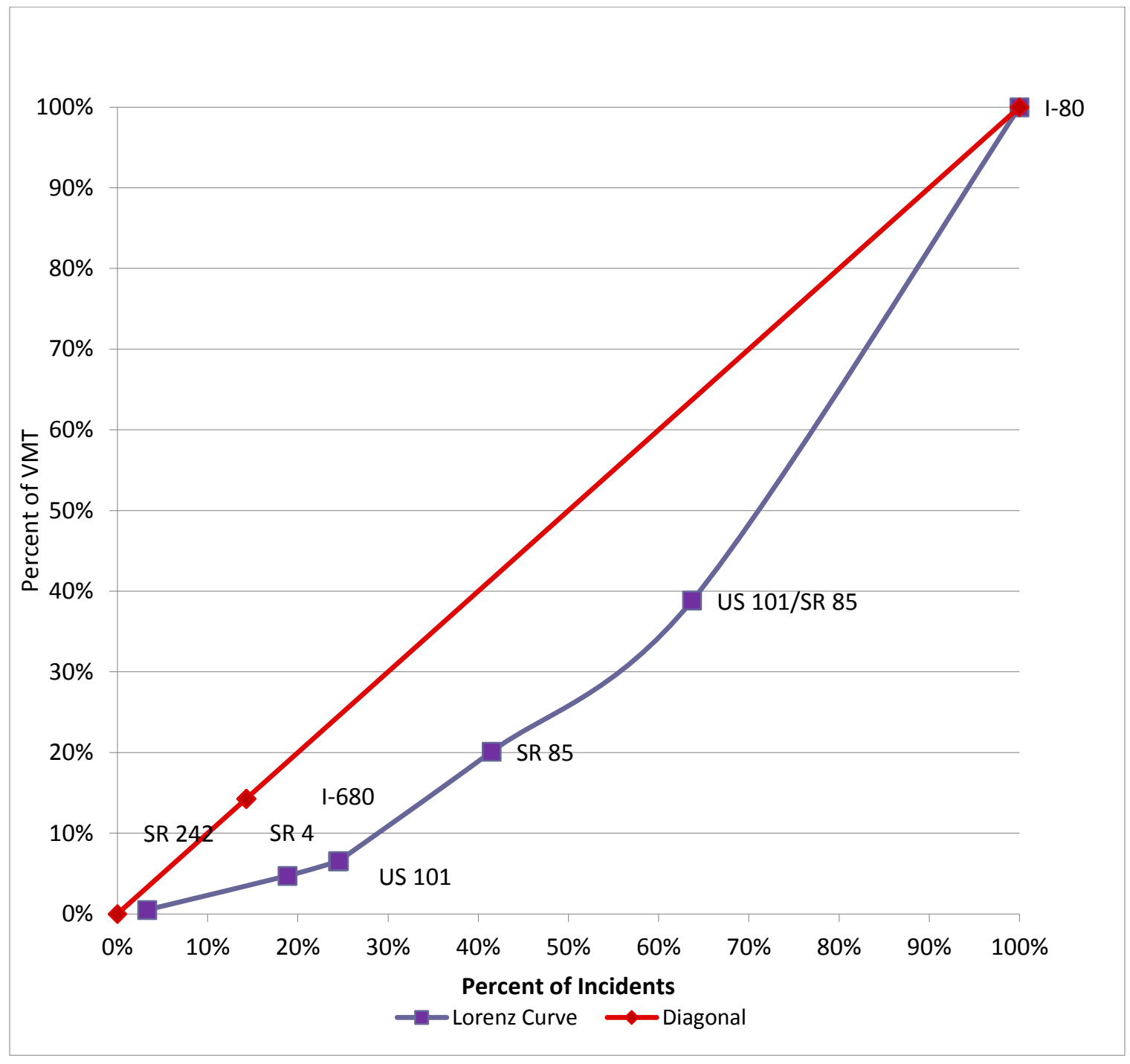

\subsubsection{Secondary Direction}

The secondary direction set reports lower VMT, incidents and assists than the primary direction. While the Gini coefficients for the secondary direction are similar to that of the primary direction, the inequality of assists, incidents and VMT are greater. With less data, Figure 19, assists and incident distribution for FSP routes show greater variability with a Gini Coefficient of 0.285 or 26 percent. 
Figure 20 shows that assists and VMT distribution for FSP has a Gini coefficient of 0.330 or 30 percent. This is greater than in the primary direction with a coefficient of 0.251. Figure 21 demonstrates a greater dispersion in frequency of incidents and VMT with a coefficient of 0.325 or 33 percent.

Figure 20. Assists and Incidents Distribution for FSP Routes

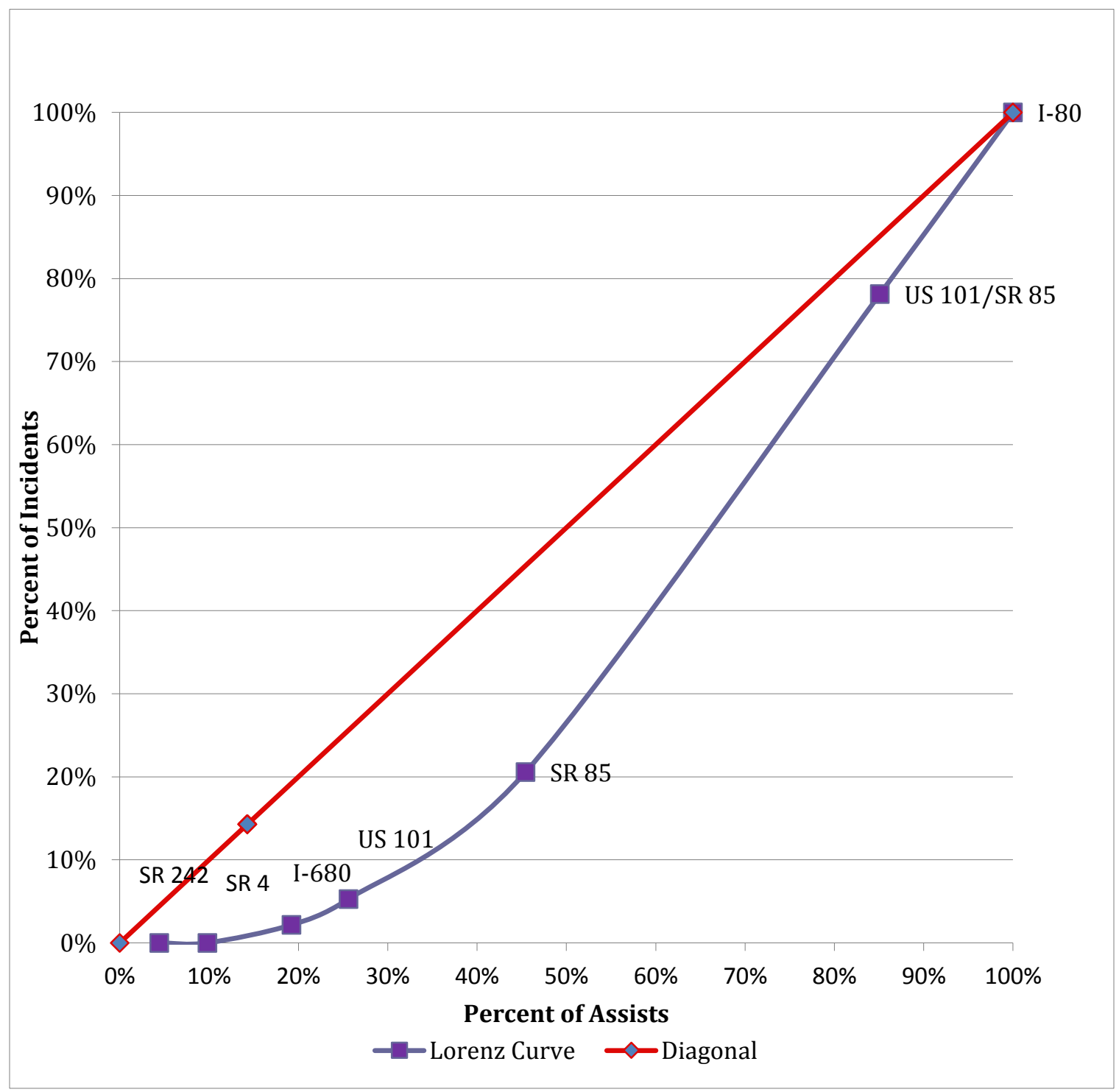


Figure 21. Assists and VMT Distribution for FSP Routes

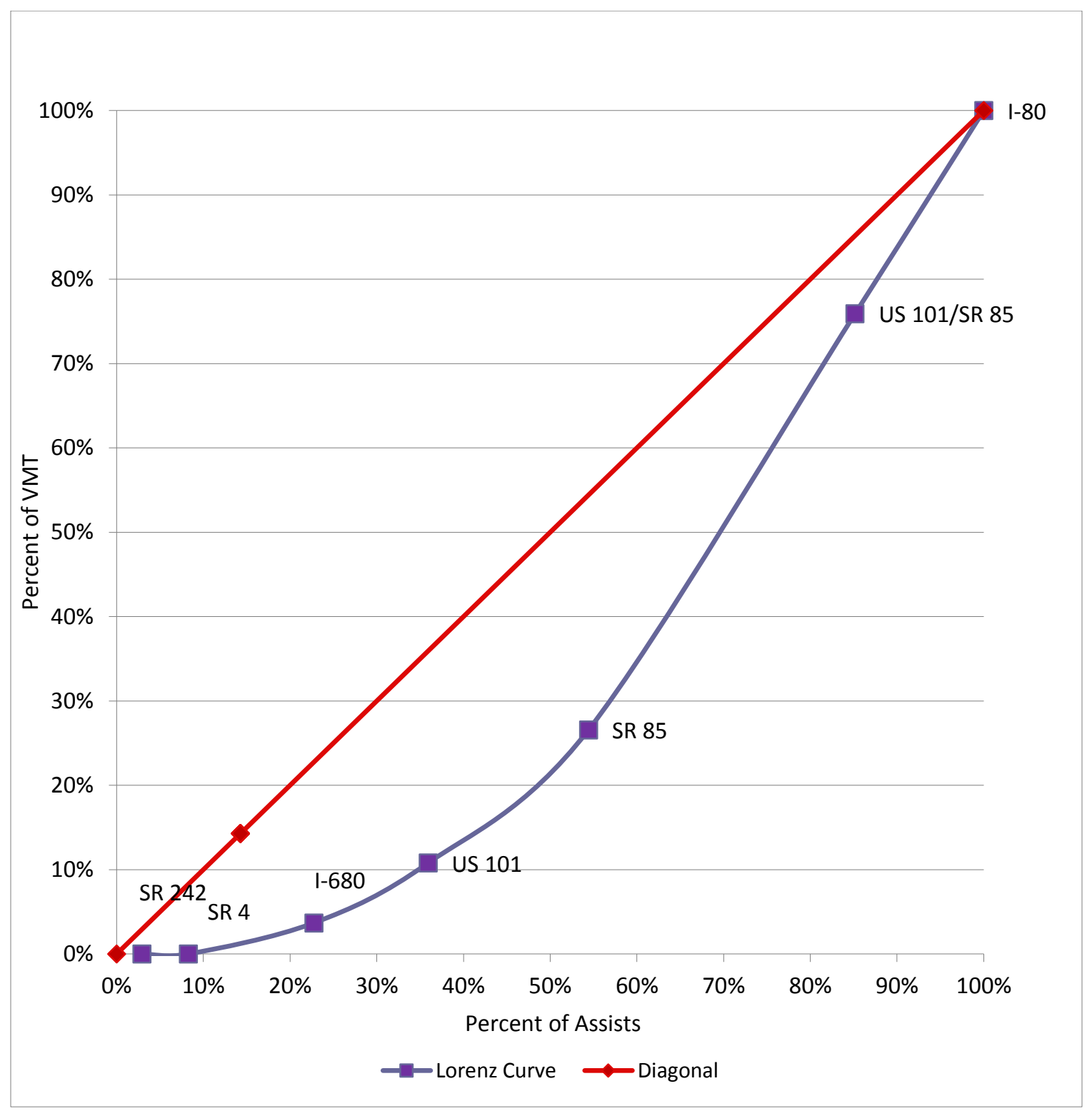


Figure 22. Assists and Incident Distribution for FSP Routes

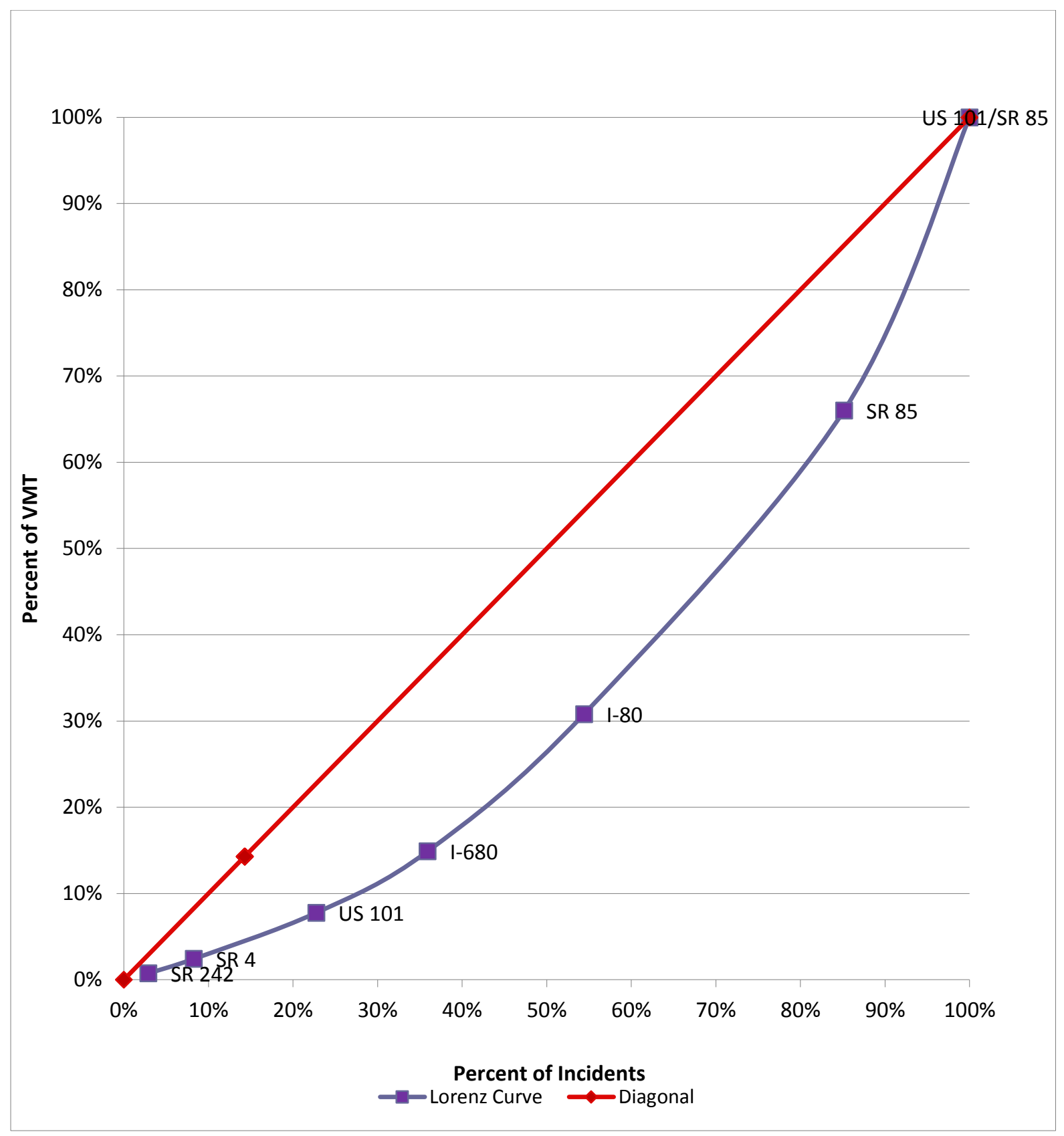




\subsection{Chi Square Test}

We want to further investigate the level of statistical variation by testing VMT versus incidents and assists over the weekday and separately, over the weekend. Since assists closely follow the pattern of incidents, we also test for their significance.

Figure 23. Freeway Service Patrol Assists Distributed over Weekdays, January 1, 2009 to December 31, 2013

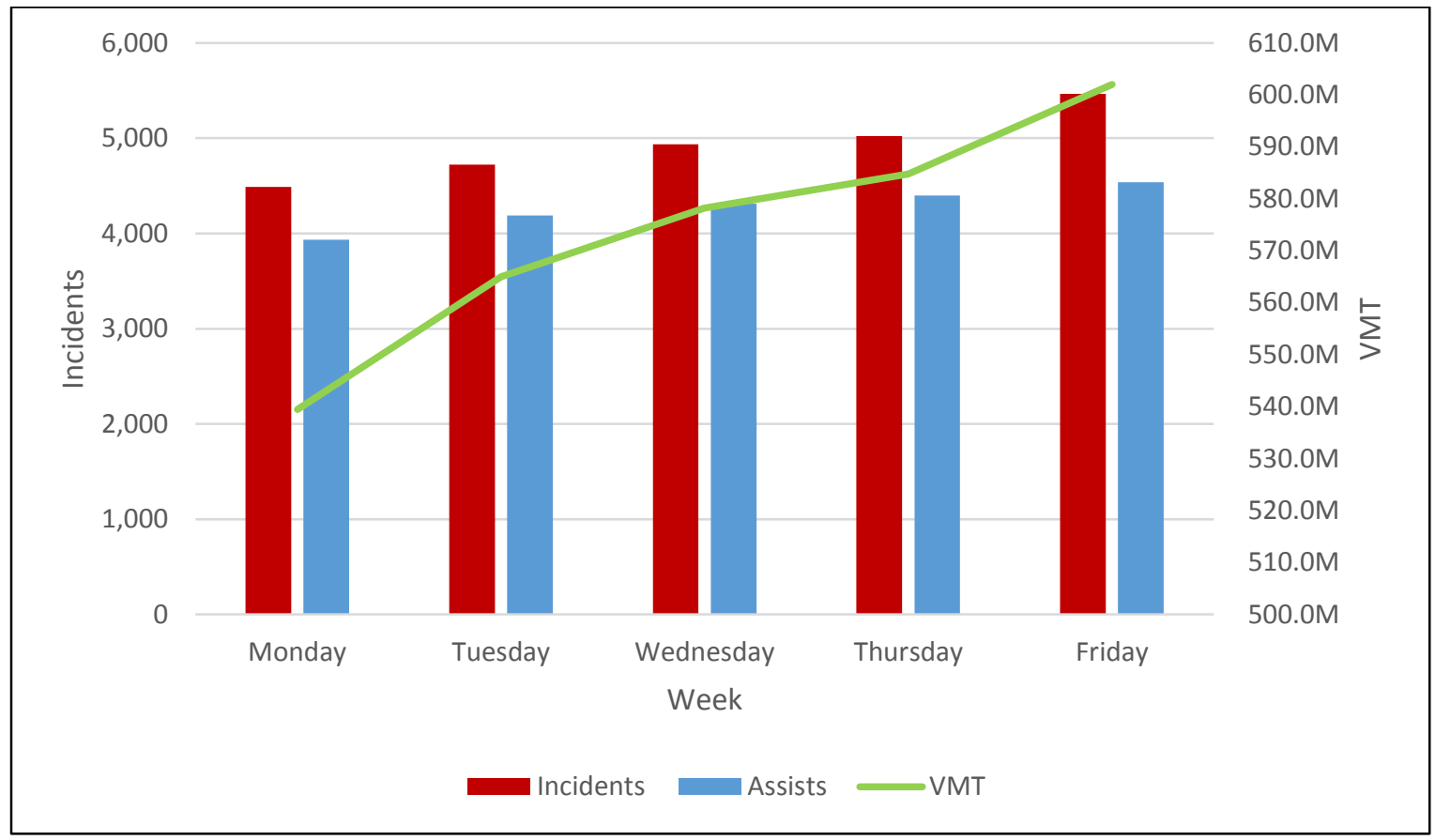

6.5 Trends and Patterns of VMT vs. Incidents during Weekdays

As seen in Figure 23, over weekdays, incidents, assists and VMT follow a pattern. Incidents and assists are higher on Mondays through Fridays than on weekends. This trend is indicative of the typical weekday travel pattern of the seven routes. Both incidents and assists peak on Thursday and Friday. VMT follows a similar pattern experienced by incidents and assists. 


\subsection{Test Results}

The results of the chi square test between the two variables - VMT versus incidents show that the p-value is $<0.001$, indicating significance. This means, we reject the null hypothesis, and conclude that there is a relationship between the observed and expected frequencies between VMT and incidents during the weekday. Our rejection of the null hypothesis allows us to conclude that VMT and incidents compared with one another is significant.

Table 3. Chi-Square Test Result for VMT vs. Incidents during the Weekday

\begin{tabular}{|l|c|}
\hline \multicolumn{2}{|l|}{ Chi-Square Tests } \\
\hline & $\mathrm{p}$-value \\
\hline Chi-Square & $<0.001$ \\
\hline
\end{tabular}

6.7 Trends and Patterns of VMT vs. Assists during the Weekday

Similarly, assists versus VMT follow a pattern much like incidents versus VMT. Since the number of FSP assists is limited and governed by scheduled service hours, assists are lower in comparison to reported incidents. However, the trend in assists tracks the number of incidents closely as shown in Figure 14.

\subsection{Test Results}

We can see that the chi square test between VMT versus assists show a p-value $<0.001$. This also indicates significance. We can conclude that VMT and assists compared with one another is significant. We reject the null hypothesis, and note that there is a relationship between the two variables during the weekday. 
Table 4. Chi-Square Test Result for VMT vs. Assists during the Weekday

\begin{tabular}{|l|l|}
\hline \multicolumn{2}{|l|}{ Chi-Square Tests } \\
\hline & p-value \\
\hline Chi-Square & $<0.001$ \\
\hline
\end{tabular}

6.9 Trends and Patterns of Incidents vs. Assists during the Weekday

As observed in Figure 14, assists track incidents closely during the weekday. Due to the AM and PM scheduled hours of FSP service, congestion-related factors and alternative motorist aid services, FSP is not proportional to all CHP-related incidents.

\subsection{Test Results}

Again, we see a p-value $<0.001$, indicating significance. We reject the null hypothesis and conclude that there is a relationship between incidents and assists. When we compare incidents to assists, we can see that there is a relationship.

Table 5. Chi-Square Test Result for Incidents vs. Assists during the Weekday

\begin{tabular}{|l|l|}
\hline \multicolumn{2}{|l|}{ Chi-Square Tests } \\
\hline & p-value \\
\hline Chi-Square & $<0.001$ \\
\hline
\end{tabular}


Figure 24. Freeway Service Patrol Assists Distributed over the Weekend, January 1, 2009 to December 31, 2013

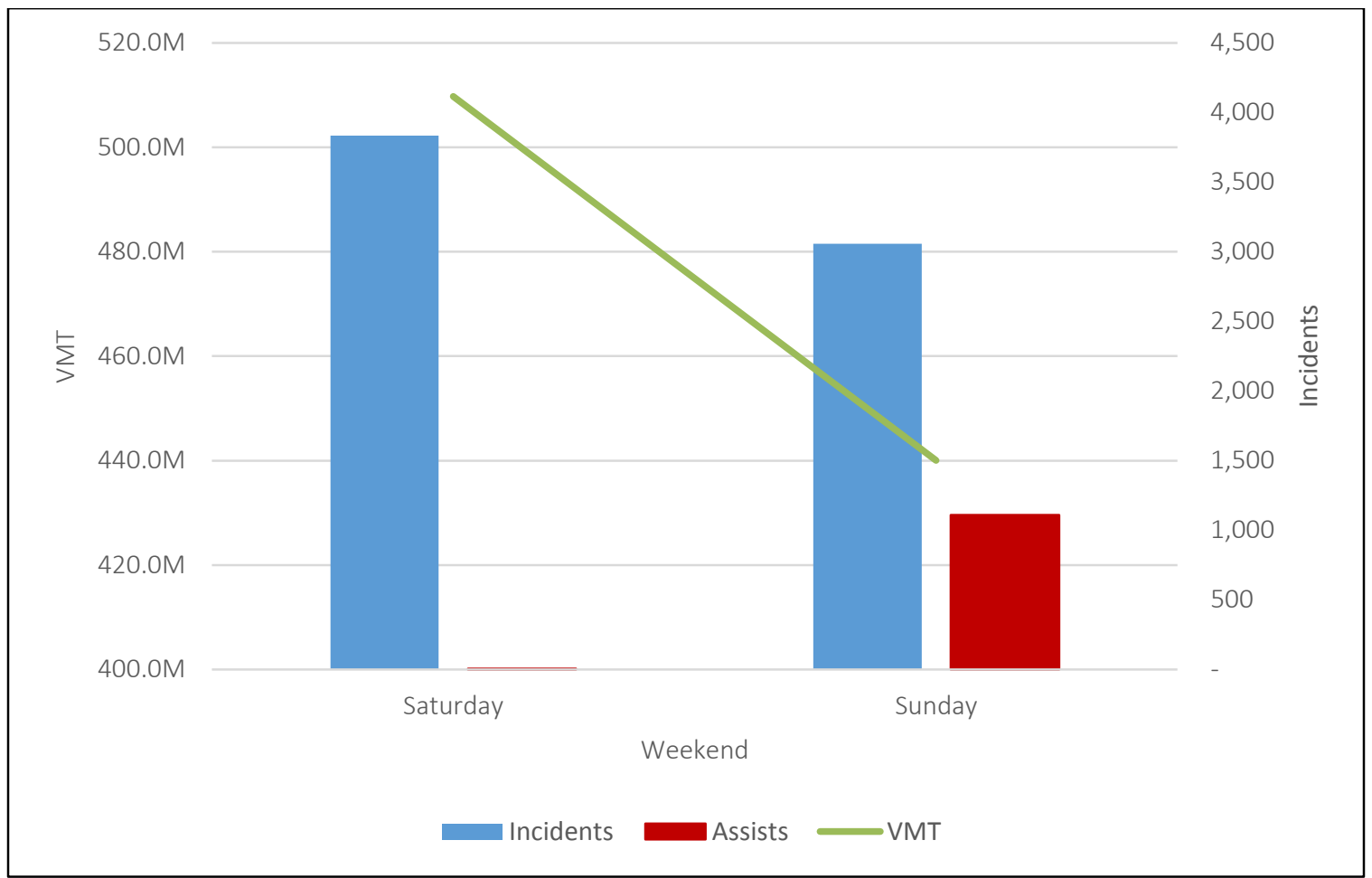

6.11 Trends and Patterns of VMT vs. Incidents during the Weekend

As shown in Figure 24, the pattern for VMT, incidents and assists vary as compared to the weekday. Incidents are higher on Saturday than Sunday with fewer assists on Saturday than Sunday. In general, FSP response is significantly lower on the weekend as compared to the weekday because VMT is lower during the weekend. It should be noted that there are fewer FSP responses to the higher number of incidents on Saturday as compared to Sunday.

\subsection{Test Results}

Our chi square test indicates that there is significance with a p-value $<0.0001$. We can reject the null hypothesis. In comparing our two variables, VMT versus incidents during the weekend, we know that there is a relationship. 
Table 6.Chi-Square Test Result for VMT vs. Incidents during the Weekend

\begin{tabular}{|l|l|}
\hline \multicolumn{2}{|l|}{ Chi-Square Tests } \\
\hline & $\mathrm{p}$-value \\
\hline Chi-Square & $<0.001$ \\
& \\
\hline
\end{tabular}

6.13 Trends and Patterns of VMT vs. Assists during the Weekend

VMT and assists do not follow a similar trend during the weekend. VMT tracks incidents, declining from a total of over 500 million VMT to 480 million by Sunday. As compared to VMT, there are few assists on Saturday, with over a thousand reported assists on Sunday.

\subsection{Test Results}

Despite the variation in patterns, FSP assists and VMT also shared some significance with a p-value $<0.001$. FSP provided assistance during mostly "mediumhigh" (2,939 to 82,705) and "high" $(94,712$ to 104,374$)$ levels of VMT. As seen in Table

6 , we reject the null hypothesis and note that there is a relationship between VMT and assists during the weekend.

Table 7.Chi-Square Test Result for VMT vs. Assists during the Weekend

\begin{tabular}{|l|l|}
\hline \multicolumn{2}{|l|}{ Chi-Square Tests } \\
\hline & $\mathrm{p}$-value \\
\hline Chi-Square & $<0.001$ \\
\hline
\end{tabular}

6.15 Trends and Patterns of Incidents vs. Assists during the Weekend

The trend between incidents and assists appears to vary. There are greater assists and less incidents on Sundays compared to Saturday. The number of trucks deployed during this period of time and scheduled service hours may have influenced the number 
of motorists assists. Generally, FSP reduces its service hours and assists during the weekend because there tends to be fewer incidents and VMT on the weekend when compared to the weekday. The reduction in service hours during the weekend is costeffective because fewer motorists are commuting to and from work.

\subsection{Test Results}

Table 8. Chi-Square Test Result for Incidents vs. Assists during the Weekend

\begin{tabular}{|l|l|}
\hline \multicolumn{2}{|l|}{ Chi-Square Tests } \\
\hline & $\mathrm{p}$-value \\
\hline Chi-Square & $<0.001$ \\
\hline
\end{tabular}

Figure 25. Freeway Service Patrol Assists Distributed Seasonally, January 1, 2009 to December 31, 2013

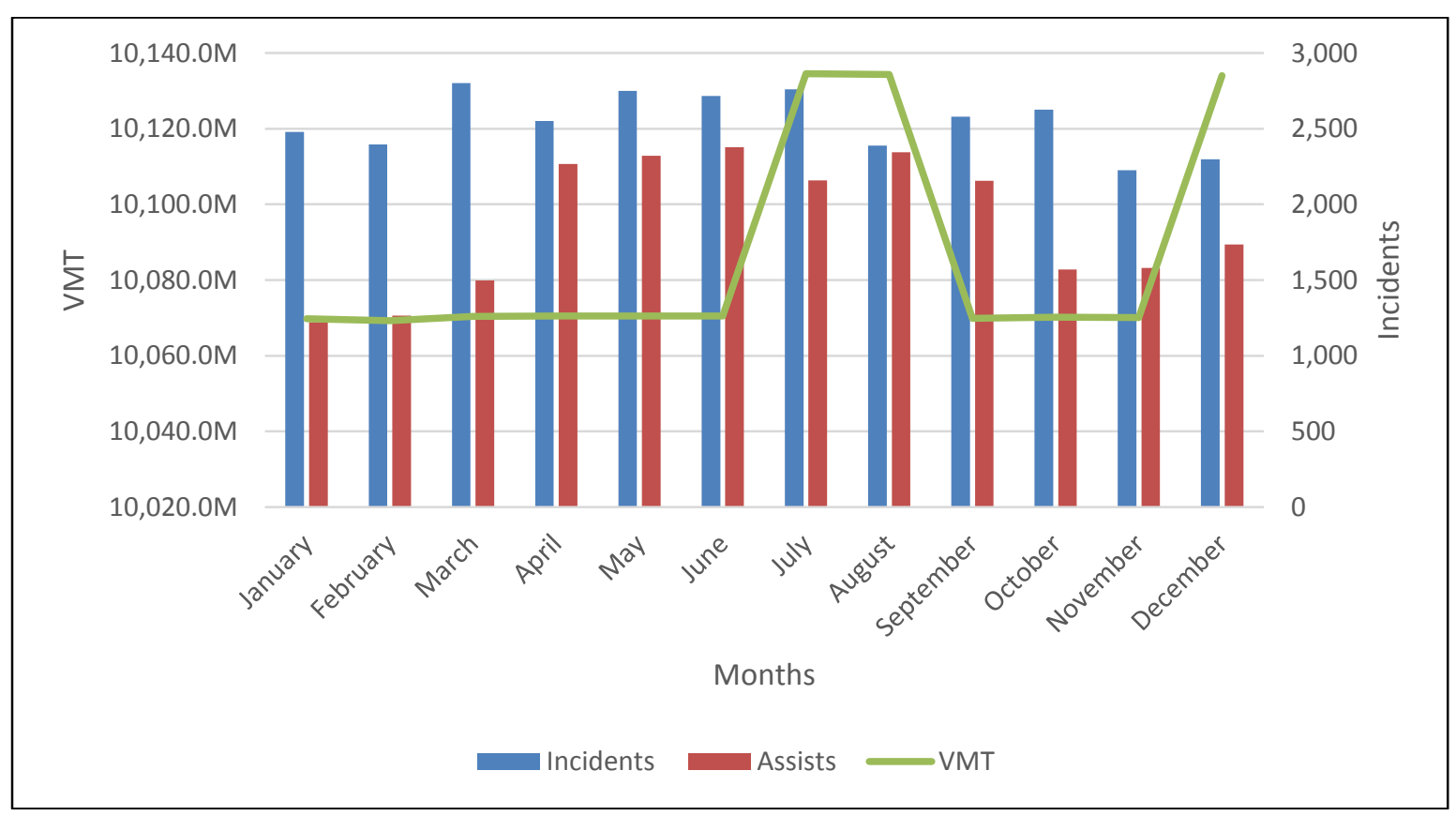

6.17 Trends and Patterns of Seasonally VMT vs. Incidents during the Weekday

We can observe the seasonal pattern between incidents and VMT over the year for the seven routes in Figure 25 (See Appendices, Table 26 for total VMT data points). 
During winter (January to February with the exception of December) VMT is generally flat. In spring, (March to May), incidents increase slightly because there are more motorists on the road. During the summer months (June and July), VMT spikes, like incidents. Incidents and VMT begin to flatten by fall (August, September, October and November) and decrease.

\subsection{Test Results}

Our $\mathrm{p}$-value is $<0.0001$. This means, there is significance. In comparing the two variables, VMT and incidents, we know that there is a connection between the occurrence of incidents and the total number of VMT due to an increase in exposure over the course of the year, based on the season of the year.

Table 9.Chi-Square Test Result for Seasonal VMT vs. Incidents during the Weekday

\begin{tabular}{|l|l|}
\hline \multicolumn{2}{|l|}{ Chi-Square Tests } \\
\hline & p-value \\
\hline Chi-Square & $<$ \\
& 0.000005 \\
\hline
\end{tabular}

6.19 Trends and Patterns of Seasonal VMT vs. Assists during the Weekday Assists and VMT track one another closely in Figure 16. Assists and VMT flatten through the January and February months. In spring, assists increase steadily while VMT increases slightly. VMT jumps in June and begins to flatten and decrease much like incidents in the fall. This pattern is consistent with general travel patterns, with motorists traveling more in June, July and December months. 


\subsection{Test Results}

As shown in Table 10, the seasonal pattern of VMT vs. assists shows a p-value of $<0.0001$. We know that there is a relationship and can therefore, reject the null hypothesis. There is significance and the observed and expected frequencies do not vary greatly from one another

Table 10.Chi-Square Test Result for Seasonal VMT vs. Incidents during the Weekday

\begin{tabular}{|l|l|}
\hline \multicolumn{2}{|l|}{ Chi-Square Tests } \\
\hline & p-value \\
\hline Chi-Square & $<0.0001$ \\
\hline
\end{tabular}

6.21 Trends and Patterns of Seasonal Incidents vs. Assists during the Weekday

In Figure 25, incidents and assists follow a similar pattern. However, incidents are consistent through much of the year. As shown, incidents and assists increase during the spring months (March, April and May). Both variables are higher during June and July and begin flattening by the fall months of August through November.

\subsection{Test Results}

In Table 11, the p-value for the chi square test of incidents vs. assists during the weekday is $<0.0001$. This means, there is significance. We can reject the null hypothesis and conclude that the two variables share a relationship, with the seasonal factor slightly influencing the probability of an incident and assist occurring.

Table 11.Chi-Square Test Result for Seasonal Incidents vs. Assists during the Weekday

\begin{tabular}{|l|l|}
\hline \multicolumn{2}{|l|}{ Chi-Square Tests } \\
\hline & $\mathrm{p}$-value \\
\hline Chi-Square & $<0.0001$ \\
& \\
\hline
\end{tabular}




\subsection{Investigating Route US 101/SR 85}

The chi square tests provided an overview of the seven routes as a whole. A bivariate plot of Route US 101/SR 85 looks at the change over time for this heavily traveled corridor. Figure 26 shows Route US 101/SR 85's total incident and assists bivariate plot for five years. This graph demonstrates a concentration of incidents during the 2010 to 2011 period, and reflects an overall decreasing trend line in assists and consistency in incidents. A closer look at the beginning of the study period in Figure 27, for the year 2009 shows fewer assists and incidents, due to the recession. However, Figure 28 shows a rebound in incidents and assists as compared to Figure 27 and a flat to downward trajectory for assists. In looking at the graphs, we can see that incidents and assists are not directly proportional, given factors such as beat length, truck hours and

number of trucks, which play a role in determining the level of exposure FSP trucks have to incidents. 
Figure 26. US 101/SR 85 Bivariate Plot over Five Years

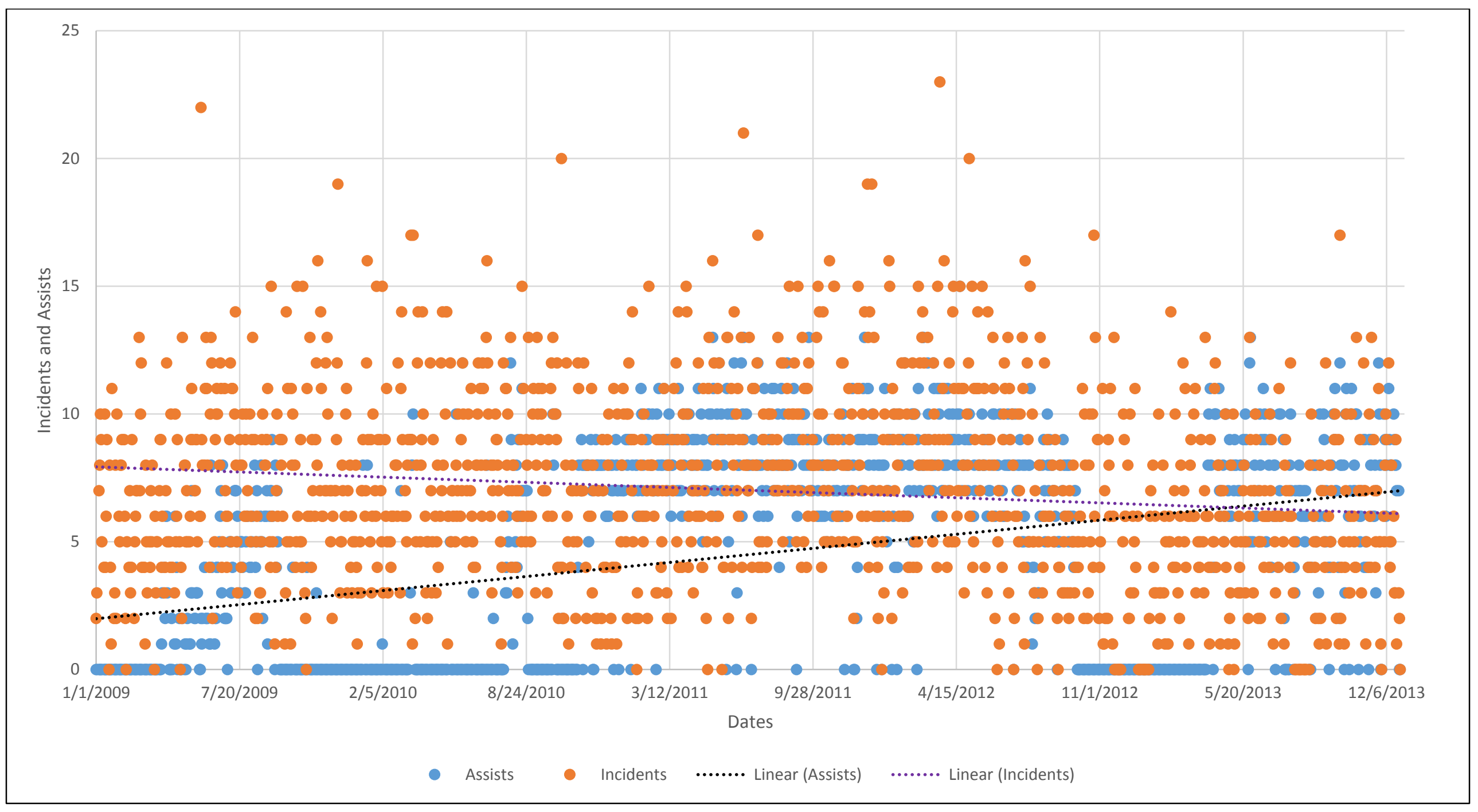


Figure 27. US 101/SR 85 Bivariate Plot for 2009

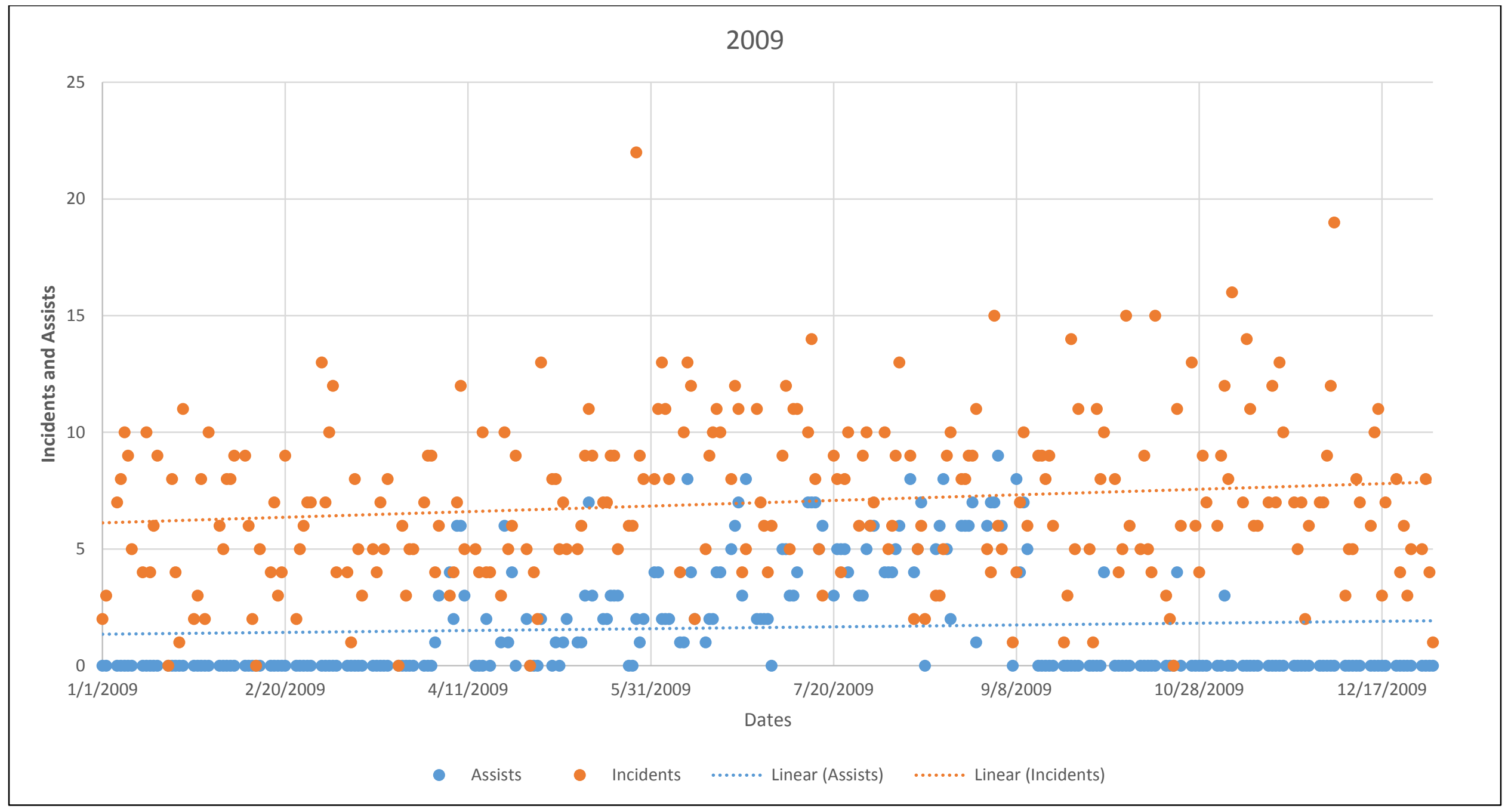


Figure 28. US 101/SR 85 Bivariate Plot for2013

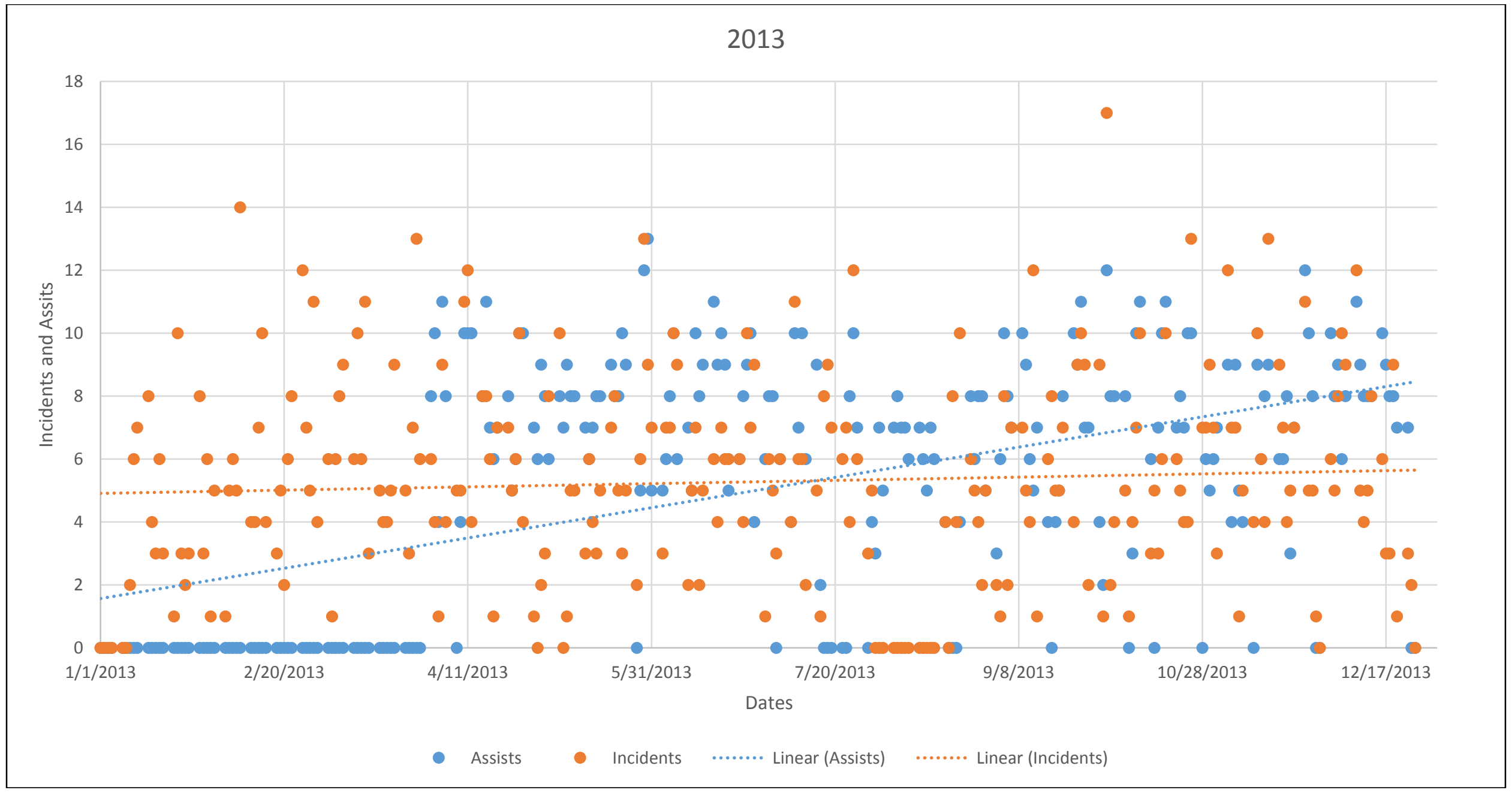


In this chapter, we discussed the results of the two way frequency tables, displayed the variation between VMT, incidents and assists in the Lorenz Curve, chi square tests and further investigated US 101/SR 85's bivariate plot of incidents and assists. We know that incidents, VMT and assists inform the location, the service hours and amount of time staff allocate to FSP trucks and service. Our bivariate plot of US 101/SR 85 further demonstrate the variability between assists and incidents. In the next section, we review our background, findings, and results. 


\section{CONCLUSIONS}

The Bay Area Freeway Service Patrol is a program that operates along congested freeways during peak hour traffic in the morning and evening. While the program has assisted over 2.4 million motorists throughout its 21-year operation, over the past two years, it is experiencing a slight decline in reported assistance. An analysis of the program's assisted incidents is reviewed and analyzed. Seven beats were selected for further testing. Background research provided additional insight into federal policies affecting the vehicle fleet turnover along U.S. highways. The analysis of the program's existing assists revealed that the activity types are not changing. In fact, breakdown assists and ancillary assists are proportional in their decline. This suggests that all service assists aside from crashes are declining as a whole.

In further investigating traffic volumes, we conducted three tests as well as a graphical display of inequality for our three variables: VMT, CHP reported incidents and FSP assists for a five-year period. We can tell from the bivariate table that incidents and assist occur frequently when VMT is higher during the weekday period. It can also be ascertained that there is a degree of significance between the month of the year, day of the week, and time of day for when incidents and assists happen. A deeper exploration into the distribution of incident, assist and VMT frequency through the use of a Lorenz curve and Gini coefficient showed the degree of inequality between our three variables. Though there are a disproportionate number of truck hours to incidents, there is dependence between the assists to VMT and incidents. Given that CHP helps with incidents over the 24-hour period for a greater number of hours, FSP is primarily 
deployed during peak hours. The number of trucks per route is responding to about 30 percent of the incidents that are occurring over these routes.

The U.S. vehicle fleet turnover, assessed by researchers Yacobucci and Canis on the 2009 Cash-for-Clunkers program and $\mathrm{Li}$ et al. on new car technology, describes changes in vehicle types, improvements in safety and fuel-efficiency over January 1, 2009 to December 31, 2013 study period. Other perspectives from auto research groups such J.D. Power and Associates add that vehicle technology continues to improve safety and performance, increasing the motorists' awareness of potential mechanical issues with their vehicles and preventing breakdowns or failures.

A culminating series of social, economic and technological factors are inhibiting a change in incidents and therefore, the number of Freeway Service Patrol assists. This study assesses the dependence between Bay Area vehicle miles traveled and incidents versus FSP assists through statistical tests including bivariate tables, chi square testing and visualizes the variability in these three factors through the Lorenz Curve and Gini Coefficient analysis. Finally, this study summarizes research assessing the broader changes in vehicle technology and how it is improving the safety and performance of vehicles on the road. These improvements may have some effects on motor vehicles, the number and types of incidents occurring on the highway and the likelihood of FSP responding to these incidents. 
While this report asserts that changes in VMT and incidents affect the number of assists, a more concise study which includes the tow truck service hours, CHP reported incident type information and consistent data can help to inform future decisions. With the implementation of a new database reporting system, the Freeway Service Patrol will be able to study and analyze more accurately, its trends and patterns. A future study with updated data will provide a more precise investigation into the decline in assists. 


\section{REFERENCES}

Baker, S. (2006). Multiple Regression Theory. Retrieved 2014 from University of South Carolina: http://hspm.sph.sc.edu/Courses/J716/pdf/7163\%20Multiple\%20Regression.pdf

(2014). Bay Area FSP Program - Number of Centerline Miles by Year. Oakland, California.

Bertini, R., \& Rose, M. (2004). Evaluation of the "COMET” Incident Response Program.

Caltrans' PeMS. (n.d.). VMT - PeMs. Retrieved from PeMs.

Caltrans' Quarterly Reports. (2006-2014). Caltrans Quarterly Reports. San Francisco Bay Area.

(n.d.). Caltrans VMT and Incident Reports, January 1, 2009 to December 31, 2014. Sacramento, CA: Iteris, Inc.

Ewing, R., \& Cervero, R. (2001). Travel and the Built Environment: A Synthesis. Transportation Research Record, , 87-114.

Federal Highway Administration. (2005). Federal Highway Administration Service Patrol Handbook. Washington, DC.

Federal Highway Administration. (2012). Retrieved from 2012 Urban Congestion Trends - Operations: The Key to Reliable Travel:

http://ops.fhwa.dot.gov/publications/fhwahop13016/fhwahop13016.pdf

Giuliano, G. (1989). Incident characteristics, frequency, and duration on a high volume urban freeway. Transportation Research.

Healey, J. (2011). Bivariate Correlation. In J. F. Healey, Statistics: A Social Research Tool.

Healey, J. (2011). Chi Square Testing. In J. Healey, Statistics: A Tool for Social Research.

Healey, J. F. (2011). Spearman's Rho. In J. F. Healey, Statistics: A Tool for Social Research.

Healey, J. F. (2012). Statistics: A Tool for Social Research. Belmont, CA: Wadsworth, Cengage Learning.

Huang, J.-T., Kuo, C.-C., \& Kao, A.-P. (2003). The Inequality of Regional Economic Development. Journal of Chinese Economic and Business Studies, Vol. 1, No. 3, 
278-280. Retrieved from North Carolina Central University:

http://www.cdrf.org.cn/2006cdf/news_Harmony.htm

Hymel, K. M. (2014). Factors Influencing Vehicle Miles Traveled in California:

Measurement and Analysis. California State University, Northridge, Department of Economics. Northridge: CSU Northridge.

J.D. Power and Associates. (2013, February 13). 2013 U.S. Vehicle Dependability Study. Retrieved from J.D. Power McGraw Hill Financial:

http://autos.jdpower.com/content/press-release/bTiXte5/2013-u-s-vehicledependability-study.htm

Konduri, S., Labi, S., \& Sinha, K. C. (2013). Incident Occurrence Models for Freeway Incident Management. Transportation Research Record: Journal of the Transportation Research Board.

Lave, C. (June 1991). Things Won't Get a Lot Worse: The Future of U.S. Traffic Congestion. The University of California Transportation Center.

Li, S., Linn, J., \& Spiller, E. (2013). Evaluating “'Cash-forClunkers":Programeffectsonautosales. Journal of Environmental Economics and Management, 3-10.

Lou, Y., Yin, Y., \& Lawphongpanich, S. (2010). Freeway service patrol deployment planning for incident management and congestion mitigation. Transportation Research.

Mannering, F., \& Kilareski, W. a. (2003). Principles of Highway Engineering and Traffic Analysis, Third Edition, Chapter 5.

Mauch, M. (2015 January). Freeway Service Patrol. (N. Chin, Interviewer)

Mauch, M., Skabardonis, A., \& Davis, L. (2014). Validating the Cost Effectiveness Model for California's Freeway Incident Management Program. Synposium Celebrating 50 Years of Traffic Flow Theory. Portland: Transportation Research Board.

McBride, В. (2014 йил 10-September). Vehicle Sales: Fleet Turnover Ratio. From Calculated Risk: Finance \& Economics:

http://www.calculatedriskblog.com/2014/09/vehicle-sales-fleet-turnoverratio.html

Millard-Ball, A., \& Schipper, L. (2011). TRENDS IN PASSENGER TRANSPORT IN EIGHT INDUSTRIALIZED COUNTRIES. 
Pal, R., \& Sinha, K. С. (2002 йил July). Simulation Model for Evaluating and Improving Effectiveness of Freeway Service Patrol Programs. Journal of Transportation Engineering.

Rich, R. (2015 January ). Bay Area MTC Freeway Service Patrol. (N. Chin, Interviewer)

Skabardonis, A., Noeimi, H., Petty, K., Rydzewski, D., Varaiya, P., \& Al-Deek, H. (1994 June). Freeway Service Patrol Evaluation. University of California, Berkeley, California PATH Research Report UCB-ITS-PRR-95-5. Oakland: UC Berkeley PATH.

Skabardonis, A., Petty, K., Varaiya, P., \& Bertini, R. (1991). Evaluation of the Freeway Service Patrol (FSP) in Los Angeles. University of California, Berkeley, California PATH Program. eScholarship UC Berkeley.

Spahr, C., \& McCahill, C. (n.d.). VMT Inflection Point: Factors Affecting 21 st Century Travel. U.S. Department of Transportation, State Smart Transportation Initiative. U.S. DOT.

Transportation, U. D. (n.d.). Office of Highway Policy Information Traffic Monitoring. Traffic Volume Trends. Washington DC, Maryland, US.

U.S. Department of Transportation Federal Highway Administration. (2013 йил 3December). Traffic Congestion and Reliability: Trends and Advanced Strategies for Congestion Mitigation. Retrieved 2014 29-December from Office of Operations Final Report:

http://www.ops.fhwa.dot.gov/congestion_report/chapter2.htm

U.S. Department of Transportation, F. H. (2013, December 3). Emergency Transportation Operations. Retrieved August 26, 2014, from US Department of Transportation: (http://ops.fhwa.dot.gov/eto_tim_pse/docs/incident_mgmt_perf/section2.htm)

Yacobucci, B. D., \& Canis, B. (2009, August 10). Accelerated Vehicle Retirement for Fuel Economy: "Cash for Clunkers". Retrieved from http://assets.opencrs.com/rpts/R40654_20090810.pdf 


\section{APPENDICES}

Figure 29. Incident Tree for Total Assist Type

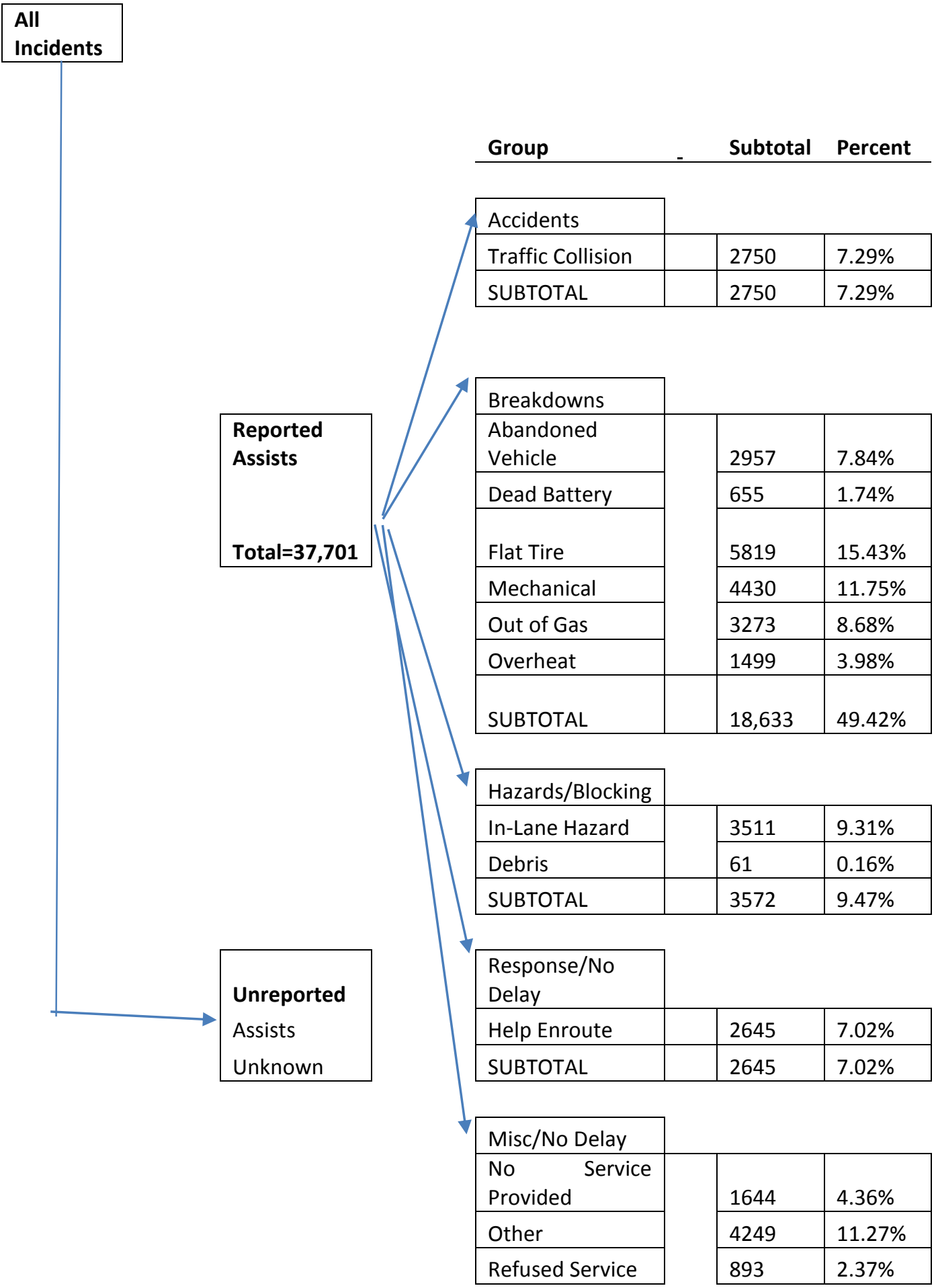




\begin{tabular}{|l|l|l|l|} 
Drive Off & & 2922 & $7.75 \%$ \\
\cline { 4 - 4 } $\begin{array}{l}\text { Provided } \\
\text { Transportation }\end{array}$ & & 143 & $0.38 \%$ \\
\cline { 1 - 1 } $\begin{array}{l}\text { Assist FSP Beat } \\
\text { Partner }\end{array}$ & & 250 & $0.66 \%$ \\
\hline SUBTOTAL & 10,101 & $26.79 \%$ \\
\hline \begin{tabular}{|l|l|l|}
\hline \multicolumn{3}{|l|}{} \\
TOTAL
\end{tabular} & 37,701 & $100.00 \%$ \\
\hline
\end{tabular}

(Bertini \& Rose, 2004) 
Figure 30. Number of Trucks over Five Years

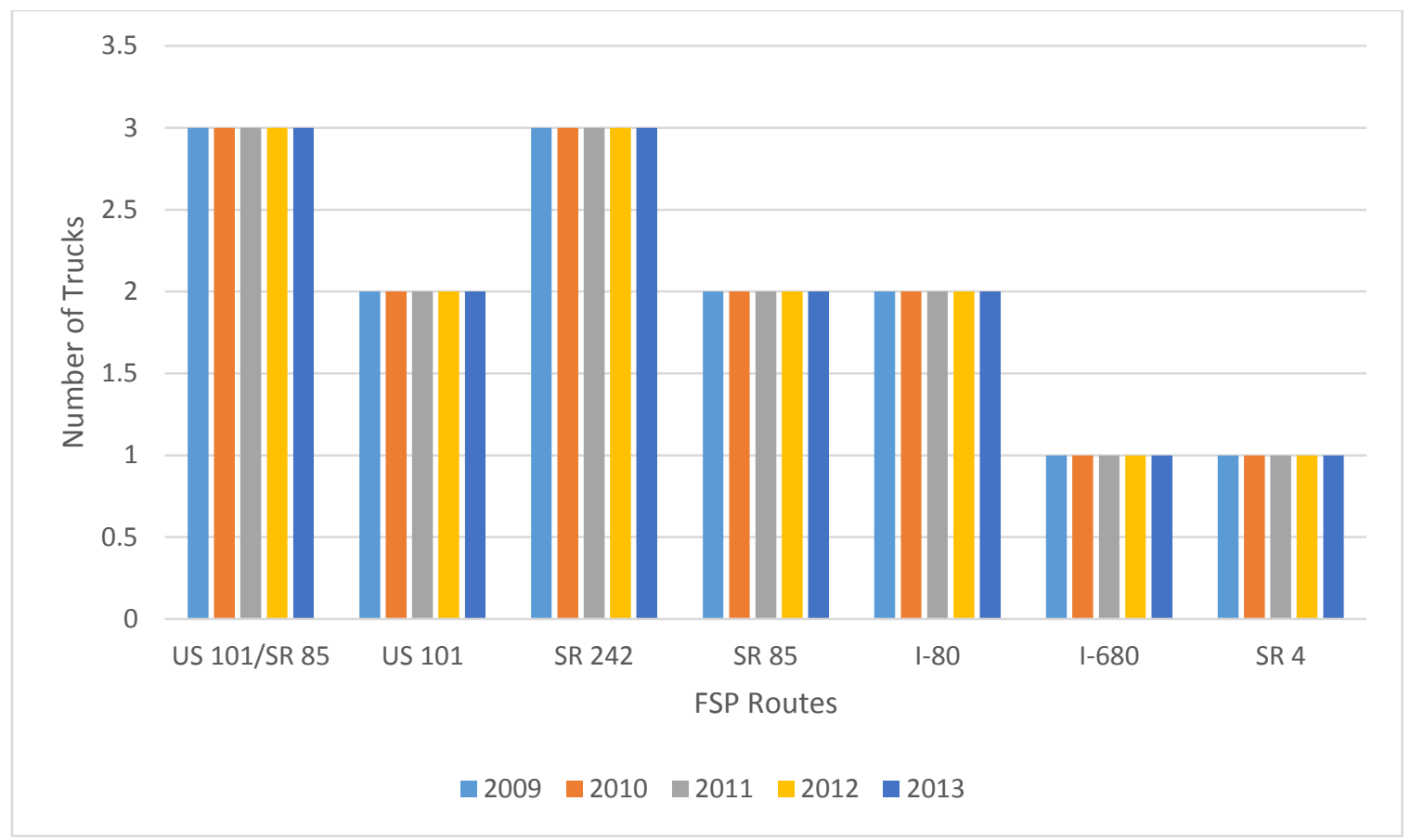

Figure 31. FSP Route Length over Five Years

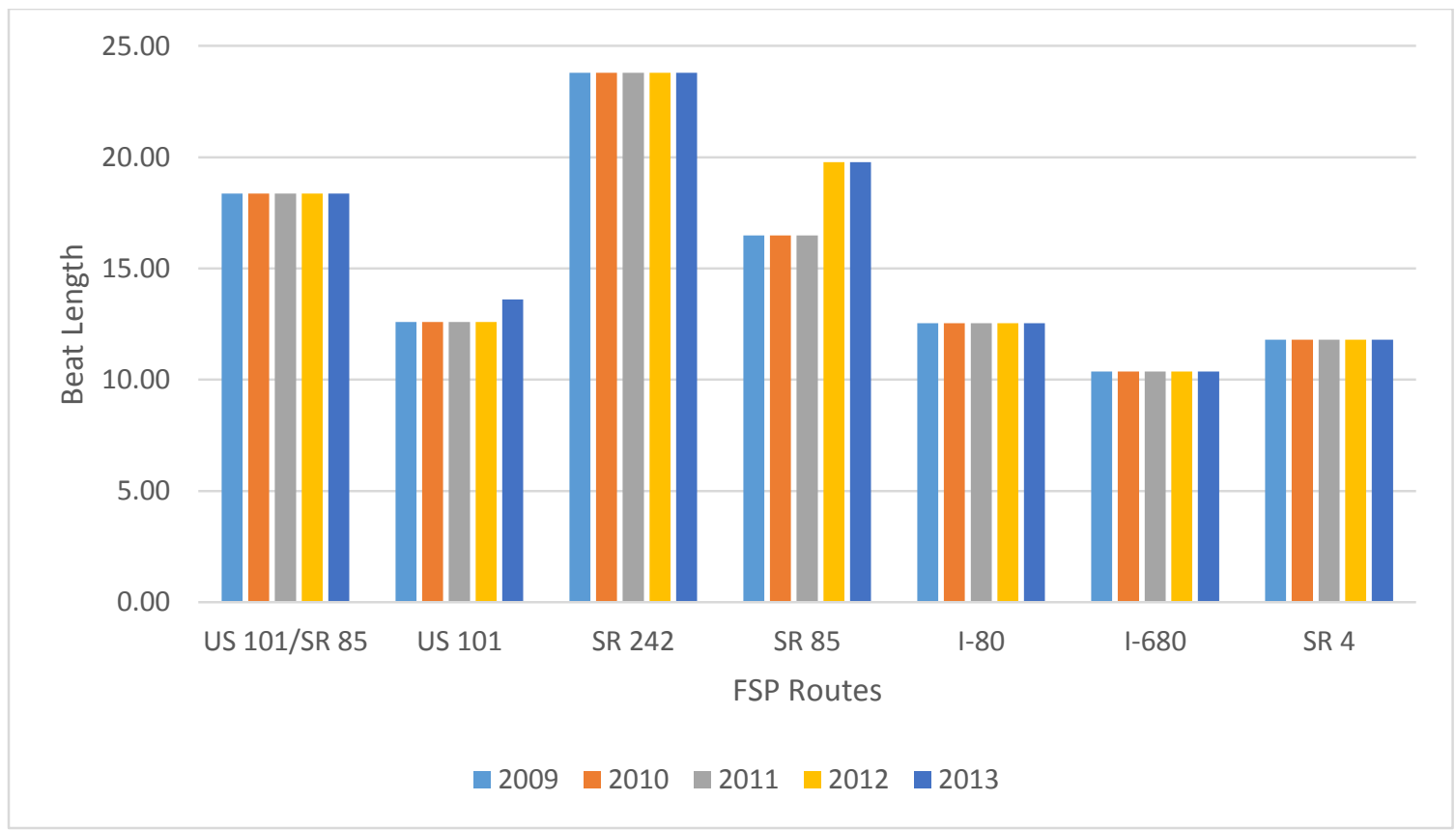


Table 12.Lorenz Curve and Gini Coefficient - Assist and Incident Distribution Table for the Primary Direction

\begin{tabular}{|c|c|c|c|c|c|c|c|c|c|c|c|c|c|c|c|}
\hline \multirow{2}{*}{ k } & \multicolumn{8}{|c|}{ Assist and Incident Distribution } & & & & \multirow{3}{*}{$\begin{array}{c}\text { Lorenz X } \\
0\end{array}$} & \multirow{3}{*}{$\begin{array}{l}\text { Lorenz } Y \\
0.0 \%\end{array}$} & \multirow{3}{*}{$\begin{array}{r}\text { Diagonal } \mathbf{X} \\
\\
\\
0 \% \\
\end{array}$} & \multirow{3}{*}{$\begin{array}{r}\text { Diagonal } \mathbf{Y} \\
\\
\\
0 \%\end{array}$} \\
\hline & \multirow[t]{2}{*}{ Income Range } & \multirow[t]{2}{*}{ Assists } & \multirow[t]{2}{*}{ Incidents } & \multirow[t]{2}{*}{$\begin{array}{l}\text { \% of All } \\
\text { Incidents }\end{array}$} & \multirow{2}{*}{$\begin{array}{c}\text { Total Assists and } \\
\text { Incidents }\end{array}$} & \multirow{2}{*}{$\begin{array}{c}\begin{array}{c}\% \text { of Assists and } \\
\text { Incidents }\end{array} \\
\end{array}$} & \multirow{2}{*}{\begin{tabular}{|c}
$\begin{array}{c}\text { Cumulative } \\
\% \text { of All } \\
\text { Incidents }\end{array}$ \\
$\mathrm{X}_{\mathrm{k}}$ \\
\end{tabular}} & \multirow{2}{*}{\begin{tabular}{|c}
$\begin{array}{c}\text { Cumulative } \\
\% \text { of Assists } \\
\text { and Incidents }\end{array}$ \\
$Y_{k}$ \\
\end{tabular}} & \multicolumn{3}{|c|}{ Calculation of Gini Coefficient } & & & & \\
\hline & & & & & & & & & $\mathbf{X k - X k - 1}$ & $Y k+Y k-1$ & $(\mathrm{Xk}-\mathrm{Xk}-1)(\mathrm{Yk}+\mathrm{Yk}-1)$ & & & & \\
\hline 0 & & & & & & & & & & & & $3.3 \%$ & $0.0 \%$ & $14 \%$ & $14 \%$ \\
\hline 1 & SR 242 & 0 & 1,028 & $3.3 \%$ & 0 & $0.0 \%$ & $3.3 \%$ & $0.0 \%$ & 0.03 & 0.00 & 0.000 & $10.1 \%$ & $6.0 \%$ & $14 \%$ & $14 \%$ \\
\hline 2 & SR 4 & 0 & 2,149 & $6.8 \%$ & 0 & $0.0 \%$ & $10.1 \%$ & $0.0 \%$ & 0.07 & 0.00 & 0.000 & $22.7 \%$ & $9.6 \%$ & $14 \%$ & $14 \%$ \\
\hline 3 & 1680 & 2,193 & 3,989 & $12.7 \%$ & $8,747,877$ & $6.0 \%$ & $22.7 \%$ & $6.0 \%$ & 0.13 & 0.06 & 0.008 & $28.6 \%$ & $27.6 \%$ & $14 \%$ & $14 \%$ \\
\hline 4 & Hwy 101 & 2,842 & 1,836 & $5.8 \%$ & $5,217,912$ & $3.6 \%$ & $28.6 \%$ & $9.6 \%$ & 0.06 & 0.16 & 0.009 & $46.6 \%$ & $73.7 \%$ & $14 \%$ & $14 \%$ \\
\hline 5 & SR 85 & 4,566 & 5,699 & $18.1 \%$ & $26,021,634$ & $17.9 \%$ & $46.6 \%$ & $27.6 \%$ & 0.18 & 0.37 & 0.067 & $82.8 \%$ & $100.0 \%$ & $14 \%$ & $14 \%$ \\
\hline 6 & $101 / 85$ & 5,868 & 11,408 & $36.2 \%$ & $66,942,144$ & $46.2 \%$ & $82.8 \%$ & $73.7 \%$ & 0.36 & 1.01 & 0.367 & $100.0 \%$ & & $100 \%$ & $100 \%$ \\
\hline \multirow[t]{8}{*}{7} & 180 & 7,021 & 5,421 & $17.2 \%$ & $38,060,841$ & $26.3 \%$ & $100.0 \%$ & $100.0 \%$ & 0.17 & 1.74 & 0.299 & & & & \\
\hline & & & & & & & & & & & & & & & \\
\hline & Total & & 31,530 & $100.0 \%$ & $144,990,408$ & $100.0 \%$ & & & 1.00 & & 0.749 & & & & \\
\hline & & & & & & & & & ini Coeffi & 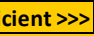 & 0.251 & & & & \\
\hline & & & & & & & Wha & t do the results & 5 of the $\mathrm{Gi}$ & ini Coeffic & cient mean... & & & & \\
\hline & & & & & & & \multirow{4}{*}{\multicolumn{5}{|c|}{$\begin{array}{l}\text { This measures assist and incident inequality. This shows us that } \\
\text { there is inequality at } 25 \% \text { from Perfect Equality. }\end{array}$}} & & & & \\
\hline & & & & & & & & & & & & & & & \\
\hline & & & & & & & & & & & & & & & \\
\hline & & & & & & & & & & & & & & & \\
\hline
\end{tabular}


Table 13.Lorenz Curve and Gini Coefficient - Assist and VMT Distribution Table for the Primary Direction

\begin{tabular}{|c|c|c|c|c|c|c|c|c|c|c|c|c|c|c|}
\hline \multicolumn{15}{|c|}{ Assist and VMT Distribution } \\
\hline \multirow[t]{3}{*}{ Income Range } & \multirow[t]{2}{*}{ Assists } & \multirow[t]{2}{*}{ VMT } & \multirow[t]{2}{*}{$\%$ of All VMT } & \multirow{2}{*}{$\begin{array}{c}\text { Total Assists and } \\
\text { VMT } \\
\text { C X D }\end{array}$} & \multirow{2}{*}{$\begin{array}{c}\% \text { of Assists and } \\
\text { VMT }\end{array}$} & \multirow{2}{*}{\begin{tabular}{|c|}
$\begin{array}{c}\text { Cumulative } \\
\% \text { of All VMT }\end{array}$ \\
$\mathrm{X}_{\mathrm{k}}$ \\
\end{tabular}} & \multirow{2}{*}{$\begin{array}{c}\begin{array}{c}\text { Cumulative } \\
\% \text { of Assists } \\
\text { and VMT }\end{array} \\
Y_{k}\end{array}$} & \multicolumn{3}{|c|}{ Calculation of Gini Coefficient } & \multirow{2}{*}{$\begin{array}{r}\text { Lorenz } \mathrm{X} \\
\\
\\
3.3 \%\end{array}$} & \multirow{2}{*}{$\begin{array}{r}\text { Lorenz } Y \\
\\
0.0 \%\end{array}$} & \multirow{2}{*}{$\begin{array}{r}\text { Diagonal } \mathbf{X} \\
\\
0 \%\end{array}$} & \multirow{2}{*}{$\begin{array}{r}\text { Diagonal } \mathbf{Y} \\
\\
0 \%\end{array}$} \\
\hline & & & & & & & & Xk -Xk-1 & $Y k+Y k-1$ & $(\mathbf{X k}-\mathbf{X k}-1)(\mathrm{Yk}+\mathbf{Y k}-1)$ & & & & \\
\hline & & & & & & & & & & & $8.9 \%$ & $0.0 \%$ & $14 \%$ & $14 \%$ \\
\hline SR 242 & 0 & $285,130,244$ & $3.3 \%$ & 0 & $0.0 \%$ & $3.3 \%$ & $0.0 \%$ & 0.03 & 0.00 & 0.000 & $9.0 \%$ & $0.0 \%$ & $14 \%$ & $14 \%$ \\
\hline SR 4 & 0 & $487,046,444$ & $5.6 \%$ & 0 & $0.0 \%$ & $8.9 \%$ & $0.0 \%$ & 0.06 & 0.00 & 0.000 & $24.5 \%$ & $9.3 \%$ & $14 \%$ & $14 \%$ \\
\hline 1680 & 2,193 & $8,147,319$ & $0.1 \%$ & $\begin{array}{l}17,867,070,567 \\
\end{array}$ & $0.0 \%$ & $9.0 \%$ & $0.0 \%$ & 0.00 & 0.00 & 0.000 & $46.8 \%$ & $30.5 \%$ & $14 \%$ & $14 \%$ \\
\hline Hwy 101 & 2,842 & $1,351,803,077$ & $15.6 \%$ & $3,841,824,344,834$ & $9.3 \%$ & $24.5 \%$ & $9.3 \%$ & 0.16 & 0.09 & 0.015 & $83.1 \%$ & $75.1 \%$ & $14 \%$ & $14 \%$ \\
\hline SR 85 & 4,566 & $1,931,749,823$ & $22.2 \%$ & $8,820,369,691,818$ & $21.2 \%$ & $46.8 \%$ & $30.5 \%$ & 0.22 & 0.40 & 0.089 & $100.0 \%$ & $100.0 \%$ & $14 \%$ & $14 \%$ \\
\hline $101 / 85$ & 5,868 & $3,153,531,768$ & $36.3 \%$ & $18,504,924,414,624$ & $44.6 \%$ & $83.1 \%$ & $75.1 \%$ & 0.36 & 1.06 & 0.383 & & & $14 \%$ & $14 \%$ \\
\hline \multirow[t]{2}{*}{180} & 7,021 & $1,472,038,330$ & $16.9 \%$ & $10,335,181,114,930$ & $24.9 \%$ & $100.0 \%$ & $100.0 \%$ & 0.17 & 1.75 & 0.297 & & & $100 \%$ & $100 \%$ \\
\hline & & & & & & & & & & & & & & \\
\hline \multirow[t]{6}{*}{ Total } & & $8,689,447,005$ & $100.0 \%$ & \begin{tabular}{|l|}
$41,520,166,636,773$ \\
\end{tabular} & $100.0 \%$ & & & 1.00 & & 0.783 & & & & \\
\hline & & & & & & \multicolumn{4}{|c|}{ Gini Coefficient 》» } & 0.217 & & & & \\
\hline & & & & & & \multicolumn{5}{|c|}{ What do the results of the Gini Coefficient mean... } & & & & \\
\hline & & & & & & \multirow{4}{*}{\multicolumn{5}{|c|}{$\begin{array}{l}\text { This measures assist and incident inequality. This shows us that } \\
\text { there is inequality at } 22 \% \text { from Perfect Equality. }\end{array}$}} & & & & \\
\hline & & & & & & & & & & & & & & \\
\hline & & & & & & & & & & & & & & \\
\hline & & & & & & & & & & & & & & \\
\hline
\end{tabular}


Table 14.Lorenz Curve and Gini Coefficient - Incident and VMT Distribution Table for the Primary Direction

Incident and VMT Distribution

\begin{tabular}{|c|c|c|c|c|c|c|c|c|c|c|c|c|c|c|c|}
\hline \multirow[t]{2}{*}{ k } & \multirow[t]{2}{*}{ Income Range } & \multirow[t]{2}{*}{ Incidents } & \multirow[t]{2}{*}{ VMT } & \multirow{2}{*}{\begin{tabular}{|l|}
$\%$ of All VMT \\
\end{tabular}} & \multirow{2}{*}{\begin{tabular}{|c|}
$\begin{array}{c}\text { Total Incidents and } \\
\text { VMT }\end{array}$ \\
CX D \\
\end{tabular}} & \multirow{2}{*}{\begin{tabular}{|c|}
$\begin{array}{c}\% \text { of Incidents } \\
\text { and VMT }\end{array}$ \\
\\
\end{tabular}} & \multirow{2}{*}{\begin{tabular}{|c|}
$\begin{array}{c}\text { Cumulative } \\
\text { \% of All VMT }\end{array}$ \\
$X_{k}$ \\
\end{tabular}} & \multirow{2}{*}{\begin{tabular}{|c|}
$\begin{array}{c}\text { Cumulative } \\
\% \text { of } \\
\text { Incidents and } \\
\text { VMT }\end{array}$ \\
$Y_{k}$ \\
\end{tabular}} & \multicolumn{3}{|c|}{ Calculation of Gini Coefficient } & \multirow{2}{*}{$\begin{array}{r}\text { Lorenz X } \\
3.3 \% \\
\end{array}$} & \multirow{2}{*}{$\begin{array}{r}\text { Lorenz Y } \\
0.5 \%\end{array}$} & \multirow{2}{*}{$\begin{array}{r}\text { Diagonal } \mathbf{X} \\
\\
0 \% \\
\end{array}$} & \multirow{2}{*}{$\begin{array}{r}\text { Diagonal Y } \\
0 \%\end{array}$} \\
\hline & & & & & & & & & Xk-Xk-1 & $1 \mathrm{Yk}+\mathrm{Yk}-1$ & $(X k-X k-1)(Y k+Y k-1)$ & & & & \\
\hline 0 & & & & & & & & & & & & $18.8 \%$ & $4.7 \%$ & $14 \%$ & $14 \%$ \\
\hline 1 & SR 242 & 1,028 & $285,130,244$ & $3.3 \%$ & $293,113,890,832$ & $0.5 \%$ & $3.3 \%$ & $0.5 \%$ & 0.03 & 0.00 & 0.000 & $24.4 \%$ & $6.5 \%$ & $14 \%$ & $14 \%$ \\
\hline 2 & Hwy 101 & 1,836 & $1,351,803,077$ & $15.6 \%$ & $2,481,910,449,372$ & $4.2 \%$ & $18.8 \%$ & $4.7 \%$ & 0.16 & 0.05 & 0.008 & $24.5 \%$ & $6.6 \%$ & $14 \%$ & $14 \%$ \\
\hline 3 & SR 4 & 2,149 & $487,046,444$ & $5.6 \%$ & $1,046,662,808,156$ & $1.8 \%$ & $24.4 \%$ & $6.5 \%$ & 0.06 & 0.11 & 0.006 & $41.5 \%$ & $20.1 \%$ & $14 \%$ & $14 \%$ \\
\hline 4 & 1680 & 3,989 & $8,147,319$ & $0.1 \%$ & $32,499,655,491$ & $0.1 \%$ & $24.5 \%$ & $6.6 \%$ & 0.00 & 0.13 & 0.000 & $63.7 \%$ & $38.8 \%$ & $14 \%$ & $14 \%$ \\
\hline 5 & 180 & 5,421 & $1,472,038,330$ & $16.9 \%$ & $7,979,919,786,930$ & $13.6 \%$ & $41.5 \%$ & $20.1 \%$ & 0.17 & 0.27 & 0.045 & $100.0 \%$ & $100.0 \%$ & $14 \%$ & $14 \%$ \\
\hline 6 & SR 85 & 5,699 & $1,931,749,823$ & $22.2 \%$ & $11,009,042,241,277$ & $18.7 \%$ & $63.7 \%$ & $38.8 \%$ & 0.22 & 0.59 & 0.131 & & & $100 \%$ & $100 \%$ \\
\hline \multirow[t]{8}{*}{7} & $101 / 85$ & 11,408 & $3,153,531,768$ & $36.3 \%$ & $35,975,490,409,344$ & $61.2 \%$ & $100.0 \%$ & $100.0 \%$ & 0.36 & 1.39 & 0.504 & & & & \\
\hline & & & & & & & & & & & & & & & \\
\hline & Total & & $8,689,447,005$ & $100.0 \%$ & $58,818,639,241,402$ & $100.0 \%$ & & & 1.00 & & 0.695 & & & & \\
\hline & & & & & & & & & Sini Coeffi & fficient $\gg \gg$ & 0.305 & & & & \\
\hline & & & & & & & What & th do the results & $s$ of the Gi & Gini Coeffic & cient mean... & & & & \\
\hline & & & & & & & \multirow{4}{*}{\multicolumn{5}{|c|}{$\begin{array}{l}\text { This measures incident and VMT inequality. This shows us that there } \\
\text { is inequality at } 31 \% \text { from Perfect Equality. }\end{array}$}} & & & & \\
\hline & & & & & & & & & & & & & & & \\
\hline & & & & & & & & & & & & & & & \\
\hline & & & & & & & & & & & & & & & \\
\hline
\end{tabular}


Table 15. Lorenz Curve and Gini Coefficient - Assist and Incident Distribution Table for the Secondary Direction

\begin{tabular}{|c|c|c|c|c|c|c|c|c|c|c|c|c|c|c|c|}
\hline \multirow{3}{*}{ k } & \multicolumn{8}{|c|}{ Assist and Incident Distribution } & & & & \multirow{3}{*}{$\begin{array}{r}\text { Lorenz X } \\
4.4 \%\end{array}$} & \multirow{3}{*}{$\begin{array}{r}\text { Lorenz Y } \\
0.0 \%\end{array}$} & \multirow{3}{*}{$\begin{array}{r}\text { Diagonal X } \\
0 \%\end{array}$} & \multirow{3}{*}{$\begin{array}{r}\text { Diagonal Y } \\
\\
0 \%\end{array}$} \\
\hline & \multirow[t]{2}{*}{ Income Range } & \multirow[t]{2}{*}{ Assists } & \multirow[t]{2}{*}{ Incidents } & \multirow[t]{2}{*}{$\begin{array}{l}\% \text { of All } \\
\text { Incidents }\end{array}$} & \multirow{2}{*}{$\begin{array}{c}\text { Total Assists and } \\
\text { Incidents } \\
\text { C X D }\end{array}$} & \multirow{2}{*}{\begin{tabular}{|c|}
$\begin{array}{c}\% \text { of Assists and } \\
\text { Incidents }\end{array}$ \\
\end{tabular}} & \multirow{2}{*}{\begin{tabular}{|c}
$\begin{array}{c}\text { Cumulative } \\
\% \text { of All } \\
\text { Incidents }\end{array}$ \\
$x_{k}$
\end{tabular}} & \multirow{2}{*}{$\begin{array}{c}\begin{array}{c}\text { Cumulative } \\
\text { \% of Assists } \\
\text { and Incidents }\end{array} \\
\mathbf{Y}_{\mathrm{k}}\end{array}$} & \multicolumn{3}{|c|}{ Calculation of Gini Coefficient } & & & & \\
\hline & & & & & & & & & Xk-Xk-1 & Yk+Yk-1 & $(X k-X k-1)(Y k+Y k-1)$ & & & & \\
\hline 0 & & & & & & & & & & & & $9.8 \%$ & $0.0 \%$ & $14 \%$ & $14 \%$ \\
\hline 1 & SR 242 & 0 & 1,456 & $4.4 \%$ & 0 & $0.0 \%$ & $4.4 \%$ & $0.0 \%$ & 0.04 & 0.00 & 0.000 & $19.2 \%$ & $2.2 \%$ & $14 \%$ & $14 \%$ \\
\hline 2 & SR 4 & 0 & 1,788 & $5.4 \%$ & 0 & $0.0 \%$ & $9.8 \%$ & $0.0 \%$ & 0.05 & 0.00 & 0.000 & $25.6 \%$ & $5.3 \%$ & $14 \%$ & $14 \%$ \\
\hline 3 & 1680 & 618 & 3,101 & $9.4 \%$ & $1,916,418$ & $2.2 \%$ & $19.2 \%$ & $2.2 \%$ & 0.09 & 0.02 & 0.002 & $45.4 \%$ & $20.6 \%$ & $14 \%$ & $14 \%$ \\
\hline 4 & Hwy 101 & 1,311 & 2,113 & $6.4 \%$ & $2,770,143$ & $3.1 \%$ & $25.6 \%$ & $5.3 \%$ & 0.06 & 0.07 & 0.005 & $85.1 \%$ & $78.1 \%$ & $14 \%$ & $14 \%$ \\
\hline 5 & SR 85 & 2,073 & 6,556 & $19.8 \%$ & $13,590,588$ & $15.3 \%$ & $45.4 \%$ & $20.6 \%$ & 0.20 & 0.26 & 0.051 & $100.0 \%$ & $100.0 \%$ & $14 \%$ & $14 \%$ \\
\hline 6 & $101 / 85$ & 3,902 & 13,108 & $39.7 \%$ & $51,147,416$ & $57.6 \%$ & $85.1 \%$ & $78.1 \%$ & 0.40 & 0.99 & 0.391 & & & $100 \%$ & $100 \%$ \\
\hline 7 & 180 & 3,945 & 4,926 & $14.9 \%$ & $19,433,070$ & $21.9 \%$ & $100.0 \%$ & $100.0 \%$ & 0.15 & 1.78 & 0.266 & & & & \\
\hline & & & & & & & & & & & & & & & \\
\hline & Total & & 33,048 & $100.0 \%$ & $88,857,635$ & $100.0 \%$ & & & 1.00 & & 0.715 & & & & \\
\hline & & & & & & & & & Gini Coeffic & icient 》〉 & 0.285 & & & & \\
\hline & & & & & & & Wha & at do the results & ts of the $\mathrm{Gi}$ & ini Coeffi & cient mean... & & & & \\
\hline & & & & & & & & & & & & & & & \\
\hline & & & & & & & This measures & $\mathrm{s}$ assist and inci & ident ineq & quality. Th & is shows us that & & & & \\
\hline & & & & & & & there is inequ & uality at $28 \%$ fro & om Perfect & tt Equality & & & & & \\
\hline & & & & & & & & & & & & & & & \\
\hline
\end{tabular}


Table 16. Lorenz Curve and Gini Coefficient - Assist and VMT Distribution Table for the Secondary Direction

\begin{tabular}{|c|c|c|c|c|c|c|c|c|c|c|c|c|c|c|c|}
\hline \multirow{3}{*}{ k } & \multicolumn{8}{|c|}{ Assist and Incident Distribution } & & & & \multirow{3}{*}{$\begin{array}{r}\text { Lorenz X } \\
2.9 \%\end{array}$} & \multirow{3}{*}{$\begin{array}{r}\text { Lorenz } Y \\
0.0 \% \\
\end{array}$} & \multirow{3}{*}{$\begin{array}{r}\text { Diagonal } \mathbf{X} \\
0 \%\end{array}$} & \multirow{3}{*}{\begin{tabular}{|r|} 
Diagonal Y \\
$0 \%$ \\
\end{tabular}} \\
\hline & \multirow[t]{2}{*}{ Income Range } & \multirow[t]{2}{*}{ Assists } & \multirow[t]{2}{*}{ VMT } & \multirow[t]{2}{*}{$\%$ of All VMT } & \multirow{2}{*}{$\begin{array}{c}\begin{array}{c}\text { Total Assists and } \\
\text { VMT }\end{array} \\
\text { CX D }\end{array}$} & \multirow{2}{*}{$\begin{array}{c}\begin{array}{c}\text { of Assists and } \\
\text { VMT }\end{array} \\
\end{array}$} & \multirow{2}{*}{\begin{tabular}{|c|}
$\begin{array}{c}\text { Cumulative } \\
\% \text { of All VMT }\end{array}$ \\
$\mathbf{x}_{\mathrm{k}}$ \\
\end{tabular}} & \multirow{2}{*}{\begin{tabular}{|c|}
$\begin{array}{c}\text { Cumulative } \\
\% \text { of Assists } \\
\text { and VMT }\end{array}$ \\
$Y_{k}$ \\
\end{tabular}} & \multicolumn{3}{|c|}{ Calculation of Gini Coefficient } & & & & \\
\hline & & & & & & & & & Xk-Xk-1 & $Y k+Y k-1$ & $(X k-X k-1)(Y k+Y k-1)$ & & & & \\
\hline 0 & & & & & & & & & & & & $8.3 \%$ & $0.0 \%$ & $14 \%$ & $14 \%$ \\
\hline 1 & SR 242 & 0 & $296,699,039$ & $2.9 \%$ & 0 & $0.0 \%$ & $2.9 \%$ & $0.0 \%$ & 0.03 & 0.00 & 0.000 & $22.7 \%$ & $3.7 \%$ & $14 \%$ & $14 \%$ \\
\hline 2 & SR 4 & 0 & $547,645,452$ & $5.4 \%$ & 0 & $0.0 \%$ & $8.3 \%$ & $0.0 \%$ & 0.05 & 0.00 & 0.000 & $35.9 \%$ & $10.8 \%$ & $14 \%$ & $14 \%$ \\
\hline 3 & 1680 & 618 & $1,478,462,891$ & $14.5 \%$ & $913,690,066,638$ & $3.7 \%$ & $22.7 \%$ & $3.7 \%$ & 0.14 & 0.04 & 0.005 & $54.4 \%$ & $26.6 \%$ & $14 \%$ & $14 \%$ \\
\hline 4 & Hwy 101 & 1,311 & $1,345,126,899$ & $13.2 \%$ & $1,763,461,364,589$ & $7.1 \%$ & $35.9 \%$ & $10.8 \%$ & 0.13 & 0.14 & 0.019 & $85.2 \%$ & $75.9 \%$ & $14 \%$ & $14 \%$ \\
\hline 5 & SR 85 & 2,073 & \begin{tabular}{|l|}
$1,888,198,910$ \\
\end{tabular} & $18.5 \%$ & $3,914,236,340,430$ & $15.8 \%$ & $54.4 \%$ & $26.6 \%$ & 0.18 & 0.37 & 0.069 & $100.0 \%$ & $100.0 \%$ & $14 \%$ & $14 \%$ \\
\hline 6 & $101 / 85$ & 3,902 & \begin{tabular}{|l|}
$3,138,579,143$ \\
\end{tabular} & $30.7 \%$ & $12,246,735,815,986$ & $49.3 \%$ & $85.2 \%$ & $75.9 \%$ & 0.31 & 1.02 & 0.315 & & & $100 \%$ & $100 \%$ \\
\hline \multirow[t]{9}{*}{7} & 180 & 3,945 & \begin{tabular}{|l|}
$1,516,000,040$ \\
\end{tabular} & $14.8 \%$ & $5,980,620,157,800$ & $24.1 \%$ & $100.0 \%$ & $100.0 \%$ & 0.15 & 1.76 & 0.261 & & & & \\
\hline & & & & & & & & & & & & & & & \\
\hline & Total & & \begin{tabular}{|l|}
$10,210,712,374$ \\
\end{tabular} & $100.0 \%$ & $24,818,743,745,443$ & $100.0 \%$ & & & 1.00 & & 0.670 & & & & \\
\hline & & & & & & & & & ini Coeffi & icient 〉〉> & 0.330 & & & & \\
\hline & & & & & & & What & $t$ do the results & $s$ of the Gi & ini Coeffic & cient mean... & & & & \\
\hline & & & & & & & \multirow{4}{*}{\multicolumn{5}{|c|}{$\begin{array}{l}\text { This measures assist and incident inequality. This shows us that } \\
\text { there is inequality at } 28 \% \text { from Perfect Equality. }\end{array}$}} & & & & \\
\hline & & & & & & & & & & & & & & & \\
\hline & & & & & & & & & & & & & & & \\
\hline & & & & & & & & & & & & & & & \\
\hline
\end{tabular}


Table 17.Lorenz Curve and Gini Coefficient - Incident and VMT Distribution Table for the Secondary Direction

\begin{tabular}{|c|c|c|c|c|c|c|c|c|c|c|c|c|c|c|c|}
\hline \multirow[b]{2}{*}{ k } & \multicolumn{8}{|c|}{ Assist and Incident Distribution } & & & & \multirow{3}{*}{$\begin{array}{c}\text { Lorenz X } \\
0 \%\end{array}$} & \multirow{3}{*}{$\begin{array}{r}\text { Lorenz } \mathbf{Y} \\
0.7 \%\end{array}$} & \multirow{3}{*}{\begin{tabular}{|r|} 
Diagonal X \\
$0 \%$
\end{tabular}} & \\
\hline & \multirow[t]{2}{*}{ Income Range } & \multirow[t]{2}{*}{ Incidents } & \multirow[t]{2}{*}{ VMT } & \multirow[t]{2}{*}{$\begin{array}{l}\text { \% of All } \\
\text { Incidents }\end{array}$} & \multirow{2}{*}{$\begin{array}{c}\begin{array}{c}\text { Total Incidents and } \\
\text { VMT }\end{array} \\
\text { C X D }\end{array}$} & \multirow[t]{2}{*}{$\begin{array}{l}\text { \% of Incidents } \\
\text { and VMT }\end{array}$} & \multirow{2}{*}{\begin{tabular}{|c}
$\begin{array}{c}\text { Cumulative } \\
\text { \% of All VMT }\end{array}$ \\
$x_{k}$ \\
\end{tabular}} & \multirow{2}{*}{\begin{tabular}{|c|}
$\begin{array}{c}\text { Cumulative } \\
\% \text { of } \\
\text { Incidents and } \\
\text { VMT }\end{array}$ \\
$Y_{k}$ \\
\end{tabular}} & \multicolumn{3}{|c|}{ Calculation of Gini Coefficient } & & & & \multirow{2}{*}{\begin{tabular}{|r|} 
Diagonal Y \\
$0 \%$
\end{tabular}} \\
\hline & & & & & & & & & Xk-Xk-1 & $Y k+Y k-1$ & $(\mathrm{Xk}-\mathrm{Xk}-1)(\mathrm{Yk}+\mathrm{Yk}-1)$ & & & & \\
\hline 0 & & & & & & & & & & & & $2.9 \%$ & $2.4 \%$ & $14 \%$ & $14 \%$ \\
\hline 1 & SR 242 & 1,456 & $296,699,039$ & $2.9 \%$ & $431,993,800,784$ & $0.7 \%$ & $2.9 \%$ & $0.7 \%$ & 0.03 & 0.01 & 0.000 & $8.3 \%$ & $7.8 \%$ & $14 \%$ & $14 \%$ \\
\hline 2 & SR 4 & 1,788 & $547,645,452$ & $5.4 \%$ & $979,190,068,176$ & $1.7 \%$ & $8.3 \%$ & $2.4 \%$ & 0.05 & 0.03 & 0.002 & $22.7 \%$ & $14.9 \%$ & $14 \%$ & $14 \%$ \\
\hline 3 & Hwy 101 & 2,113 & $1,478,462,891$ & $14.5 \%$ & $3,123,992,088,683$ & $5.3 \%$ & $22.7 \%$ & $7.8 \%$ & 0.14 & 0.10 & 0.015 & $35.9 \%$ & $30.8 \%$ & $14 \%$ & $14 \%$ \\
\hline 4 & 1680 & 3,101 & $1,345,126,899$ & $13.2 \%$ & $4,171,238,513,799$ & $7.1 \%$ & $35.9 \%$ & $14.9 \%$ & 0.13 & 0.23 & 0.030 & $54.4 \%$ & $66.0 \%$ & $14 \%$ & $14 \%$ \\
\hline 5 & 180 & 4,926 & \begin{tabular}{|l|}
$1,888,198,910$ \\
\end{tabular} & $18.5 \%$ & $9,301,267,830,660$ & $15.9 \%$ & $54.4 \%$ & $30.8 \%$ & 0.18 & 0.46 & 0.085 & $85.2 \%$ & $100.0 \%$ & $14 \%$ & $14 \%$ \\
\hline 6 & SR 85 & 6,556 & \begin{tabular}{|l|}
$3,138,579,143$ \\
\end{tabular} & $30.7 \%$ & $20,576,524,861,508$ & $35.2 \%$ & $85.2 \%$ & $66.0 \%$ & 0.31 & 0.97 & 0.298 & $100.0 \%$ & & $100 \%$ & $100 \%$ \\
\hline \multirow[t]{9}{*}{7} & $101 / 85$ & 13,108 & $1,516,000,040$ & $14.8 \%$ & $19,871,728,524,320$ & $34.0 \%$ & $100.0 \%$ & $100.0 \%$ & 0.15 & 1.66 & 0.246 & & & & \\
\hline & & & & & & & & & & & & & & & \\
\hline & Total & & 10,210,712,374 & $100.0 \%$ & $58,455,935,687,930$ & $100.0 \%$ & & & 1.00 & & 0.675 & & & & \\
\hline & & & & & & & & & Gini Coeffi & 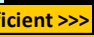 & 0.325 & & & & \\
\hline & & & & & & & Wha & at do the results & $s$ of the $\mathrm{Gi}$ & ini Coeffic & cient mean... & & & & \\
\hline & & & & & & & \multirow{4}{*}{\multicolumn{5}{|c|}{$\begin{array}{l}\text { This measures assist and incident inequality. This shows us that } \\
\text { there is inequality at } 28 \% \text { from Perfect Equality. }\end{array}$}} & & & & \\
\hline & & & & & & & & & & & & & & & \\
\hline & & & & & & & & & & & & & & & \\
\hline & & & & & & & & & & & & & & & \\
\hline
\end{tabular}


Table 18.Lorenz Curve and Gini Coefficient - Incident and Assists Distribution Table for Peak Travel Times

\begin{tabular}{|c|c|c|c|c|c|c|c|c|c|c|c|c|c|c|c|}
\hline \multirow{3}{*}{ k } & \multicolumn{8}{|c|}{ Assist and Incident Distribution } & & & & \multirow{3}{*}{$\begin{array}{c}\text { Lorenz X } \\
0\end{array}$} & \multirow{3}{*}{$\begin{array}{r}\text { Lorenz } \mathbf{Y} \\
0.0 \% \\
\end{array}$} & \multirow{3}{*}{$\begin{array}{r}\text { Diagonal X } \\
0 \%\end{array}$} & \multirow{3}{*}{$\begin{array}{r}\text { Diagonal } Y \\
\\
0 \%\end{array}$} \\
\hline & \multirow[t]{2}{*}{ Income Range } & \multirow[t]{2}{*}{ Assists } & \multirow[t]{2}{*}{ Incidents } & \multirow[t]{2}{*}{$\begin{array}{l}\text { \% of All } \\
\text { Incidents }\end{array}$} & \multirow{2}{*}{$\begin{array}{c}\begin{array}{c}\text { Total Assists and } \\
\text { Incidents }\end{array} \\
\text { C X D }\end{array}$} & \multirow{2}{*}{\begin{tabular}{|c|}
$\begin{array}{c}\% \text { of Assists and } \\
\text { Incidents }\end{array}$ \\
\end{tabular}} & \multirow{2}{*}{\begin{tabular}{|c|}
$\begin{array}{c}\text { Cumulative } \\
\text { \% of All } \\
\text { Incidents }\end{array}$ \\
$X_{k}$ \\
\end{tabular}} & \multirow{2}{*}{$\begin{array}{c}\begin{array}{c}\text { Cumulative } \\
\text { \% of Assists } \\
\text { and Incidents }\end{array} \\
\mathbf{Y}_{\mathrm{k}}\end{array}$} & \multicolumn{3}{|c|}{ Calculation of Gini Coefficient } & & & & \\
\hline & & & & & & & & & Xk -Xk-1 & $Y k+Y k-1$ & $(\mathrm{Xk}-\mathrm{Xk}-1)(\mathrm{Yk}+\mathrm{Yk}-1)$ & & & & \\
\hline 0 & & & & & & & & & & & & $2.7 \%$ & $0.0 \%$ & $14 \%$ & $14 \%$ \\
\hline 1 & SR 242 & 0 & 553 & $2.7 \%$ & 0 & $0.0 \%$ & $2.7 \%$ & $0.0 \%$ & 0.03 & 0.00 & 0.000 & $9.2 \%$ & $6.1 \%$ & $14 \%$ & $14 \%$ \\
\hline 2 & SR 4 & 0 & 1,309 & $6.5 \%$ & 0 & $0.0 \%$ & $9.2 \%$ & $0.0 \%$ & 0.06 & 0.00 & 0.000 & $22.3 \%$ & $9.0 \%$ & $14 \%$ & $14 \%$ \\
\hline 3 & 1680 & 1,840 & 2,654 & $13.1 \%$ & $4,883,360$ & $6.1 \%$ & $22.3 \%$ & $6.1 \%$ & 0.13 & 0.06 & 0.008 & $27.2 \%$ & $28.9 \%$ & $14 \%$ & $14 \%$ \\
\hline 4 & Hwy 101 & 2,355 & 991 & $4.9 \%$ & $2,333,805$ & $2.9 \%$ & $27.2 \%$ & $9.0 \%$ & 0.05 & 0.15 & 0.007 & $46.7 \%$ & $79.7 \%$ & $14 \%$ & $14 \%$ \\
\hline 5 & SR 85 & 3,999 & 3,971 & $19.6 \%$ & $15,880,029$ & $19.9 \%$ & $46.7 \%$ & $28.9 \%$ & 0.20 & 0.38 & 0.074 & $84.6 \%$ & $100.0 \%$ & $14 \%$ & $14 \%$ \\
\hline 6 & $101 / 85$ & 5,295 & 7,670 & $37.8 \%$ & $40,612,650$ & $50.8 \%$ & $84.6 \%$ & $79.7 \%$ & 0.38 & 1.09 & 0.411 & $100.0 \%$ & & $100 \%$ & $100 \%$ \\
\hline \multirow[t]{8}{*}{7} & 180 & 5,197 & 3,127 & $15.4 \%$ & $16,251,019$ & $20.3 \%$ & $100.0 \%$ & $100.0 \%$ & 0.15 & 1.80 & 0.277 & & & & \\
\hline & & & & & & & & & & & & & & & \\
\hline & Total & & 20,275 & $100.0 \%$ & $79,960,863$ & $100.0 \%$ & & & 1.00 & & 0.777 & & & & \\
\hline & & & & & & & & & Gini Coeffic & 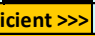 & 0.223 & & & & \\
\hline & & & & & & & Wha & at do the results & ts of the $\mathrm{Gi}$ & ini Coeffic & cient mean... & & & & \\
\hline & & & & & & & \multirow{4}{*}{\multicolumn{5}{|c|}{$\begin{array}{l}\text { This measures assist and incident inequality. This shows us that } \\
\text { there is inequality at } 25 \% \text { from Perfect Equality. }\end{array}$}} & & & & \\
\hline & & & & & & & & & & & & & & & \\
\hline & & & & & & & & & & & & & & & \\
\hline & & & & & & & & & & & & & & & \\
\hline
\end{tabular}


Table 19. Lorenz Curve and Gini Coefficient - Assists and VMT Distribution Table for Peak Travel Times

\section{Assist and VMT Distribution}

\begin{tabular}{|c|c|c|c|c|c|c|c|c|c|c|c|c|c|c|c|}
\hline \multirow[t]{2}{*}{ k } & \multirow[t]{2}{*}{ Income Range } & \multirow[t]{2}{*}{ Assists } & \multirow[t]{2}{*}{ VMT } & \multirow[t]{2}{*}{$\%$ of All VMT } & \multirow{2}{*}{$\begin{array}{c}\begin{array}{c}\text { Total Assists and } \\
\text { VMT }\end{array} \\
\text { CX D }\end{array}$} & \multirow{2}{*}{\begin{tabular}{|c|}
$\begin{array}{c}\text { \% of Assists and } \\
\text { VMT }\end{array}$ \\
\end{tabular}} & \multirow{2}{*}{\begin{tabular}{|c|}
$\begin{array}{c}\text { Cumulative } \\
\% \text { of All VMT }\end{array}$ \\
$\mathrm{X}_{\mathrm{k}}$ \\
\end{tabular}} & \multirow{2}{*}{$\begin{array}{c}\begin{array}{c}\text { Cumulative } \\
\% \text { of Assists } \\
\text { and VMT }\end{array} \\
Y_{k} \\
\end{array}$} & \multicolumn{3}{|c|}{ Calculation of Gini Coefficient } & \multirow{2}{*}{$\begin{array}{r}\text { Lorenz X } \\
2.6 \%\end{array}$} & \multirow{2}{*}{$\begin{array}{r}\text { Lorenz Y } \\
0.0 \%\end{array}$} & \multirow{2}{*}{$\begin{array}{r}\text { Diagonal X } \\
0 \%\end{array}$} & \multirow{2}{*}{$\begin{array}{r}\text { Diagonal Y } \\
0 \%\end{array}$} \\
\hline & & & & & & & & & Xk-Xk-1 & $Y k+Y k-1$ & $(X k-X k-1)(Y k+Y k-1)$ & & & & \\
\hline 0 & & & & & & & & & & & & $7.3 \%$ & $0.0 \%$ & $14 \%$ & $14 \%$ \\
\hline 1 & SR 242 & 0 & $158,517,521$ & $2.6 \%$ & 0 & $0.0 \%$ & $2.6 \%$ & $0.0 \%$ & 0.03 & 0.00 & 0.000 & $21.8 \%$ & $7.1 \%$ & $14 \%$ & $14 \%$ \\
\hline 2 & SR 4 & 0 & $284,398,502$ & $4.7 \%$ & 0 & $0.0 \%$ & $7.3 \%$ & $0.0 \%$ & 0.05 & 0.00 & 0.000 & $34.6 \%$ & $15.1 \%$ & $14 \%$ & $14 \%$ \\
\hline 3 & 1680 & 1,840 & $890,943,000$ & $14.6 \%$ & $1,639,335,120,000$ & $7.1 \%$ & $21.8 \%$ & $7.1 \%$ & 0.15 & 0.07 & 0.010 & $54.6 \%$ & $36.5 \%$ & $14 \%$ & $14 \%$ \\
\hline 4 & Hwy 101 & 2,358 & \begin{tabular}{|l|}
$776,108,978$ \\
\end{tabular} & $12.7 \%$ & $1,830,064,970,124$ & $8.0 \%$ & $34.6 \%$ & $15.1 \%$ & 0.13 & 0.22 & 0.028 & $86.0 \%$ & $80.6 \%$ & $14 \%$ & $14 \%$ \\
\hline 5 & SR 85 & 3,999 & $1,226,950,300$ & $20.1 \%$ & $4,906,574,249,700$ & $21.4 \%$ & $54.6 \%$ & $36.5 \%$ & 0.20 & 0.52 & 0.104 & $100.0 \%$ & $100.0 \%$ & $14 \%$ & $14 \%$ \\
\hline 6 & $101 / 85$ & 5,295 & $1,913,372,515$ & $31.3 \%$ & $10,131,307,466,925$ & $44.1 \%$ & $86.0 \%$ & $80.6 \%$ & 0.31 & 1.17 & 0.367 & & & $14 \%$ & $14 \%$ \\
\hline \multirow[t]{5}{*}{7} & 180 & 5,197 & $856,599,414$ & $14.0 \%$ & $4,451,747,154,558$ & $19.4 \%$ & $100.0 \%$ & $100.0 \%$ & 0.14 & 1.81 & 0.253 & & & $100 \%$ & $100 \%$ \\
\hline & & & & & & & & & & & & & & & \\
\hline & Total & & $6,106,890,230$ & $100.0 \%$ & $22,959,028,961,307$ & $100.0 \%$ & & & 1.00 & & 0.763 & & & & \\
\hline & & & & & & & & & Sini Coeffi & 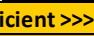 & 0.237 & & & & \\
\hline & & & & & & & What & do the results & $s$ of the $\mathrm{Gi}$ & ini Coeffi & icient mean... & & & & \\
\hline & & & & & & & \multirow{4}{*}{\multicolumn{5}{|c|}{$\begin{array}{l}\text { This measures assist and incident inequality. This shows us that } \\
\text { there is inequality at } 22 \% \text { from Perfect Equality. }\end{array}$}} & & & & \\
\hline & & & & & & & & & & & & & & & \\
\hline & & & & & & & & & & & & & & & \\
\hline & & & & & & & & & & & & & & & \\
\hline
\end{tabular}


Table 20. Lorenz Curve and Gini Coefficient - Incident and VMT Distribution Table for the Secondary Direction

\begin{tabular}{|c|c|c|c|c|c|c|c|c|c|c|c|c|c|c|c|}
\hline & \multicolumn{8}{|c|}{ Incident and VMT Distribution } & & & & & & & \\
\hline & \multirow[t]{2}{*}{ Income Range } & \multirow[t]{2}{*}{ Incidents } & \multirow[t]{2}{*}{ VMT } & \multirow[t]{2}{*}{$\%$ of All VMT } & \multirow{2}{*}{\begin{tabular}{|c}
$\begin{array}{c}\text { Total Incidents and } \\
\text { VMT }\end{array}$ \\
C X D \\
\end{tabular}} & \multirow[t]{2}{*}{\begin{tabular}{|c}
$\begin{array}{c}\% \text { of Incidents } \\
\text { and VMT }\end{array}$ \\
\end{tabular}} & \multirow{2}{*}{\begin{tabular}{|c|}
$\begin{array}{c}\text { Cumulative } \\
\text { \% of All VMT }\end{array}$ \\
$x_{k}$ \\
\end{tabular}} & \multirow{2}{*}{\begin{tabular}{|c|}
$\begin{array}{c}\text { Cumulative } \\
\% \text { of } \\
\text { Incidents and } \\
\text { VMT }\end{array}$ \\
$Y_{k}$
\end{tabular}} & \multicolumn{3}{|c|}{ Calculation of Gini Coefficient } & \multirow{2}{*}{$\begin{array}{r}\text { Lorenz X } \\
2.6 \% \\
\end{array}$} & \multirow{2}{*}{$\begin{array}{l}\text { Lorenz } \mathbf{Y} \\
\\
\\
0.4 \%\end{array}$} & \multirow{2}{*}{$\begin{array}{r}\text { Diagonal X } \\
\\
0 \%\end{array}$} & \multirow{2}{*}{\begin{tabular}{|r|} 
Diagonal $\mathbf{Y}$ \\
$0 \%$ \\
\end{tabular}} \\
\hline k & & & & & & & & & Xk -Xk-1 & $Y k+Y k-1$ & $(\mathrm{Xk}-\mathrm{Xk}-1)(\mathrm{Yk}+\mathrm{Yk}-1)$ & & & & \\
\hline 0 & & & & & & & & & & & & $7.3 \%$ & $1.7 \%$ & $14 \%$ & $14 \%$ \\
\hline 1 & SR 242 & 553 & $158,517,521$ & $2.6 \%$ & $87,660,189,113$ & $0.4 \%$ & $2.6 \%$ & $0.4 \%$ & 0.03 & 0.00 & 0.000 & $21.8 \%$ & $7.1 \%$ & $14 \%$ & $14 \%$ \\
\hline 2 & Hwy 101 & 991 & $284,398,502$ & $4.7 \%$ & $281,838,915,482$ & $1.3 \%$ & $7.3 \%$ & $1.7 \%$ & 0.05 & 0.02 & 0.001 & $34.6 \%$ & $16.6 \%$ & $14 \%$ & $14 \%$ \\
\hline 3 & SR 4 & 1,309 & $890,943,000$ & $14.6 \%$ & $1,166,244,387,000$ & $5.4 \%$ & $21.8 \%$ & $7.1 \%$ & 0.15 & 0.09 & 0.013 & $54.6 \%$ & $34.4 \%$ & $14 \%$ & $14 \%$ \\
\hline 4 & 1680 & 2,654 & $776,108,978$ & $12.7 \%$ & $2,059,793,227,612$ & $9.5 \%$ & $34.6 \%$ & $16.6 \%$ & 0.13 & 0.24 & 0.030 & $86.0 \%$ & $69.6 \%$ & $14 \%$ & $14 \%$ \\
\hline 5 & 180 & 3,127 & $1,226,950,300$ & $20.1 \%$ & $3,836,673,588,100$ & $17.8 \%$ & $54.6 \%$ & $34.4 \%$ & 0.20 & 0.51 & 0.103 & $100.0 \%$ & $100.0 \%$ & $14 \%$ & $14 \%$ \\
\hline 6 & SR 85 & 3,971 & $1,913,372,515$ & $31.3 \%$ & $7,598,002,257,065$ & $35.2 \%$ & $86.0 \%$ & $69.6 \%$ & 0.31 & 1.04 & 0.326 & & & $100 \%$ & $100 \%$ \\
\hline \multirow[t]{9}{*}{7} & $101 / 85$ & 7,670 & $856,599,414$ & $14.0 \%$ & $6,570,117,505,380$ & $30.4 \%$ & $100.0 \%$ & $100.0 \%$ & 0.14 & 1.70 & 0.238 & & & & \\
\hline & & & & & & & & & & & & & & & \\
\hline & Total & & $6,106,890,230$ & $100.0 \%$ & $21,600,330,069,752$ & $100.0 \%$ & & & 1.00 & & 0.710 & & & & \\
\hline & & & & & & & & & Gini Coeffi & 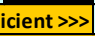 & 0.290 & & & & \\
\hline & & & & & & & Wha & at do the results & ts of the $G i$ & ini Coeffic & cient mean... & & & & \\
\hline & & & & & & & \multirow{4}{*}{\multicolumn{5}{|c|}{$\begin{array}{l}\text { This measures incident and VMT inequality. This shows us that there } \\
\text { is inequality at } 31 \% \text { from Perfect Equality. }\end{array}$}} & & & & \\
\hline & & & & & & & & & & & & & & & \\
\hline & & & & & & & & & & & & & & & \\
\hline & & & & & & & & & & & & & & & \\
\hline
\end{tabular}


Figure 32. Assists and Incidents Distribution for FSP Routes during Peak Travel Time

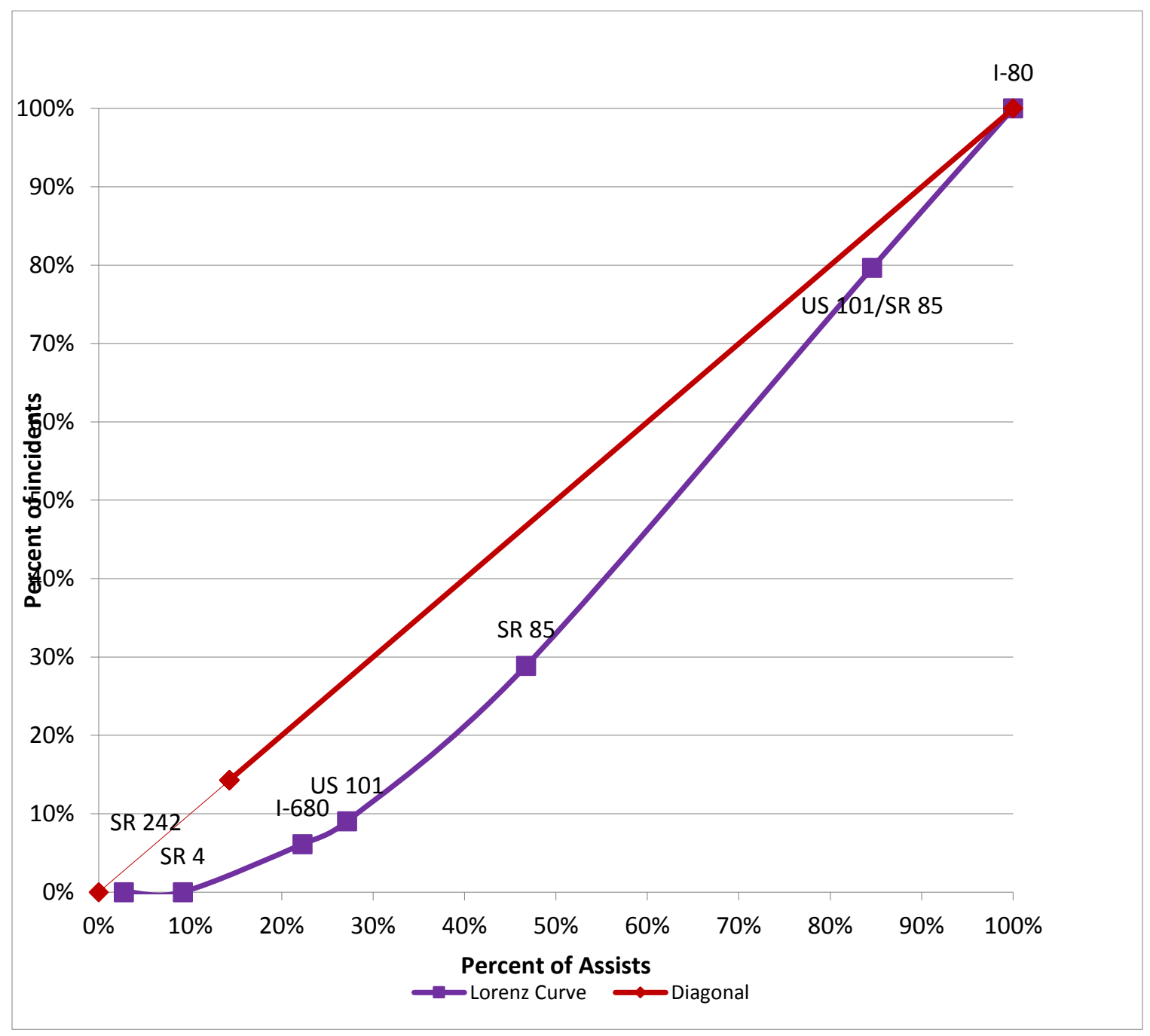


Figure 33. Assists and VMT Distribution for FSP Routes during Peak Travel Time

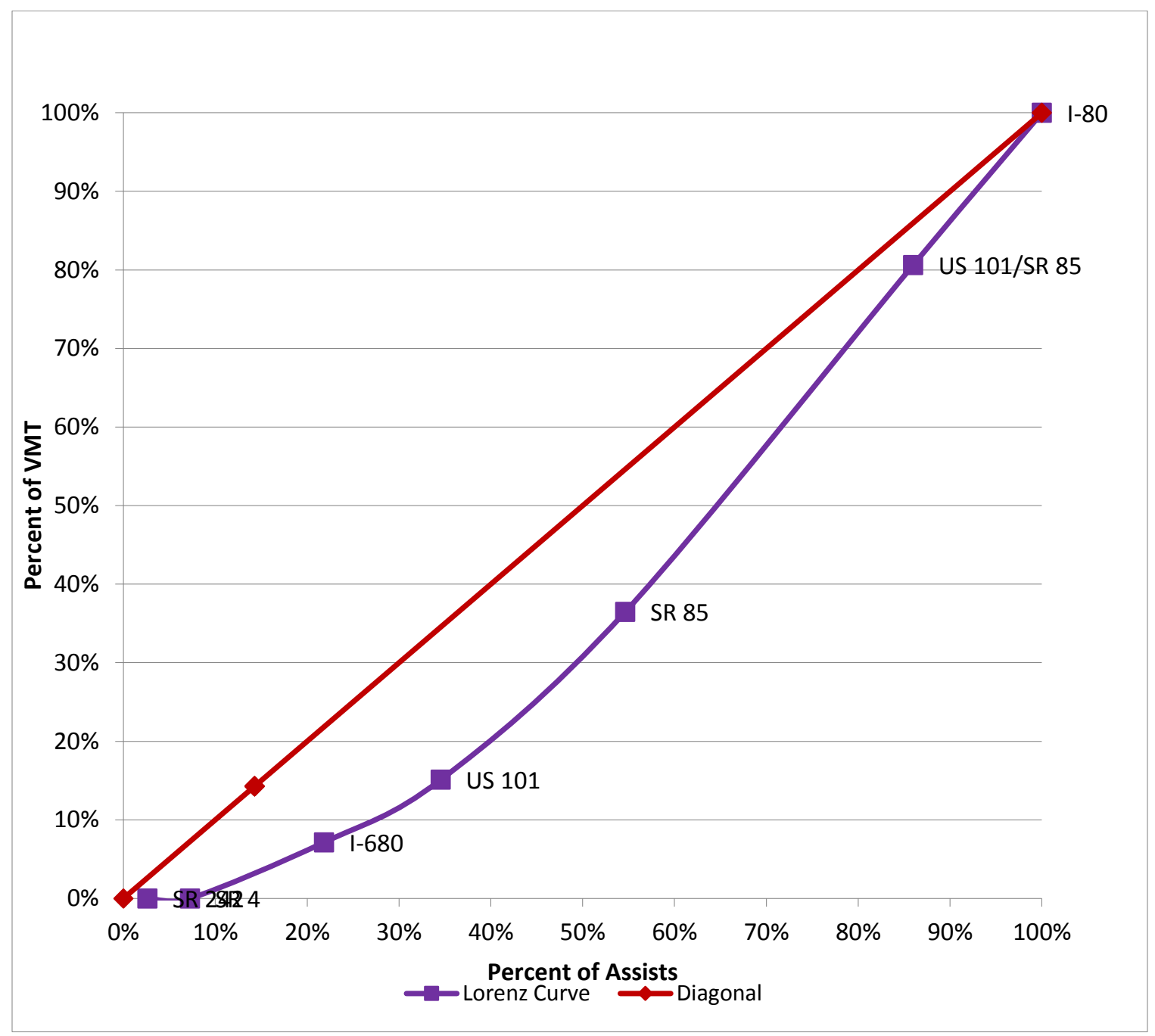


Figure 34. Incident and VMT Distribution for FSP Routes during Peak Travel Times

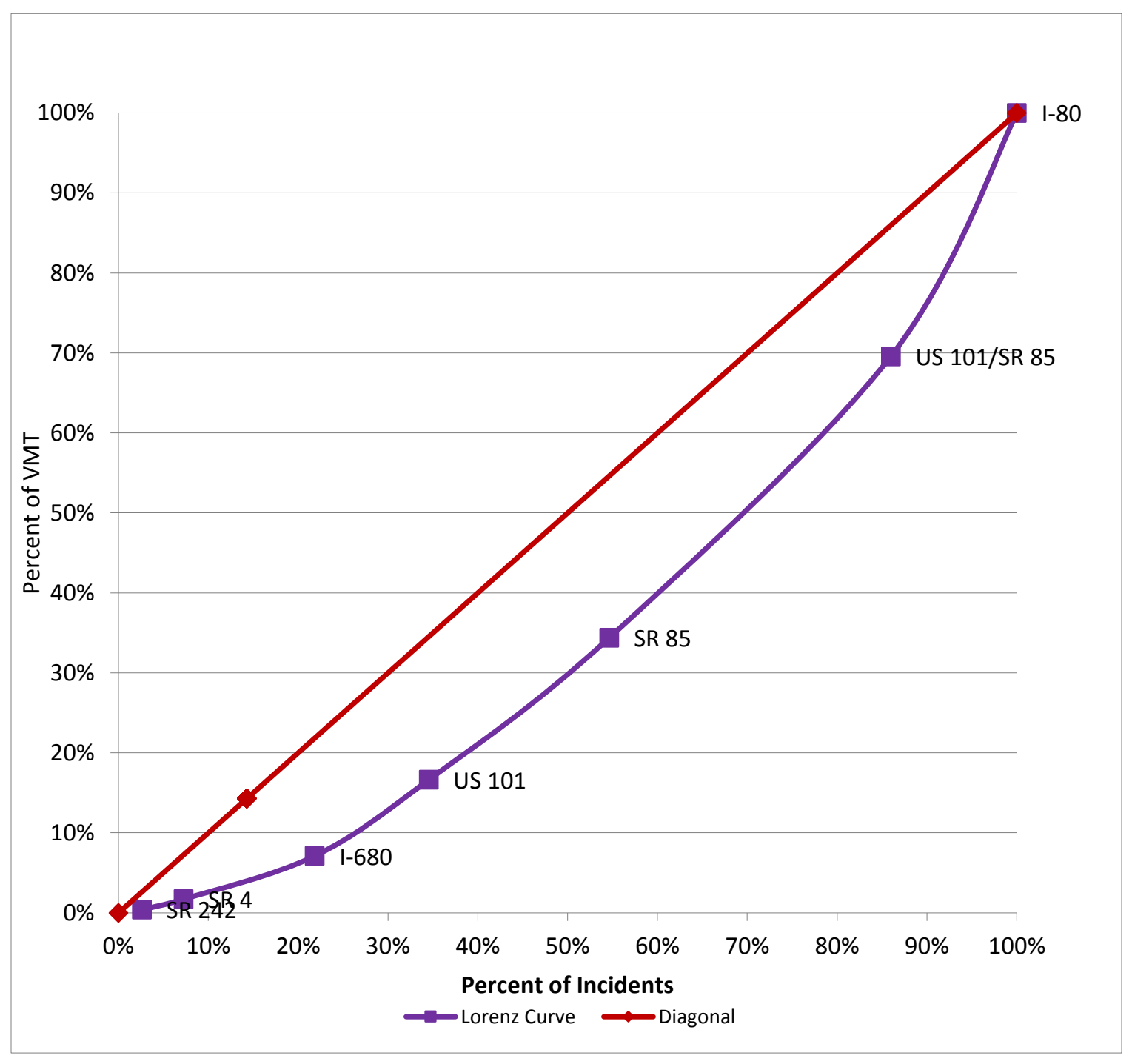


Table 21.Primary Direction Chi Square Test for Months vs. Incidents

\begin{tabular}{|c|c|c|c|c|c|c|c|c|c|c|c|c|c|}
\hline & \multicolumn{12}{|c|}{ Months, Primary Direction } & \multirow[t]{2}{*}{ Total } \\
\hline & Jan. & Feb. & $\begin{array}{l}\text { Mar } \\
\text { ch }\end{array}$ & $\begin{array}{l}\text { Apr } \\
\text { il }\end{array}$ & May & June & July & Aug & Sept. & Oct. & Nov & $\begin{array}{l}\text { Dec } \\
\text {. }\end{array}$ & \\
\hline Count & 2508 & $\begin{array}{l}2,39 \\
5\end{array}$ & $\begin{array}{l}2,82 \\
3 \\
\end{array}$ & $\begin{array}{l}2,55 \\
3\end{array}$ & $\begin{array}{l}2,76 \\
2\end{array}$ & $\begin{array}{l}2,72 \\
4\end{array}$ & $\begin{array}{l}2,76 \\
1\end{array}$ & $\begin{array}{l}2,52 \\
7\end{array}$ & $\begin{array}{l}2,74 \\
8\end{array}$ & $\begin{array}{l}2,84 \\
6 \\
\end{array}$ & $\begin{array}{l}2,38 \\
6\end{array}$ & $\begin{array}{l}2,49 \\
7\end{array}$ & $\begin{array}{l}31,5 \\
30\end{array}$ \\
\hline $\begin{array}{l}\text { Expect } \\
\text { ed } \\
\text { Count }\end{array}$ & $\begin{array}{l}2672 \\
.8\end{array}$ & $\begin{array}{l}2,42 \\
8\end{array}$ & $\begin{array}{l}2,67 \\
9\end{array}$ & $\begin{array}{l}2,58 \\
7\end{array}$ & $\begin{array}{l}2,68 \\
3\end{array}$ & $\begin{array}{l}2,59 \\
5\end{array}$ & $\begin{array}{l}2,67 \\
6\end{array}$ & $\begin{array}{l}2,67 \\
2\end{array}$ & $\begin{array}{l}2,59 \\
5\end{array}$ & $\begin{array}{l}2,68 \\
2\end{array}$ & $\begin{array}{l}2,58 \\
6\end{array}$ & $\begin{array}{l}2,67 \\
4\end{array}$ & $\begin{array}{l}31,5 \\
30\end{array}$ \\
\hline $\begin{array}{l}\% \\
\text { within } \\
\text { Incide } \\
\text { nt }\end{array}$ & $8.0 \%$ & $\begin{array}{l}7.6 \\
\%\end{array}$ & $\begin{array}{l}9.0 \\
\%\end{array}$ & $\begin{array}{l}8.1 \\
\%\end{array}$ & $\begin{array}{l}8.8 \\
\%\end{array}$ & $\begin{array}{l}8.6 \\
\%\end{array}$ & $\begin{array}{l}8.8 \\
\%\end{array}$ & $\begin{array}{l}8.0 \\
\%\end{array}$ & $\begin{array}{l}8.7 \\
\%\end{array}$ & $\begin{array}{l}9.0 \\
\%\end{array}$ & $\begin{array}{l}7.6 \\
\%\end{array}$ & $\begin{array}{l}7.9 \\
\%\end{array}$ & $\begin{array}{l}100 \\
\%\end{array}$ \\
\hline $\begin{array}{l}\% \\
\text { within } \\
\text { Month } \\
\text { s }\end{array}$ & $9.5 \%$ & $\begin{array}{l}9.9 \\
\%\end{array}$ & $\begin{array}{l}10.6 \\
\%\end{array}$ & $\begin{array}{l}9.9 \\
\%\end{array}$ & $\begin{array}{l}10.4 \\
\%\end{array}$ & $\begin{array}{l}10.6 \\
\%\end{array}$ & $\begin{array}{l}10.4 \\
\%\end{array}$ & $\begin{array}{l}9.5 \\
\%\end{array}$ & $\begin{array}{l}10.7 \\
\%\end{array}$ & $\begin{array}{l}10.7 \\
\%\end{array}$ & $\begin{array}{l}9.3 \\
\%\end{array}$ & $\begin{array}{l}9.4 \\
\%\end{array}$ & $\begin{array}{l}10.1 \\
\%\end{array}$ \\
\hline
\end{tabular}

\begin{tabular}{|l|l|}
\hline \multicolumn{2}{|l|}{ Chi-Square Tests } \\
\hline & $\begin{array}{l}\text { Asymp. } \\
\text { Sig. (2- } \\
\text { sided) }\end{array}$ \\
\hline Chi-Square & .000 \\
\hline
\end{tabular}

Table 22. Secondary Direction Chi Square Test for Incidents and Months

\begin{tabular}{|c|c|c|c|c|c|c|c|c|c|c|c|c|c|}
\hline & \multicolumn{12}{|c|}{ Months, Secondary Direction } & \multirow{2}{*}{ Total } \\
\hline & $\begin{array}{l}\text { Jan } \\
.\end{array}$ & Feb. & March & April & May & June & July & Aug. & Sept. & Oct. & Nov. & Dec & \\
\hline Count & $\begin{array}{l}2,5 \\
94 \\
\end{array}$ & 2,513 & 2,954 & 2,864 & 2,780 & 2,813 & 2,933 & 2,821 & 2,927 & 2,965 & $\begin{array}{l}2,42 \\
8\end{array}$ & $\begin{array}{l}2,45 \\
6\end{array}$ & 33,048 \\
\hline $\begin{array}{l}\text { Expec } \\
\text { ted } \\
\text { Count }\end{array}$ & $\begin{array}{l}2,8 \\
02\end{array}$ & 2,552 & 2,805 & 2,720 & 2,804 & 2,717 & 2,805 & 2,805 & 2,719 & 2,814 & $\begin{array}{l}2,70 \\
9\end{array}$ & $\begin{array}{l}2,79 \\
6\end{array}$ & 33,048 \\
\hline $\begin{array}{l}\% \\
\text { within } \\
\text { Incide } \\
\text { nt }\end{array}$ & $\begin{array}{l}7.8 \\
\%\end{array}$ & $7.6 \%$ & $8.9 \%$ & $8.7 \%$ & $8.4 \%$ & $8.5 \%$ & $8.9 \%$ & $8.5 \%$ & $8.9 \%$ & $9.0 \%$ & $\begin{array}{l}7.3 \\
\%\end{array}$ & $\begin{array}{l}7.4 \\
\%\end{array}$ & $\begin{array}{l}100.0 \\
\%\end{array}$ \\
\hline $\begin{array}{l}\% \\
\text { within } \\
\text { Month } \\
\text { s }\end{array}$ & $\begin{array}{l}9.8 \\
\%\end{array}$ & $10.4 \%$ & $11.1 \%$ & $11.1 \%$ & $\begin{array}{l}10.5 \\
\%\end{array}$ & $\begin{array}{l}10.9 \\
\%\end{array}$ & $\begin{array}{l}11.0 \\
\%\end{array}$ & $\begin{array}{l}10.6 \\
\%\end{array}$ & $\begin{array}{l}11.4 \\
\%\end{array}$ & $\begin{array}{l}11.1 \\
\%\end{array}$ & $\begin{array}{l}9.5 \\
\%\end{array}$ & $\begin{array}{l}9.3 \\
\%\end{array}$ & $10.6 \%$ \\
\hline
\end{tabular}




\begin{tabular}{|l|l|}
\hline \multicolumn{2}{|l|}{ Chi-Square Tests } \\
\hline & $\begin{array}{l}\text { Asymp. } \\
\text { Sig. (2- } \\
\text { sided) }\end{array}$ \\
\hline Chi-Square & .000 \\
\hline
\end{tabular}

Table 23. Primary Direction Chi Square Test for Incidents and Time of Day

\begin{tabular}{|c|c|c|c|c|c|}
\hline & \multicolumn{4}{|c|}{ Time of Day, Primary Direction } & \multirow[b]{2}{*}{ Total } \\
\hline & Evening & Mid-Day & Morning & Night & \\
\hline Count & 9,977 & 10,637 & 4,707 & 6,209 & 31,530 \\
\hline Expected Count & 5,411 & 7,917 & 3,965 & 14,237 & 31,530 \\
\hline$\%$ within Incidents & $31.6 \%$ & $33.7 \%$ & $14.9 \%$ & $19.7 \%$ & $100.0 \%$ \\
\hline $\begin{array}{l}\% \text { within Time of } \\
\text { Day }\end{array}$ & $18.6 \%$ & $13.5 \%$ & $12.0 \%$ & $4.4 \%$ & $10.1 \%$ \\
\hline
\end{tabular}

\begin{tabular}{|l|l|}
\hline \multicolumn{2}{|l|}{ Chi-Square Tests } \\
\hline & $\begin{array}{l}\text { Asymp. } \\
\text { Sig. (2- } \\
\text { sided) }\end{array}$ \\
\hline Chi-Square & 0.000 \\
\hline
\end{tabular}

Table 24. Secondary Direction Chi Square Test for Incident and Time of Day

\begin{tabular}{|l|l|l|l|l|}
\hline \multirow{2}{*}{} & \multicolumn{2}{|l|}{ Time of Day } & \multirow{2}{*}{} \\
\cline { 2 - 4 } & $\begin{array}{l}\text { Mid- } \\
\text { day }\end{array}$ & Morning & Night & Total \\
\hline Count & 20,182 & 6,343 & 6,523 & 33,048 \\
\hline Expected Count & 13,930 & 4,208 & 14,910 & 33,048 \\
\hline \% within Incident & $61.1 \%$ & $19.2 \%$ & $19.7 \%$ & $100 \%$ \\
\hline $\begin{array}{l}\text { \% within Time Of } \\
\text { Day }\end{array}$ & $15.3 \%$ & $15.9 \%$ & $4.6 \%$ & $10.6 \%$ \\
\hline
\end{tabular}

\begin{tabular}{|l|l|}
\hline \multicolumn{2}{|l|}{ Chi-Square Tests } \\
\hline & $\begin{array}{l}\text { Asymp. } \\
\text { Sig. (2- } \\
\text { sided) }\end{array}$ \\
\hline
\end{tabular}




\begin{tabular}{|l|l|l|l|l|l|l|l|l|}
\hline & \multicolumn{7}{|l|}{ Day of the Week, Primary Direction } & \multirow{2}{*}{ Total } \\
\cline { 2 - 9 } & Sunday & Monday & Tuesday & Wednesday & Thursday & Friday & Saturday & Tornt \\
\hline Count & 3,058 & 4,490 & 4,723 & 4,937 & 5,024 & 5,464 & 3,834 & 31,530 \\
\hline $\begin{array}{l}\text { Expected } \\
\text { Count }\end{array}$ & 4,457 & 4,503 & 4,520 & 4,509 & 4,529 & 4,537 & 4,475 & 31,530 \\
\hline $\begin{array}{l}\% \text { within } \\
\text { Incident }\end{array}$ & $9.7 \%$ & $14.2 \%$ & $15.0 \%$ & $15.7 \%$ & $15.9 \%$ & $17.3 \%$ & $12.2 \%$ & $100.0 \%$ \\
\hline $\begin{array}{l}\% \text { within } \\
\text { DOW }\end{array}$ & $6.9 \%$ & $10.1 \%$ & $10.5 \%$ & $11.0 \%$ & $11.2 \%$ & $12.1 \%$ & $8.6 \%$ & $10.1 \%$ \\
\hline
\end{tabular}

\begin{tabular}{|l|l|}
\hline \multicolumn{2}{|l|}{ Chi-Square Tests } \\
\hline & $\begin{array}{l}\text { Asymp. Sig. (2- } \\
\text { sided) }\end{array}$ \\
\hline Chi-Square & .000 \\
\hline
\end{tabular}

Table 25. Secondary Chi Square Test Results for Incidents and Day of the Week

\begin{tabular}{|l|r|l|l|l|l|l|l|l|}
\hline & \multicolumn{2}{|l|}{ Day of the Week, Secondary Direction } & \multirow{2}{*}{ Total } \\
\cline { 2 - 9 } & Sunday & Monday & Tuesday & Wednesday & Thursday & Friday & Saturday & Tol \\
\hline Count & 3,395 & 4,744 & 5,064 & 5,344 & 5,166 & 5,421 & 3,914 & 33,048 \\
\hline $\begin{array}{l}\text { Expected } \\
\text { Count }\end{array}$ & 4,671 & 4,722 & 4,737 & 4,734 & 4,745 & 4,749 & 4,690 & 33,048 \\
\hline $\begin{array}{l}\% \text { within } \\
\text { Incident }\end{array}$ & $10.3 \%$ & $14.4 \%$ & $15.3 \%$ & $16.2 \%$ & $15.6 \%$ & $16.4 \%$ & $11.8 \%$ & $100 \%$ \\
\hline $\begin{array}{l}\% \text { within } \\
\text { Day of } \\
\text { the } \\
\text { Week }\end{array}$ & $7.7 \%$ & $10.6 \%$ & $11.3 \%$ & $11.9 \%$ & $11.5 \%$ & $12.0 \%$ & $8.8 \%$ & $10.6 \%$ \\
\hline
\end{tabular}

\begin{tabular}{|l|l|}
\hline \multicolumn{2}{|l|}{ Chi-Square Tests } \\
\hline & $\begin{array}{l}\text { Asymp. Sig. (2- } \\
\text { sided) }\end{array}$ \\
\hline Chi-Square & .000 \\
\hline
\end{tabular}


Table 26. Primary Direction Chi Square Test Results for Incidents and Vehicle Miles Traveled

\begin{tabular}{|l|l|l|l|l|l|}
\hline \multirow{2}{*}{} & \multicolumn{3}{|l|}{ VMT, Primary Direction } & \multirow{2}{*}{} \\
\cline { 2 - 5 } & High & Low & $\begin{array}{l}\text { Low- } \\
\text { Medium }\end{array}$ & $\begin{array}{l}\text { Medium- } \\
\text { High }\end{array}$ & Total \\
\hline Count & 7,033 & 7,452 & 9,810 & 7,235 & 31,530 \\
\hline $\begin{array}{l}\text { Expected } \\
\text { Count }\end{array}$ & 1,722 & 18,005 & 8,787 & 3,016 & 31,530 \\
\hline $\begin{array}{l}\% \text { within } \\
\text { Incident }\end{array}$ & $22.3 \%$ & $23.6 \%$ & $31.1 \%$ & $22.9 \%$ & $100.0 \%$ \\
\hline $\begin{array}{l}\% \text { within } \\
\text { VMT }\end{array}$ & $41.2 \%$ & $4.2 \%$ & $11.3 \%$ & $24.2 \%$ & $10.1 \%$ \\
\hline
\end{tabular}

\begin{tabular}{|l|l|}
\hline \multicolumn{2}{|l|}{ Chi-Square Tests } \\
\hline & $\begin{array}{l}\text { Asymp. } \\
\text { Sig. (2- } \\
\text { sided) }\end{array}$ \\
\hline $\begin{array}{l}\text { Chi- } \\
\text { Square }\end{array}$ & 0.000 \\
\hline
\end{tabular}

Table 27. Secondary Direction Chi Square Test Results for Incidents and Vehicle Miles Traveled

\begin{tabular}{|l|l|l|l|l|l|}
\hline \multirow{2}{*}{} & \multicolumn{3}{|l|}{ VMT, Secondary Direction } & \multirow{2}{*}{} \\
\cline { 2 - 5 } & High & Low & $\begin{array}{l}\text { Low- } \\
\text { Medium }\end{array}$ & $\begin{array}{l}\text { Medium- } \\
\text { High }\end{array}$ & Total \\
\hline Count & 18,503 & 2,422 & 4,582 & 7,541 & 33,048 \\
\hline Expected Count & 7,106 & 9,815 & 8,523 & 7,605 & 33,048 \\
\hline \% within Incident & $56.0 \%$ & $7.3 \%$ & $13.9 \%$ & $22.8 \%$ & $100.0 \%$ \\
\hline \% within VMT & $27.5 \%$ & $2.6 \%$ & $5.7 \%$ & $10.5 \%$ & $10.6 \%$ \\
\hline \% of Total & $5.9 \%$ & $.8 \%$ & $1.5 \%$ & $2.4 \%$ & $10.6 \%$ \\
\hline
\end{tabular}

\begin{tabular}{|l|l|}
\hline \multicolumn{2}{|l|}{ Chi-Square Tests } \\
\hline & $\begin{array}{l}\text { Asymp. } \\
\text { Sig. (2- } \\
\text { sided) }\end{array}$ \\
\hline Chi-Square & 0.000 \\
\hline
\end{tabular}


Table 28. Primary Direction Chi Square Test Results for Assists and Months

\begin{tabular}{|c|c|c|c|c|c|c|c|c|c|c|c|c|c|}
\hline & \multicolumn{12}{|c|}{ Months, Primary Direction } & \multirow[t]{2}{*}{ Total } \\
\hline & Jan. & Feb. & $\begin{array}{l}\text { Marc } \\
\text { h. }\end{array}$ & $\begin{array}{l}\text { Apri } \\
1\end{array}$ & May & June & July & Aug. & Sept & Oct. & Nov & $\begin{array}{l}\text { Dec } \\
.\end{array}$ & \\
\hline Count & $\begin{array}{l}1,22 \\
1\end{array}$ & $\begin{array}{l}1,26 \\
5\end{array}$ & 1,497 & $\begin{array}{l}2,26 \\
7\end{array}$ & $\begin{array}{l}2,32 \\
2\end{array}$ & $\begin{array}{l}2,37 \\
8\end{array}$ & $\begin{array}{l}2,15 \\
8\end{array}$ & $\begin{array}{l}2,34 \\
4\end{array}$ & $\begin{array}{l}2,15 \\
5\end{array}$ & $\begin{array}{l}1,57 \\
0\end{array}$ & $\begin{array}{l}1,57 \\
9\end{array}$ & $\begin{array}{l}1,73 \\
4\end{array}$ & $\begin{array}{l}22,49 \\
0\end{array}$ \\
\hline $\begin{array}{l}\text { Expect } \\
\text { ed } \\
\text { Count }\end{array}$ & $\begin{array}{l}1,90 \\
6\end{array}$ & $\begin{array}{l}1,73 \\
2\end{array}$ & 1,911 & $\begin{array}{l}1,84 \\
6\end{array}$ & $\begin{array}{l}1,91 \\
4\end{array}$ & $\begin{array}{l}1,85 \\
1\end{array}$ & $\begin{array}{l}1,90 \\
9\end{array}$ & $\begin{array}{l}1,90 \\
6\end{array}$ & $\begin{array}{l}1,85 \\
1\end{array}$ & $\begin{array}{l}1,91 \\
3\end{array}$ & $\begin{array}{l}1,84 \\
4\end{array}$ & $\begin{array}{l}1,90 \\
7\end{array}$ & $\begin{array}{l}22,49 \\
0\end{array}$ \\
\hline $\begin{array}{l}\% \\
\text { within } \\
\text { Count }\end{array}$ & $\begin{array}{l}5.4 \\
\%\end{array}$ & $\begin{array}{l}5.6 \\
\%\end{array}$ & $6.7 \%$ & $\begin{array}{l}10.1 \\
\%\end{array}$ & $\begin{array}{l}10.3 \\
\%\end{array}$ & $\begin{array}{l}10.6 \\
\%\end{array}$ & $\begin{array}{l}9.6 \\
\%\end{array}$ & $\begin{array}{l}10.4 \\
\%\end{array}$ & $\begin{array}{l}9.6 \\
\%\end{array}$ & $\begin{array}{l}7.0 \\
\%\end{array}$ & $\begin{array}{l}7.0 \\
\%\end{array}$ & $\begin{array}{l}7.7 \\
\%\end{array}$ & $\begin{array}{l}100.0 \\
\%\end{array}$ \\
\hline $\begin{array}{l}\% \\
\text { within } \\
\text { Month }\end{array}$ & $\begin{array}{l}4.6 \\
\%\end{array}$ & $\begin{array}{l}5.3 \\
\%\end{array}$ & $5.6 \%$ & $\begin{array}{l}8.8 \\
\%\end{array}$ & $\begin{array}{l}8.7 \\
\%\end{array}$ & $\begin{array}{l}9.2 \\
\%\end{array}$ & $\begin{array}{l}8.1 \\
\%\end{array}$ & $\begin{array}{l}8.8 \\
\%\end{array}$ & $\begin{array}{l}8.4 \\
\%\end{array}$ & $\begin{array}{l}5.9 \\
\%\end{array}$ & $\begin{array}{l}6.2 \\
\%\end{array}$ & $\begin{array}{l}6.5 \\
\%\end{array}$ & $7.2 \%$ \\
\hline
\end{tabular}

\begin{tabular}{|l|l|}
\hline \multicolumn{2}{|c|}{ Chi-Square Tests } \\
\hline & $\begin{array}{l}\text { Asymp. } \\
\text { Sig. (2- } \\
\text { sided) }\end{array}$ \\
\hline $\begin{array}{l}\text { Chi- } \\
\text { Square }\end{array}$ & .000 \\
\hline
\end{tabular}

Table 29. Secondary Direction Chi Square Test Results for Assists and Months

\begin{tabular}{|c|c|c|c|c|c|c|c|c|c|c|c|c|c|}
\hline & \multicolumn{12}{|c|}{ Months, Secondary Direction } & \multirow[t]{2}{*}{ Total } \\
\hline & Jan. & Feb. & March & April & May & June. & July & Aug. & Sept. & Oct. & Nov. & Dec. & \\
\hline Count & 624 & 691 & 880 & 1,178 & 1,219 & 1,246 & 1,119 & 1,188 & 1,096 & 813 & 876 & 919 & 11,849 \\
\hline $\begin{array}{l}\text { Expected } \\
\text { Count }\end{array}$ & 1,005 & 915 & 1,006 & 975 & 1,005 & 974 & 1,006 & 1,006 & 975 & 1,009 & 971 & 1,002 & 11,849 \\
\hline $\begin{array}{l}\text { \% within } \\
\text { Assist }\end{array}$ & $5.3 \%$ & $5.8 \%$ & $7.4 \%$ & $9.9 \%$ & $10.3 \%$ & $10.5 \%$ & $9.4 \%$ & $10.0 \%$ & $9.2 \%$ & $6.9 \%$ & $7.4 \%$ & $7.8 \%$ & $100 \%$ \\
\hline $\begin{array}{l}\% \text { within } \\
\text { month }\end{array}$ & $2.3 \%$ & $2.9 \%$ & $3.3 \%$ & $4.6 \%$ & $4.6 \%$ & $4.8 \%$ & $4.2 \%$ & $4.5 \%$ & $4.3 \%$ & $3.0 \%$ & $3.4 \%$ & $3.5 \%$ & $3.8 \%$ \\
\hline
\end{tabular}

\begin{tabular}{|l|l|}
\hline \multicolumn{2}{|c|}{ Chi-Square Tests } \\
\hline & $\begin{array}{l}\text { Asymp. } \\
\text { Sig. (2- } \\
\text { sided) }\end{array}$ \\
\hline
\end{tabular}


Table 30. Primary Direction Chi Square Test Results for Assists and Time of Day

\begin{tabular}{|l|l|l|l|l|l|}
\hline \multirow{2}{*}{} & \multicolumn{3}{|l|}{ Time of Day } & \multirow{2}{*}{ Total } \\
\cline { 2 - 5 } & Evening & Mid-Day & Morning & Night & \\
\hline Count & 10,482 & 3,267 & 6,052 & 2,689 & 22,490 \\
\hline Expected Count & 3,860 & 5,647 & 2,828 & 10,155 & 22,490 \\
\hline \% within Assist & $46.6 \%$ & $14.5 \%$ & $26.9 \%$ & $12.0 \%$ & $100.0 \%$ \\
\hline $\begin{array}{l}\text { \% within Time } \\
\text { of the Day }\end{array}$ & $19.5 \%$ & $4.2 \%$ & $15.4 \%$ & $1.9 \%$ & $7.2 \%$ \\
\hline
\end{tabular}

\begin{tabular}{|l|l|}
\hline \multicolumn{2}{|l|}{ Chi-Square Tests } \\
\hline & $\begin{array}{l}\text { Asymp. } \\
\text { Sig. } \\
\text { sided })\end{array}$ \\
\hline Chi-Square & 0.000 \\
\hline
\end{tabular}

Table 31. Secondary Direction Chi Square Test Results for Assists and Time of Day

\begin{tabular}{|l|l|l|l|l|}
\hline \multirow{2}{*}{} & \multicolumn{2}{|l|}{$\begin{array}{l}\text { Time of Day, Secondary } \\
\text { Direction }\end{array}$} & \multirow{2}{*}{ Total } \\
\cline { 2 - 4 } & Mid-day & Morning & Night & Tount \\
\cline { 2 - 4 } & 7,812 & 2,836 & 1,201 & 11,849 \\
\hline Expected Count & 4,995 & 1,509 & 5,346 & 11,849 \\
\hline \% within Assist & $65.9 \%$ & $23.9 \%$ & $10.1 \%$ & $100.0 \%$ \\
\hline $\begin{array}{l}\text { \% within Time of } \\
\text { Day }\end{array}$ & $5.9 \%$ & $7.1 \%$ & $.8 \%$ & $3.8 \%$ \\
\hline
\end{tabular}

\begin{tabular}{|l|l|}
\hline \multicolumn{2}{|l|}{ Chi-Square Tests } \\
\hline & $\begin{array}{l}\text { Asymp. } \\
\text { Sig. (2- } \\
\text { sided) }\end{array}$ \\
\hline Chi-Square & 0.000 \\
\hline
\end{tabular}

Table 32. Primary Direction Chi Square Test Results for Assists and Day of the Week 


\begin{tabular}{|l|l|l|l|l|l|l|l|l|}
\hline & Sunday & Monday & Tuesday & Wednesday & Thursday & Friday & Saturday & \\
\hline Count & 1,110 & 3,936 & 4,190 & 4,312 & 4,398 & 4,539 & 5 & 22,490 \\
\hline $\begin{array}{l}\text { Expected } \\
\text { Count }\end{array}$ & 3,179 & 3,212 & 3,224 & 3,216 & 3,231 & 3,236 & 3,192 & 22,490 \\
\hline $\begin{array}{l}\% \text { within Assist } \\
\text { n w within Day }\end{array}$ & $2.9 \%$ & $17.5 \%$ & $18.6 \%$ & $19.2 \%$ & $19.6 \%$ & $20.2 \%$ & $.0 \%$ & $100.0 \%$ \\
\hline \begin{tabular}{l} 
of the Week \\
\hline
\end{tabular} & $8.5 \%$ & $9.3 \%$ & $9.6 \%$ & $9.8 \%$ & $10.1 \%$ & $.0 \%$ & $7.2 \%$ \\
\hline
\end{tabular}

\begin{tabular}{|l|l|}
\hline \multicolumn{2}{|l|}{ Chi-Square Tests } \\
\hline & $\begin{array}{l}\text { Asymp. } \\
\text { Sig. (2- } \\
\text { sided) }\end{array}$ \\
\hline $\begin{array}{l}\text { Chi- } \\
\text { Square }\end{array}$ & 0.000 \\
\hline
\end{tabular}

Table 33. Secondary Direction Chi Square Test Results for Assists and Day of the Week

\begin{tabular}{|l|l|l|l|l|l|l|l|l|}
\hline \multirow{2}{*}{} & \multicolumn{2}{|l|}{ Day of the Week } & \multirow{2}{*}{ Total } \\
\cline { 2 - 8 } & Sunday & Monday & Tuesday & Wednesday & Thursday & Friday & Saturday & Tount \\
\hline Co4 & 2,049 & 2,168 & 2,197 & 2,298 & 2,433 & - & 11,849 \\
\hline $\begin{array}{l}\text { Expected } \\
\text { Count }\end{array}$ & 1,675 & 1,693 & 1,698 & 1,697 & 1,701 & 1,703 & 1,682 & 11,849 \\
\hline$\%$ within Assist & $5.9 \%$ & $17.3 \%$ & $18.3 \%$ & $18.5 \%$ & $19.4 \%$ & $20.5 \%$ & $0.0 \%$ & $100.0 \%$ \\
\hline $\begin{array}{l}\text { \% within Day } \\
\text { of the Week }\end{array}$ & $1.6 \%$ & $4.6 \%$ & $4.8 \%$ & $4.9 \%$ & $5.1 \%$ & $5.4 \%$ & $0.0 \%$ & $3.8 \%$ \\
\hline$\%$ of Total & $.2 \%$ & $.7 \%$ & $.7 \%$ & $.7 \%$ & $.7 \%$ & $.8 \%$ & $0.0 \%$ & $3.8 \%$ \\
\hline
\end{tabular}

\begin{tabular}{|l|l|}
\hline \multicolumn{2}{|l|}{ Chi-Square Tests } \\
\hline & $\begin{array}{l}\text { Asymp. } \\
\text { Sig. (2- } \\
\text { sided) }\end{array}$ \\
\hline Chi-Square & 0.000 \\
\hline
\end{tabular}

Table 34. Primary Direction Chi Square Test Results for Assists and Vehicle Miles Traveled 


\begin{tabular}{|l|l|l|l|l|l|}
\hline & \multicolumn{2}{|l|}{ VMT } & \multicolumn{2}{l|}{} \\
\cline { 2 - 5 } & High & Low & $\begin{array}{l}\text { Low- } \\
\text { Medium }\end{array}$ & $\begin{array}{l}\text { Medium- } \\
\text { High }\end{array}$ & Total \\
\hline Count & 5,477 & 2,532 & 8,286 & 6,195 & 22,490 \\
\hline $\begin{array}{l}\text { Expected } \\
\text { Count }\end{array}$ & 1,228 & 12,843 & 6,268 & 2,151 & 22,490 \\
\hline $\begin{array}{l}\% \text { within } \\
\text { Assist }\end{array}$ & $24.4 \%$ & $11.3 \%$ & $36.8 \%$ & $27.5 \%$ & $100.0 \%$ \\
\hline $\begin{array}{l}\% \text { within } \\
\text { VMT }\end{array}$ & $32.1 \%$ & $1.4 \%$ & $9.5 \%$ & $20.7 \%$ & $7.2 \%$ \\
\hline
\end{tabular}

\begin{tabular}{|l|l|}
\hline \multicolumn{2}{|l|}{ Chi-Square Tests } \\
\hline & $\begin{array}{l}\text { Asymp. } \\
\text { Sig. (2- } \\
\text { sided) }\end{array}$ \\
\hline Chi-Square & 0.000 \\
\hline
\end{tabular}

Table 35. Secondary Direction Chi Square Test Results for Assists and Vehicle Miles Traveled

\begin{tabular}{|l|l|l|l|l|l|}
\hline \multirow{2}{*}{} & \multicolumn{4}{|c|}{ VMT, Secondary Direction } & \multirow{2}{*}{} \\
\cline { 2 - 6 } & High & Low & $\begin{array}{l}\text { Low- } \\
\text { Medium }\end{array}$ & $\begin{array}{l}\text { Medium- } \\
\text { High }\end{array}$ & Total \\
\hline Count & 8,236 & 62 & 196 & 3,355 & 11,849 \\
\hline Expected Count & 2,548 & 3,519 & 3,056 & 2,727 & 11,849 \\
\hline \% within Assist & $69.5 \%$ & $.5 \%$ & $1.7 \%$ & $28.3 \%$ & $100 \%$ \\
\hline \% within VMT & $12.2 \%$ & $.1 \%$ & $.2 \%$ & $4.7 \%$ & $3.8 \%$ \\
\hline \% of Total & $2.6 \%$ & $.0 \%$ & $.1 \%$ & $1.1 \%$ & $3.8 \%$ \\
\hline
\end{tabular}

\begin{tabular}{|l|l|}
\hline \multicolumn{2}{|l|}{ Chi-Square Tests } \\
\hline & $\begin{array}{l}\text { Asymp. } \\
\text { Sig. (2- } \\
\text { sided) }\end{array}$ \\
\hline Chi-Square & 0.000 \\
\hline
\end{tabular}


Table 36. Primary Direction Chi Square Test Results for Assists and Incidents

\begin{tabular}{|c|c|c|c|c|c|}
\hline \multicolumn{6}{|c|}{ Assists Vs. Incidents, Primary Direction } \\
\hline & & & \multicolumn{2}{|c|}{ Incidents } & \multirow{2}{*}{ Total } \\
\hline & & & 0 & 1 & \\
\hline \multirow{9}{*}{ Assists } & \multirow{5}{*}{0} & Count & 265,036 & 25,224 & 290,260 \\
\hline & & Expected Count & 260,997 & 29,263 & 290,260 \\
\hline & & $\%$ within Assist & $91.30 \%$ & $8.70 \%$ & $100 \%$ \\
\hline & & $\%$ within Incident & $94.20 \%$ & $80.00 \%$ & $92.80 \%$ \\
\hline & & Count & 16,184 & 6,306 & 22,490 \\
\hline & \multirow{4}{*}{1} & Expected Count & 20,223 & 2,267 & 22,490 \\
\hline & & $\%$ within Assist & $72 \%$ & $28 \%$ & $100 \%$ \\
\hline & & $\%$ within Incident & $5.80 \%$ & $20 \%$ & $7.20 \%$ \\
\hline & & $\%$ of Total & $5.20 \%$ & $2 \%$ & $7.20 \%$ \\
\hline
\end{tabular}

\begin{tabular}{|l|l|}
\hline \multicolumn{2}{|l|}{ Chi-Square Tests } \\
\hline & $\begin{array}{l}\text { Asymp. Sig. } \\
\text { (2-sided) }\end{array}$ \\
\hline Chi-Square & 0.000 \\
\hline
\end{tabular}

Table 37. Secondary Direction Chi Square Test Results for Assists and Incidents

\begin{tabular}{|c|c|c|c|c|c|}
\hline \multicolumn{6}{|c|}{ Assists Vs. Incidents, Secondary Direction } \\
\hline & & & \multicolumn{2}{|l|}{ Incidents } & \multirow[b]{2}{*}{ Total } \\
\hline & & & 0 & 1 & \\
\hline \multirow[t]{8}{*}{ Assists } & \multirow[t]{4}{*}{0} & Count & 272,413 & 28,962 & 301,375 \\
\hline & & Expected Count & 269,577 & 31,798 & 301,375 \\
\hline & & $\%$ within Assists & $90.4 \%$ & $9.6 \%$ & $100.0 \%$ \\
\hline & & $\%$ within Incidents & $97.2 \%$ & $87.6 \%$ & $96.2 \%$ \\
\hline & \multirow[t]{4}{*}{1} & Count & 7.763 & 4.086 & 11,849 \\
\hline & & Expected Count & 10,599 & 1,250 & 11,849 \\
\hline & & $\%$ within Assists & $65.5 \%$ & $34.5 \%$ & $100.0 \%$ \\
\hline & & $\%$ within Incidents & $2.8 \%$ & $12.4 \%$ & $3.8 \%$ \\
\hline
\end{tabular}




\begin{tabular}{|l|l|}
\hline \multicolumn{2}{|l|}{ Chi-Square Tests } \\
\hline & $\begin{array}{l}\text { Asymp. } \\
\text { Sig. (2- } \\
\text { sided) }\end{array}$ \\
\hline Chi-Square & 0.000 \\
\hline
\end{tabular}

Table 38. VMT Totals for Monthly Chi Square Comparison

\begin{tabular}{|l|l|}
\hline & \multicolumn{1}{|c|}{ VMT } \\
\hline January & $10,069,778,106$ \\
\hline February & $10,069,295,418$ \\
\hline March & $10,070,406,018$ \\
\hline April & $10,070,517,274$ \\
\hline May & $10,070,472,313$ \\
\hline June & $10,070,534,718$ \\
\hline July & $10,134,520,242$ \\
\hline August & $10,134,297,988$ \\
\hline September & $10,069,873,641$ \\
\hline October & $10,070,147,125$ \\
\hline November & $10,700,853,560$ \\
\hline December & $10,134,021,360$ \\
\hline
\end{tabular}

